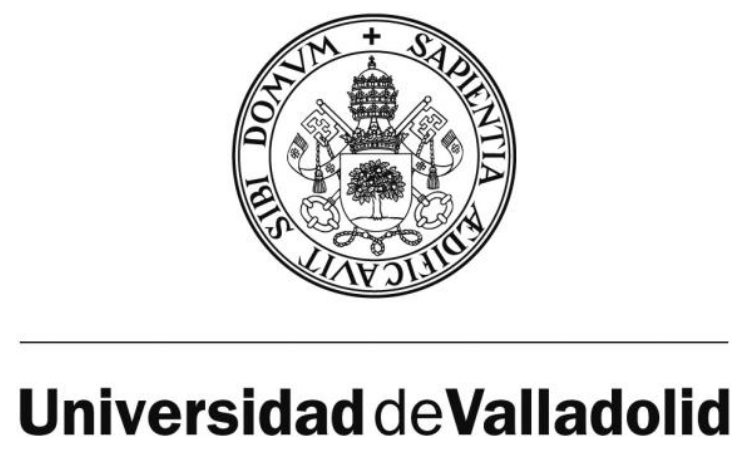

ESCUELA UNIVERSITARIA INGENIERÍAS AGRARIAS

DEPARTAMENTO PRODUCCION VEGETAL Y

RECURSOS FORESTALES

TESIS DOCTORAL

\title{
ARSENICO EN AGUAS SUBTERRANEAS SU TRANSFERENCIA AL SUELO Y A LA PLANTA
}

\author{
Presentada por $\mathrm{M}^{\mathrm{a}}$ Paloma Mayorga Moreno \\ para optar al grado de doctora por la \\ Universidad de Valladolid
}

Dirigida por: Amelia Moyano Gardini y Antonio García Sánchez 
Esta Tesis Doctoral fue realizada en el Instituto Recursos Naturales y Agrobiología de Salamanca de Consejo Superior de Investigaciones Científicas (IRNASA-CSIC) y en la Escuela Universitaria de Ingenierías Agrarias de la Universidad de Valladolid. 


\section{ÍNDICE}

ÍNDICE DE TABLAS Y FIGURAS............................................................................... II INTRODUCCIÓN ............................................................................................................. 1

OBJETIVOS..............................................................................................................................

MATERIAL Y MÉTODOS .............................................................................................. 11

RESULTADOS Y DISCUSIÓN ...................................................................................... 17

CONCLUSIONES............................................................................................................. 40

BIBLIOGRAFÍA.......................................................................................................... 42 


\section{Índice de tablas y figuras}

Tabla 1. Composición química de las aguas

Tabla 2. Resultados del análisis microbiológico

Tabla 3. Propiedades del suelo y concentración de As en el agua de riego

Tabla 4. Resumen estadístico de las propiedades de las aguas

Tabla 5. Características fisicoquímicas del suelo

Figura 1. Carácteristicas litológicas del área de estudio

Figura 2. Modelo de flujo del agua subterránea en el área de estudio

Figura 3. Relación As-bicarbonato

Figura 4. Relación calcio-sulfatos

Figura 5. Modelo de competición de adsorción de arseniato y bicarbonato (Gustafson, 2009)

Figura 6. Desorción de As en $\mathrm{FeOOH}$, con $0.1 \%$ de Fe, con el aumento del pH (Dzombak and Morel, 1990)

Figura 7. Box and whisker plots de la concentración de As en rocas y sedimentos de las columnas estratigráficas de la Cuenca del Duero y la concentración de As en los suelos agrícolas

Figura 8. Box and whisker plots de la concentración de As el en agua de riego y la concentración de As soluble en el suelo.

Figura 9. Box and whisker plots del arsénico contenido en las muestras vegetales estudiadas.

Figura 10. Diagrama de Piper

Figura 11. Relación entre $\mathrm{pH}$ y Ln As

Figura 12. Relación entre Ln As con Ln nitratos

Figura 13. Medias con intervalos LSD al 95\%, de la concentración de As (expresada como Ln) en los tres años de muestreos

Figura 14. Gráfico de medias y 95\% Fisher LSD, (concentración expresada Ln $\mathrm{NO}^{-}$) en los tres años de muestreos 
Figura 15. Box and whisker plots de As en hojas, regadas con concentraciones de As crecientes

Figura 16. Box and whisker plots de As en raíces, regadas con concentraciones de As crecientes

Figura 17. Medias con intervalos LSD al 95\%, del coeficiente de bioacumulación en las raíces

Figura 18. Medias con intervalos LSD al 95\%, del coeficiente de bioacumulación en las hojas

Figura 19. Box and whisker plots de la relación As raíz/As hojas

Figura 20. Ecuación lineal de la relación As en raíz/coeficiente de bioacumulación en raíz

Figura 21. Ecuación lineal de la relación As en hojas/coeficiente de bioacumulación en hojas 


\section{Introducción}

El arsénico (As) es un elemento tóxico y ubicuo en la naturaleza, donde se encuentra en concentraciones traza, y donde su movilidad depende de diversos procesos bióticos y abióticos. Este elemento se encuentra en un nivel prioritario entre los principales contaminantes del medio ambiente a escala global. La presencia de altos niveles en el agua, el suelo y los cultivos en muchas regiones del mundo, amenaza la salud humana (Kahlown et al., 2002, Mukherjee et al., 2005, Farooqi et al., 2007, Carbonell-Barrachina et al., 2009). Aunque el agua es la principal vía de entrada en la cadena alimentaria humana también el consumo de alimentos contaminados de origen vegetal y animal puede ser otra vía importante de captación. Las manifestaciones clínicas de la intoxicación crónica están asociadas con diversas formas de enfermedades de la piel y daños en órganos internos: alteraciones cardiovasculares, renales, circulatorias y respiratorias, en última instancia aparece el cáncer (Hossain, 2006). El inicio de la arsenicosis puede agravarse con la malnutrición y las deficiencias de micronutrientes u otras enfermedades relacionadas. Williams et al., (2009) informaron que el As podría perturbar el balance de micronutrientes en el arroz, limitando los niveles de $\mathrm{Se}, \mathrm{Zn}$ y Ni.

El agua de bebida normalmente procede de aguas superficiales aunque también de aguas subterráneas, dependiendo de la disponibilidad local. El contenido de arsénico es muy variable, aunque las mayores concentraciones se han encontrado en aguas subterráneas. En muchas partes del mundo, como Argentina, Bangladesh, Chile, China, Hungría, India, México, Taiwán, Estados Unidos etc., hay numerosas áreas con aguas subterráneas que tienen contenidos de arsénico mayores de $50 \mu \mathrm{g} / 1$, superando las directrices de la WHO (1993) de $10 \mu \mathrm{g} / 1$ para el agua de bebida. Estas aguas han sido encontradas en ambientes muy diversos, en acuíferos de distintas profundidades, tanto en ambientes reductores como oxidantes. A medida que en los análisis de control de aguas para consumo humano se ha incluido este elemento, se han encontrado recientemente nuevos casos de aguas con altas concentraciones de As. Algunas áreas de España presentan concentraciones de arsénico mayores de $10 \mu \mathrm{g} / \mathrm{l}$, pueden ser 
consideradas como una anomalía geoquímica natural (Baur and Onishi 1978, Welch et al., 2000, Smedley and Kinniburgh, 2002) pues en estas áreas, no parece probable un origen antropológico, bien sea, industrial, minero o agrícola.

Entre las especies de As en agua, suelo y sedimentos, los arseniatos predominan en condiciones oxidantes, Eh 400-700 mV (Sadiq et al., 1983, Haswell et al., 1985).

La adsorción del As (V) en las superficies de los coloides de suelos y sedimentos es un proceso muy importante, que afecta su movilidad (Tamaki and Frankenberger, 1992). Los grupos hidroxilo de la superficie de algunos minerales son los sitios de adsorción más abundantes y reactivos, particularmente en los óxidos e hidróxidos de hierro, aluminio y magnesio que tienen una fuerte afinidad por el As (V) (Pierce and Moore, 1982, Gustafsson and Jacks, 1995, Wilkie and Hering, 1996, Smith et al., 1998). La fuerte retención del As (V) en óxidos e hidróxidos es probablemente debido a la formación de complejos de esfera interna monodentados o bidentados, mononucleados o binucleados (Sun and Doner, 1996, Waychunas et al., 1993, Fendorf et al., 1997). Bajo condiciones moderadamente reductoras la solubilidad del arsénico puede ser condicionada por la disolución de los oxihidróxidos (Masscheleyn et al., 1991).

Las especies solubles de arsénico en un sistema acuático natural son controladas por la combinación del potencial redox, $\mathrm{pH}$, reacciones de adsorción en la superficie mineral y la actividad microbiológica (Matisoff et al., 1983). Hay diferentes mecanismos de movilización de As en las aguas subterráneas. Smedley and Kinniburgh (2002) señalan que la naturaleza anóxica de algunas aguas subterráneas reduciría al As (V) a As (III) y causaría la disolución del arsénico porque el As (III) es adsorbido menos fuertemente por los oxihidróxidos; sin embargo, bajo condiciones oxidantes predominaría el As (V) y a valores altos de pH se movilizaría. Nickson et al., (1998, 2000), McArthur et al., (2001), Kneebone et al., (2002) han descrito que la disolución reductora de los oxihidróxidos y la reducción de As (V) deben ser considerados como los mecanismos más probables para movilizar altas concentraciones de As en la aguas subterráneas de algunas regiones. Appelo et al., (2002) puntualizaron el efecto del 
desplazamiento por el anión bicarbonato de los arseniatos y arsenitos adsorbidos sobre la ferrihidrita debido a la competencia por los sitios de adsorción.

La movilización del As de los sedimentos por los microorganismos, ha sido descrita en condiciones anaeróbicas en aquellas bacterias que utilizan el Fe (III) como aceptor de electrones en la respiración (Ahman et al., 1997, Cumming et al., 1999, Jones et al., 2000, Zobrist et al., 2000, Langner and Inskeep, 2000, Haas and Dichristina, 2002). Estos estudios enfatizan el papel potencial que tienen los microorganismos en la solubilización del arsénico asociado a las fases sólidas del Fe (III), independientemente de que además el As (V) sea también reducido a As (III).

En medios aeróbicos los microorganismos pueden producir sideróforos, substancias orgánicas que complejan y reducen al Fe (III), ocasionando la disolución de los oxihidróxidos de hierro y otros minerales (Newman and Banfield, 2002). La degradación microbiana de la materia orgánica requiere del consumo de oxidantes, como el nitrato, que se encuentra después de $\mathrm{O}_{2}$, y antes de Fe (III), en la escala de óxido-reducción (Mc Bride, 1994). Algunos autores (Benz et al., 1998) sugieren que a $\mathrm{pH}$ alrededor de la neutralidad, es posible que se produzca la oxidación de Fe (II), en un proceso realizado por bacterias reductoras de nitrato de nutrición quimioheterótrofa, que utilizan también compuestos orgánicos como co-sustrato dador de electrones. Más recientemente, algunos estudios (Weber et al., 2001, Rhine et al., 2007, Sun et al., 2008) han identificado las bacterias que realizan la oxidación tanto de $\mathrm{Fe}$ (II) y As (III) con NO3estando este proceso asociado a la fijación de $\mathrm{CO}_{2}$ (quimioautótrofas).

En los ecosistemas acuáticos, la contaminación por nitratos ejerce una fuerte influencia en el ciclo del arsénico, debido a la oxidación de Fe (II) que promueve la aparición de partículas de $\mathrm{FeOOH}$ que pueden adsorber As y también puede generar la forma más oxidada As (V), que es más reactivo en este proceso de adsorción que el As (III) (Senn and Hemond, 2002). Además, los procesos bióticos (desnitrificación) y abióticos de reducción del $\mathrm{NO}^{-}$, preservarían la reducción de Fe (III), promoviendo la estabilidad de la coprecipitación o adsorción de As en los FeOOH de los sedimentos. Por lo tanto, el aumento del contenido de nitrato en el agua subterránea puede por una parte disminuir la 
liberación de As de los sedimentos inhibiendo la reducción del Fe (III) y por otra parte propiciar la precipitación de $\mathrm{FeOOH}$ que proporcionan un mecanismo para la inmovilización de As a través de la adsorción y precipitación, disminuyendo el contenido de arsénico de las aguas subterráneas. En una prueba realizada en Bangladesh, se demostró que los niveles de arsénico disuelto disminuían cuando se inyectaba nitrato en el acuífero, relacionándose este proceso con mecanismos de adsorción en FeOOH (Harvey et al., 2002).

A pesar de que la abundancia geoquímica del arsénico es baja (la media en la corteza terrestre es $1.8 \mathrm{mg} / \mathrm{kg}$; Baur and Onishi, 1978) la movilización de una parte de este arsénico puede causar problemas de contaminación en las aguas y en los suelos agrícolas. Los suelos agrícolas no contaminados contienen 1-20 mg/kg As Wauchope, 1983), pero los suelos contaminados de áreas mineras o industriales pueden tener 45-2600 mg/kg (Dudas, 1984; García-Sánchez and Álvarez-Ayuso, 2003; Anawar et al., 2006). En muchos casos el uso en el riego de aguas subterráneas contaminadas, ha promovido la aparición de altas concentraciones de arsénico en suelos agrícolas (Pandey et al., 2002, Alam et al., 2003). Este hecho puede inducir baja productividad del suelo (Liebig, 1966), ser tóxico para las plantas y entrar en los cultivos (Marin, 1995, Helgensen and Larsen, 1998, Abedin et al., 2002, Nordstrum, 2002, Alam et al., 2003, Roberts et al., 2007, Moyano et al. 2009, De la Fuente et al., 2010; Neumann et al., 2011). Este uso extensivo y continuado de aguas subterráneas con altas concentraciones de As para el riego, ha llevado al aumento de la concentración de As en suelos agrícolas de países como Bangladesh, India, Vietnam, Tailandia, Taiwán, Argentina, Chile y España, sobrepasándose el nivel de referencia de $(0.1$ a 40 $\mathrm{mg} / \mathrm{kg}$ ) (Chen et al., 2002, Tu and Ma, 2004)

En el suelo, al igual que en los acuíferos, el contenido de óxidos de hierro, el pH, el Eh, la materia orgánica, y la actividad microbiana también tienen efectos influyentes en la adsorción y la movilidad del As (Elkhatib et al., 1984; O'Neill, 1995; Kumpiene et al., 2007). Cabe destacar la importancia de la materia orgánica como componente estructural del suelo, esta materia orgánica, disminuye el grado de adsorción de ambas formas de arsénico, arseniato y arsenito, en hematita, e influye en su movilidad (Redman et al., 2002; Carey et al., 1996). Esto es debido 
al bloqueo de los sitios de adsorción del suelo por parte de la fracción soluble de la materia orgánica (ácidos fúlvicos y húmicos), y la reducción de la adsorción de As por el mismo.

En el suelo la fracción disponible de arsénico para las plantas depende de las distintas propiedades físicas y químicas del mismo. Los diferentes métodos de extracción, incluido la simple extracción química y extracciones secuenciales, son adecuados para conocer la especiación química del arsénico en el suelo (KabataPendias, 2004, Anawar et al., 2008), aunque es difícil cuantificar la cantidad disponible para la planta. Se ha descrito una buena relación entre el As del suelo soluble en agua y el arsénico en los cultivos (Woolson et al., 1971, Deuel and Swoboda, 1972, Sadiq, 1986). Por consiguiente el arsénico soluble en agua puede ser considerado un indicador aceptable de biodisponibilidad de As en suelos agrícolas. La concentración de As soluble en agua varía de $0.01 \mathrm{mg} / \mathrm{kg}$ en suelos no contaminados a $5 \mathrm{mg} / \mathrm{kg}$ en suelos mineros (Anawar et al., 2006) y $13 \mathrm{mg} / \mathrm{kg}$ en suelos muy contaminados por actividades industriales diversas (Meharg, 1994). La concentración de arsénico en las plantas raramente excede de $1 \mathrm{mg} / \mathrm{kg}$ de peso seco (Adriano, 2001). La cantidad de arsénico de referencia para plantas (Markert, 1997) es de $0.1 \mathrm{mg} / \mathrm{kg}$ de peso seco. Unas pocas especies (Ma et al., 2001, Francesconi et al., 2002) son conocidas por ser acumuladores o hiperacumuladores de arsénico en su biomasa, cuando crecen en suelos contaminados industrialmente o por actividad minera, por ejemplo algunas especies de gramíneas del género Agrostis (Porter and Peterson, 1975, De Koe, 1994, García-Sánchez et al., 1996) y algunos helechos, Pteris vittata L. (Ma et al., 2001, Francesconi et al., 2002). La concentración de arsénico en plantas es característica de la especie y del órgano analizado, generalmente las semillas y los frutos tienen baja concentración de arsénico. Las cosechas europeas de trigo, centeno y cebada contienen en general menos de $1 \mathrm{mg} / \mathrm{kg}$ (Anke, 2001); no obstante, la concentración de arsénico descrita en arroz varía entre 0.03 y 1.83 $\mathrm{mg} / \mathrm{kg}$, y los mayores contenidos se encuentran en Bangladesh, India y Estados Unidos (Meharg, 2004, Williams et al., 2005). La concentración de arsénico total no puede dar una información exacta de los riesgos para la salud humana ya que el arsénico se presenta en formas inorgánicas (As (III) y As (V) y formas orgánicas, 
las más importantes son monometil arsónico (MAA), dimetil arsínico (DMA), arsenobetaína y arsenocolina. La toxicidad de estos compuestos es muy diferente y la mayor se corresponde con las formas inorgánicas, que son las más abundantes en aguas dulces, suelo y plantas terrestres (Francesconi and Kuehnelt, 2002, Goessler and Kuehnelt, 2002, Smith et al., 2006).

Como se ha citado anteriormente el arseniato, predominante en suelos oxidantes (Sadiq et al., 1983, Haswell, et al., 1985), es la forma dominante en cuanto a la fitodisponibilidad en suelos aeróbicos y es un análogo del fosfato (Meharg and Macnair, 1992). Se ha publicado que el arseniato se absorbe en la raíz a través de los transportadores de fosfato en todas las especies de plantas ensayadas y posteriormente es reducido a arsenito (Meharg and Macnair, 1992; Wang et al., 2002). El fosfato, incluso a baja concentración, puede desplazar al arseniato de las partículas del suelo aumentado así la disponibilidad y la fitotoxicidad; sin embargo, las grandes cantidades de fosfatos compiten con el arsénico por los transportadores en la superficie de la raíz disminuyendo así la absorción y por lo tanto la fitotoxicidad (Peterson et al., 1981).

El arsenito se encuentra unido a proteínas quelantes como el tripéptido glutatión, donde el As (III) forma complejos As-tiol, en las raíces y tallos de la especie Brassica juncea L. (Pickering et al., 2000). Se ha observado en una amplia gama de especies vegetales como mecanismo de resistencia al As, que el arseniato sufre una reducción a arsenito y forma complejos con moléculas que contienen grupos tiol como metalotioneínas (MT), fitoquelantes (PC), además del glutatión reducido $(\mathrm{GSH})$, para ser posteriormente secuestrado en las vacuolas (Pickerin et al., 2000, Schmöger et al., 2000, Hartley-Whitaker et al., 2001, Meharg and Hartley-Whitaker, 2002, Zhang et al., 2004). La defensa oxidativa es una forma que tienen las plantas para defenderse de factores de estrés externos, ésta se realiza con antioxidantes de bajo peso molecular, y antioxidantes enzimáticos.

Dentro de la familia de las umbelíferas, la zanahoria (Daucus carota L.) merece especial atención por su elevada resistencia al As y su alto consumo como alimento a escala global. En este cultivo, existen un conjunto complejo de variedades anuales o bianuales. El crecimiento de las raíces se produce en dos etapas: inicialmente hay una etapa de activa división celular que genera un 
crecimiento en longitud, con la producción y el uso de hidratos de carbono y más tarde una segunda etapa de elongación celular con extensión en diámetro (engrosamiento), con acumulación de hidratos de carbono, agua y también sustancias potencialmente tóxicas tales como los compuestos de As (Yathavakilla et al., 2008). Los rábanos (Raphanus sativus L.), que como las zanahorias tienen raíces pivotantes, presentan compuestos azufrados con As (III) en la raíz, el tallo y las hojas, lo cual indicaría que estos compuestos pueden jugar un papel importante en el transporte y almacenamiento de este elemento (Smith et al., 2008).

El desencadenante para iniciar esta tesis fue la noticia que apareció en los medios de comunicación durante el mes de julio de 2000, sobre la contaminación de los pozos que suministran agua a la población de Iscar (Valladolid), con niveles de arsénico muy superiores a $10 \mu \mathrm{g} / \mathrm{l}$.

A la vista de los datos se realizó una campaña sanitaria de análisis alrededor del núcleo de Iscar, con la intención de determinar la extensión de esta contaminación en localidades cercanas. De los análisis realizados por la Junta de Castilla y León en ese momento, se detecta la extensión del problema a localidades de las provincias de Ávila, Segovia, Valladolid.

Los principales pueblos afectados en la provincia de Ávila fueron: Albornos, Fuente el Saúz, Fuentes de año, Langa, Magazos, Muñomer de Peco, Noharre, Palacios de Goda, Palacios Rubios, Papatrigo y Villanueva del Aceral. En Segovia: Bernúy de Coca, Chañe, Ciruelos de Coca, Coca, Fuente de Santa Cruz, Fuentesaúco de Fuentidueña, Mata de Cuellar, Mata de la Asunción, Remondo, Santiuste de San Juan Bautista, Valle lado, Villagonzalo de Coca y Villaverde de Íscar. En Valladolid: Aldea de San Miguel, Bocigas, Cogeces de Iscar, Hornillos de Eresma, Íscar, La Pedraja de Portillo, Llano de Olmedo, Megeces, Mojados, Portillo, Arrabal de Portillo, Pedrajas de San Esteban, Santibáñez de Valcorba, La Zarza y Pozal de Gallinas.

La primera hipótesis difundida por los medios de comunicación, para explicar la causa de la contaminación de As, fue la sobreexplotación de los acuíferos. En estas circunstancias, la Confederación Hidrográfica del Duero realizó una campaña de sondeos para determinar el alcance de esta contaminación, declarando la no potabilidad del agua. En una solución provisional se procedió a la 
instalación de aljibes fijos recargados periódicamente con cisternas, para el abastecimiento de agua de la población. Para solucionar definitivamente el problema, la administración propuso una serie de abastecimientos mancomunados (con posibilidades de ampliación) desde los ríos Adaja y Eresma. Desde mediados de junio de 2002 el abastecimiento de agua se canaliza a medio centenar de pueblos, a través de abastecimientos mancomunado desde los ríos Adaja (Ávila) y Eresma (Valladolid y Segovia). Es por esta razón que los pozos que abastecían al servicio municipal de aguas quedaron clausurados y sólo son utilizados los pozos destinados a agua de riego.

En la actualidad (2012), debido a que el análisis del As ha sido incluido en los análisis de rutina del agua de bebida, se han contabilizado 69 municipios de Castilla y León, donde el nivel de arsénico del agua sobrepasa los límites recomendados de $10 \mu \mathrm{g} / \mathrm{l}$, las provincias afectadas son Ávila, Segovia, Valladolid, Zamora y Salamanca.

El área de estudio de esta tesis se restringe a algunos municipios de las provincias de Valladolid y Segovia, los cuales están situados en el sur de la Cuenca del Duero. 


\section{Objetivos}

El objetivo general de esta tesis es contribuir al conocimiento de las causas de la contaminación por arsénico de las aguas subterráneas de un sub-sector de la Cuenca Terciaria del Duero y su evolución temporal, así como el impacto de la distribución de As en los suelos agrícolas habitualmente regados con aguas subterráneas ricas en este elemento a través de la identificación de factores de bioacumulación en los vegetales utilizados para el consumo humano y detectar posibles riesgo para la salud.

El objetivo específico de nuestro primer trabajo publicado (García-Sánchez et al., 2005), fue contribuir al conocimiento de las causas de la contaminación por arsénico de las aguas subterráneas en el área de estudio que comprende parte de las provincias de Valladolid y Segovia del suroeste de la Cuenca del Duero. En esta área una gran cantidad de pozos y sondeos presentaban contaminación por arsénico.

Dado que los contenidos de arsénico en los acuíferos superan $50 \mu \mathrm{g} / \mathrm{l}$ y son intensivamente explotados para el riego, se planteó realizar en la misma área un estudio del agua destinada a la agricultura y conocer su incidencia en suelos y cultivos. Por consiguiente el objetivo específico del segundo trabajo publicado (Moyano et al., 2009), fue investigar la distribución de arsénico en los suelos agrícolas y los cultivos, para conocer la influencia del riego con agua contaminada por arsénico y estimar su impacto en la cadena trófica.

En el tercer trabajo se fijó como objetivo mostrar la variación temporal del contenido de As en las aguas subterráneas en tres períodos de estudio y su relación con la aparición de elevadas concentraciones de $\mathrm{NO}_{3}{ }^{-}$en las aguas de riego. Como se ha citado anteriormente la formación de complejos en la superficie de los $\mathrm{FeOOH}$ y los procesos redox con participación de los iones de hierro, tienen un efecto importante en la movilidad del As (Cummins et al., 1999). Este es el caso de los nitratos presentes en los acuíferos a causa de las prácticas agrícolas (Mayorga et al., 2012)

En el último trabajo se pretendió ampliar la información obtenida de anteriores estudios de campo realizados en las provincias de Valladolid y Segovia, sobre el impacto de la distribución de As en los suelos agrícolas, habitualmente regados con aguas subterráneas ricas en este elemento, a través de la identificación de la bioacumulación en los vegetales utilizados para el consumo humano y detectar si implica riesgo para la salud (Moyano et al., 2009). La zanahoria es un vegetal muy cultivado y consumido 
tanto en esta área como en todo el mundo, por esta razón fue elegido para investigar los resultados de estudios anteriores a través de un ensayo en invernadero (a temperatura y humedad controladas). La zanahoria presenta gran tolerancia a elevados niveles de As (Grant and Dobbs, 1977). El objetivo principal de este estudio fue determinar la absorción de As por la raíz y su acumulación tanto en las raíces como en las hojas, de zanahorias cultivadas en una muestra de suelo recogida en el área de estudio y regado con cantidades crecientes de As. Se buscó conocer el As disponible a nivel de la rizosfera y la bioacumulación, comportamiento, y localización del As en los diferentes órganos de la zanahoria. También se estimó la relación del As soluble en suelo con el As en la planta (Mayorga et al., 2012) 


\section{Material y métodos}

El área objeto de estudio se encuentra en la Cuenca Terciaria del río Duero, provincias de Valladolid y Segovia.

Geológicamente la sucesión miocena de este área (Figura 1), puede ser agrupada de forma informal en cuatro unidades estratigráficas, denominadas de muro a techo: Unidad margosa o facies Dueñas, unidad lutítica o facies Tierra de Campos, unidad yeso-margosa o facies Las Cuestas y unidad de los carbonatos o facies los Páramos (IGME, 1982, Armenteros, 1991).

La unidad margosa tiene un espesor de alrededor de $40 \mathrm{~m}$ y está formada por margas y arcillas. La unidad lutítica tiene un espesor de alrededor de $80 \mathrm{~m}$ y está formada por arcosas intercaladas con arcillas, arenas con limos, algunos paleocanales de arenas y gravas. La unidad yeso-margosa tiene un espesor de 80-100 m y está constituida por limos, arcosas, areniscas, conglomerados y algunas capas de sedimentos calizos o de yeso. La unidad de los carbonatos está compuesta principalmente por rocas calizas y tiene un espesor de 10-20 m.

Los materiales cuaternarios son principalmente arenas eólicas de 5-15 m de espesor, también existen otros sedimentos aluviales dispuestos en terrazas.

El basamento Precámbrico-Paleozoico consiste en rocas metamórficas (pizarras arenosas, fillitas, y en menos cantidad bandas de pizarras negras, grauvacas, cuarcitas y conglomerados intercalados), también hay diversos tipos de granitos hercínicos con presencia de mineralización (Sn, W, S, As, etc.) en numerosas ocasiones, sobre todo hay que destacar la presencia de pirita en las pizarras negras (IGME, 1982).

La Cuenca del río Duero contiene quizás el más importante sistema de acuíferos de la Península Ibérica, se pueden subdividir en varios acuíferos regionales (IGME, 1980). En los terrenos cuaternarios hay varios acuíferos superficiales no confinados situados en las capas de arenas de 5-15 m de espesor ("Arenales"), muy permeables. Además, en algunas zonas del área de estudio, se encuentran otros acuíferos libres en calizas (fracturas y cavidades) del Mioceno Superior (facies "Los Páramos"). Los acuíferos más importantes son los más profundos (acuífero profundo multicapas) situados en arcosas y paleocanales de arenas y gravas, facies "Villalba de Adaja" (denominación local perteneciente al Mioceno Inferior y Medio, sus sedimentos alimentaban un sistema lacustre cuyo registro actual es la facies Dueñas). 


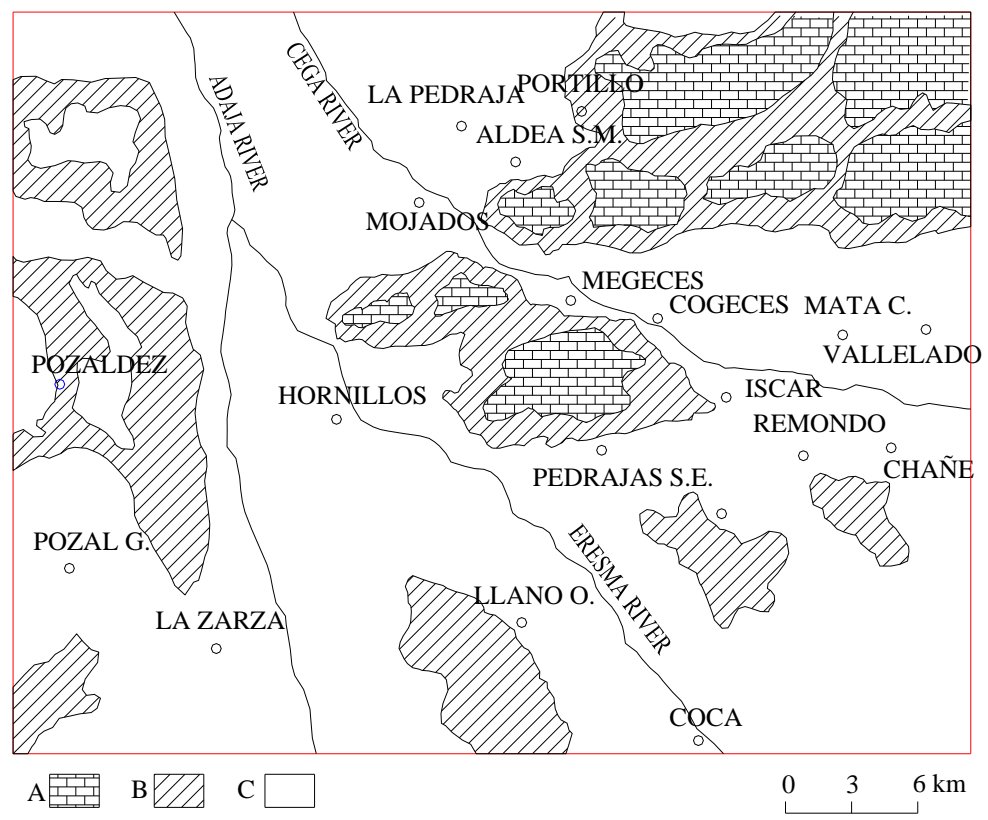

A: Limestones, Facies "Los Paramos". Upper Miocene

B: Clays, marls, gypsum, Facies "Las Cuestas". Middle-upper Miocene

C: Aeolian sands, arkoses, Quaternary, "Arenales"

\section{Figura 1. Carácteristicas litológicas del área de estudio}

Estos acuíferos, que son los más importantes en términos de producción de agua, drenan hacia la parte central de la cuenca del río Duero. Su recarga se origina en parte por las filtraciones de los acuíferos no confinados superiores, "Arenales" (Figura 2).

El clima de la región es mediterráneo continental con baja humedad, la precipitación anual es $500 \mathrm{~mm}$ muy irregular y normalmente ausente en julio y agosto. Durante la estación seca el balance hídrico es negativo.

Los pozos muestreados se localizan en las provincias de Valladolid y Segovia. En el primer estudio se muestrearon 30 pozos de febrero a mayo de 2001 (se seleccionaron 28). Para el segundo trabajo se muestrearon 35 pozos en el año 2003. Para el tercer trabajo se realizó un tercer muestreo de 30 pozos durante el año 2007 y para ver la evolución temporal utilizamos los datos de las aguas recogidas en los años 2001 y 2003, por lo tanto, se utilizaron muestras de tres períodos diferentes: 1) 30 muestras que fueron recolectadas durante el año 2001, 2) 35 muestras que fueron recolectadas durante el año 2003 y 3) 30 muestras recolectadas durante el año 2007. 


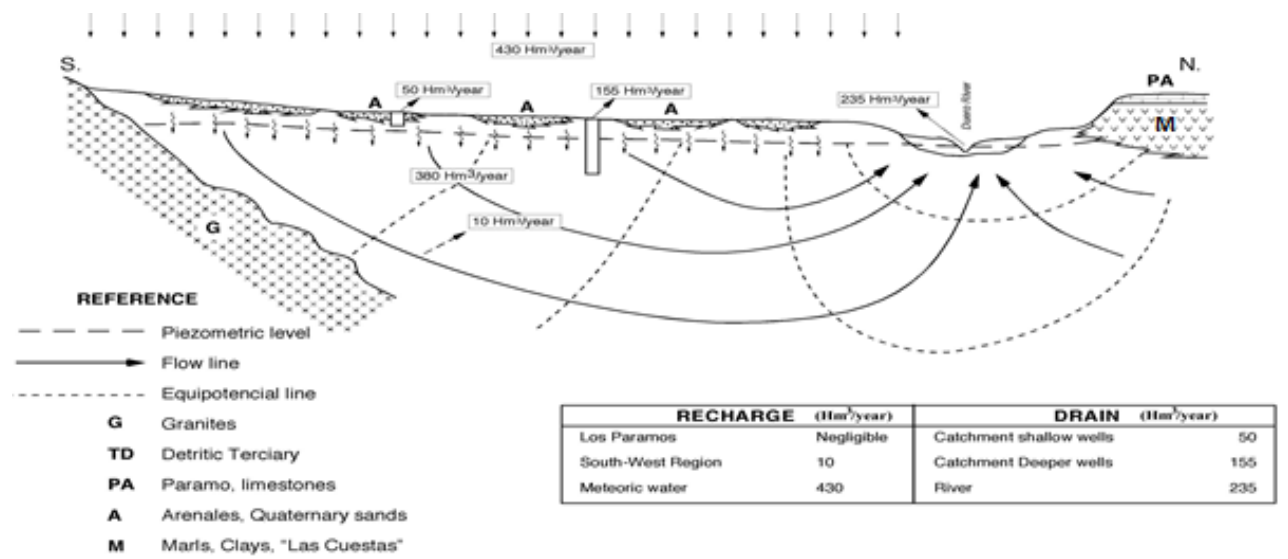

Figura 2. Modelo de flujo del agua subterránea en el área de estudio

Análisis de las aguas:

Las muestras de agua se recogieron en botes de polietileno esterilizados e "in situ" se separaron porciones de las muestras para el estudio de la concentración de hierro que fueron acidificadas con ácido clorhídrico al 1\% para evitar la precipitación de los oxihidróxidos de hierro. También "in situ" se analizó $\mathrm{pH}$, Eh, y conductividad eléctrica (CE). En el laboratorio se filtraron las aguas con filtro de 0.45 micras. El As se analizó con un espectrofotómetro de absorción atómica (AAS), Varian spectra AA-220 y generador de hidruros VGA-7A, siguiendo el método de Jiménez et al., (1996). La precisión analítica fue determinada con BCR y material de referencia CRM-320 y US Geológicas Survey Referente G-I. La precisión del método fue valorada por ejecución de análisis de 10 veces para una muestra. La desviación estándar fue 5-10\%.

Los sulfatos, cloruros y nitratos fueron analizados por cromatografía iónica (Metrohm): $\mathrm{Ca}, \mathrm{Fe}, \mathrm{Mg}, \mathrm{Na}$, y K por AAS y los bicarbonatos por titulación.

Para los análisis microbiológicos del agua, alícuotas de las muestras de algunos pozos guardadas en contenedores estériles, se almacenaron a $4^{\circ} \mathrm{C}$ hasta su análisis, que se realizó en las 24 horas siguientes. Se filtraron $50 \mathrm{ml}$ de agua en una membrana Millipore de 0.45 micras y los filtros se pusieron en la superficie de placas Petri con LB Agar (Miller 1972) y Agar de cetrimide (Brown and Lowbury 1965). Las placas se incubaron en condiciones aeróbicas a temperatura de $26^{\circ} \mathrm{C}$ durante dos días, obteniéndose las colonias aeróbicas. Se realizaron test de rutina para la identificación de las colonias (tinción Gram. y citocromo oxidasa). 
En el segundo estudio, para conocer distribución de arsénico en la columna estratigráfica se recolectaron y se estudiaron 62 muestras de rocas y sedimentos de varias secciones estratigráficas, en el área estudio o cercanas (Portillo, Cuellar, Villalba de Adaja, Zaratán, Villamayor, Los Villares y Salamanca).

Las muestras de los suelos y los cultivos fueron obtenidas en parcelas de Arrabal de Portillo, Chañé, Pozal de Gallinas, Mojados, Megeces Remondo, Pedraja de Portillo, Hornillos de Eresma, e Iscar. Se recogieron 23 muestras de suelo procedentes de parcelas regadas con agua rica en arsénico. Se recogieron tres muestras de suelo como control, en áreas cercanas a los lugares donde se había detectado la presencia de arsénico (Olmedo, Tudela de Duero).

Para alcanzar el objetivo del cuarto estudio, la muestra de suelo fue recogida en una parcela situada a ( $\left.41^{\circ} 2036.33 \mathrm{~N}^{\circ} 2844.89 \mathrm{~W}\right)$, en la localidad de Remondo, provincia de Segovia. Esta es una zona de agricultura intensiva situada en el área de estudio, afectada por la presencia de As en el agua de riego procedente de aguas subterráneas. La muestra de suelo correspondiente al horizonte Ap, se tomo en los primeros $20 \mathrm{~cm}$ de profundidad, este suelo está clasificado como Arenosol cámbico (JCYL Mapa de Suelos de Castilla y León 1988).

Análisis de propiedades del suelo:

Para el análisis de las propiedades del suelo, del segundo estudio, las muestras de suelo fueron secadas a peso constante con circulación de aire a $50{ }^{\circ} \mathrm{C}$, mezcladas, homogeneizadas y pasadas a través de un tamiz de $2 \mathrm{~mm}$. Las fracciones menores de 2 $\mathrm{mm}$ fueron usadas para determinar las propiedades en suelo, el $\mathrm{pH}$ fue determinado potenciométricamente, el carbono orgánico (CO) y carbono inorgánico (carbonato cálcico) por un cromatógrafo H.Wostoff. GMBH y la capacidad de intercambio catiónico por el método Chapman (1965).

Análisis del contenido de As de suelos y rocas:

Para el segundo estudio, las muestras de suelo y de rocas se molieron y homogeneizaron a partículas de menos de $0.1 \mathrm{~mm}$ para su análisis. Alícuotas de $0.1 \mathrm{~g}$ fueron digeridas con $5 \mathrm{ml}$ de agua regia $+1 \mathrm{ml}$ de HF usando un horno de microondas CEM MDS-2000 a presión de siete atmósferas durante 30 minutos. Las determinaciones de arsénico fueron realizados por AAS usando un Varian spectra AA-220 y generador de hidruros VGA-7A, siguiendo un método de Jiménez et al.(1996). La precisión analítica fue medida con material de referencia BCR CRM-320 (sedimento de río) y U.S. Geological Survey Reference G-2 granito. Se valoró la precisión del método con el análisis de 10 
veces la muestra. La desviación estándar relativa fue entre 5-10\%.

Análisis de As en los tejidos vegetales:

En nuestro segundo trabajo se recolectó un total de 45 muestras de zanahoria (Daucus carota L.), patata (Solanun tuberosum L.), trigo (Triticum aestivum L.) y remolacha azucarera (Beta vulgaris L.) procedentes del área contaminada y 12 muestras del área control.

Los tejidos vegetales se lavaron con agua, se enjuagaron con agua desionizada y se secaron al aire a temperatura ambiente durante varios días y después se secaron en el horno a $60^{\circ} \mathrm{C}$ hasta peso constante. Posteriormente, se homogeneizaron y molieron a menos de $1 \mathrm{~mm}$ para el análisis. Alícuotas $0.5 \mathrm{~g}$ de muestra de raíz y de hojas, fueron digeridos con $2 \mathrm{ml}$ de agua, $2 \mathrm{ml}$ de agua oxigenada y $8 \mathrm{ml} \mathrm{de} \mathrm{HNO}_{3}{ }^{-}$, usando un microondas CEM MDS-2000 sin presión durante 10 minutos y a 12 atmósferas de presión durante 15 minutos. Después de refrigerar el producto de la digestión fue pasado a través de un filtro Whatman $\mathrm{n}^{\circ}$ 540, previamente lavado. Los tubos de digestión se lavaron tres veces pasando el agua a través del filtro y los materiales resultantes de la digestión fueron enriquecidos con $\mathrm{H}_{2} \mathrm{SO}_{4}(0.5 \mathrm{ml})$. Posteriormente, se procedió al calentamiento a $230^{\circ} \mathrm{C}$ durante 2-3 horas para la concentración por evaporación hasta $0.5 \mathrm{ml}$ aproximadamente. Finalmente, se adicionaron $5 \mathrm{ml}$ de ácido ascórbico $25 \%, 5 \mathrm{ml}$ de ioduro potásico $25 \%$ y ácido clorhídrico $2 \mathrm{M}$ hasta alcanzar un volumen de digerido de $25 \mathrm{ml}$ (Hammel et al., 2000). La concentración de As fue medida por duplicado utilizando un Varian spectra AA-220 con generador de hidruros VGA-76 AAS

La curva de calibración, mostró valores de $\mathrm{R}^{2}>0.98$ en todos los casos. El análisis de un material de referencia certificado (hojas de maíz FD8 Comisión de la Comunidad Europea dentro de la agrupación de investigación ISPRA), no fue significativamente diferente del valor del certificado $0.77 \pm 0.1 \mathrm{mg} / \mathrm{kg}$ ). La mayor concentración de arsénico de los controles fue de $0.09 \mu \mathrm{g} / 1$ y el límite de detección de $0.07 \mu \mathrm{g} / \mathrm{l}$.

Para realizar el análisis del arsénico soluble en agua: se mezclaron el suelo y el agua miliQ en proporción 1:10 y la solución fue agitada 24 horas usando un agitador rotatorio. La solución fue centrifugada a $3000 \mathrm{rpm}$ y el sobrenadante fue recogido y filtrado con un filtro de 0.45 micras. La concentración de arsénico en el sobrenadante se determinó con el método AAS.

Con los datos se calculó el coeficiente de transferencia y el factor de bioacumulación. 
El coeficiente de transferencia (CT), fue calculado como la relación entre la concentración de arsénico en planta respecto la concentración de arsénico en suelo As $\mathrm{CT}=\left[\mathrm{As}_{\text {planta }} / \mathrm{As}_{\text {suelo }}\right]$ ambos en miligramos por kilogramo.

El factor de bioacumulación (FB), fue calculado como la relación entre la concentración de arsénico en planta respecto la concentración de arsénico del suelo soluble en agua. $\mathrm{As} \mathrm{FB}=\left[\mathrm{As}_{\text {planta }} / \mathrm{As}\right.$ solub suelo $]$ ambos en miligramos por kilogramo.

Los box and whisker plots se realizaron con el programa de estadística SPSS 12.0.

Ensayo en invernadero:

Para el ensayo en invernadero del cuarto estudio, que se inició el 1/6/2008, se prepararon 21 tiestos con $4 \mathrm{~kg}$ de muestra de suelo cada uno y se sembraron 6 semillas de zanahoria (Daucus carota L. variedad comercial Nantesa). En función de los valores de $\mathrm{pF}(\mathrm{pF} 4.2$, Humedad $=2.68 \%$ y $\mathrm{pF} 2.7$, Humedad $=14.79 \%)$ se regaron con un media de $200 \mathrm{~m} 1 /$ día). Se utilizaron 5 tiestos como control y el resto se regaron con aguas que contenían cantidades crecientes de As: 4 tiestos con $20 \mu \mathrm{g} / \mathrm{l}, 4$ con $50 \mu \mathrm{g} / \mathrm{l}, 4$ a $100 \mu \mathrm{g} / \mathrm{l}$ y 4 a $150 \mu \mathrm{g} / \mathrm{l}$. El abonado de realizó en dos aplicaciones (los días 01/06/2008 y 19/08/2008), con las siguientes componentes y dosis respectivamente:

$\mathrm{NH}_{4} . \mathrm{NO}_{3}: 1.143 \mathrm{~g} ; 0.171 \mathrm{~g}$;

$\mathrm{K}_{2} \mathrm{H} \mathrm{PO}_{4}: 0.503 \mathrm{~g} ; 0.075 \mathrm{~g}$;

$\mathrm{K}_{2} \mathrm{SO}_{4}: 0.245 \mathrm{~g} ; 0.037 \mathrm{~g}$

$\mathrm{CaCl}_{2} \cdot 2 \mathrm{H}_{2} \mathrm{O}: 0.522 \mathrm{~g} ; 0.078 \mathrm{~g}$

$\mathrm{MgSO}_{4} .7 \mathrm{H}_{2} \mathrm{O}: 0.304 \mathrm{~g} ; 0.045 \mathrm{~g}$

A los 30 días se hizo un clareo y se dejaron 4 plantas por tiesto. A los 131 días de iniciado el ensayo se realizó la recolección. Se obtuvieron un total de 61 muestras de tejido de raíz y 61 muestras de tejido de hojas. Para la determinación de las propiedades del suelo y los análisis de As en suelo y tejidos de zanahorias, se realizaron los mismos métodos de los estudios anteriores. 


\section{Resultados y discusión}

En el primer trabajo, los resultados obtenidos del análisis de las aguas recolectadas en 2001 (Tabla 1), muestran que los valores medios de As más elevados corresponden a pozos profundos asimismo, muestran algunas correlaciones significativas (Figura 3 y Figura 4). La concentración de bicarbonato correlaciona significativamente con la de As $(\mathrm{R}=0.66$ y $\mathrm{P}<0.01)$. Esto sugiere un posible mecanismo de liberación de As desde los sedimentos del acuífero, proceso señalado por Nickson et al., $(1998,2000)$ en aguas subterráneas de Bangladesh.

Tabla 1. Composición química de las aguas (valores en mg/l; As en $\mu \mathrm{g} / \mathrm{l}$ )

\begin{tabular}{|c|c|c|c|c|c|c|c|c|c|c|c|c|c|}
\hline $\mathrm{o}$ & $\mathrm{Lc}$ & $\mathrm{HCO}_{3}$ & $\mathrm{NO}_{3}^{-}$ & $\mathrm{SO}_{4}=$ & $=\mathrm{Cl}^{-}$ & As & $\mathrm{pH}$ & $\mathrm{Ca}$ & $\mathrm{Mg}$ & $\mathrm{K}$ & $\mathrm{Na}$ & $\mathrm{Fe}$ & $\mathrm{Eh}(\mathrm{mV})$ \\
\hline 1 & Mojados $150 \mathrm{~m}$ & 263 & 9 & 82 & 41 & 150 & 8.2 & 6 & 4.9 & 3.2 & 203 & $<0.01$ & 231 \\
\hline 2 & Megeces $116 \mathrm{~m}$ & 269 & 6 & 40 & 19 & 260 & 9.1 & 2 & 0.9 & 6.8 & 230 & 0.02 & 218 \\
\hline 3 & Megeces $3 \mathrm{~m}$ & 263 & 218 & 766 & 74 & 90 & 8.1 & 251 & 11.7 & 13.3 & 355 & 0.01 & 247 \\
\hline 4 & Coca $130 \mathrm{~m}$ & 132 & 1 & 4 & 8 & 100 & 7.9 & 1 & 0.2 & 5.9 & 81 & $<0.01$ & 199 \\
\hline 5 & Cogeces $130 \mathrm{n}$ & 198 & 3 & 9 & 11 & 180 & 8.1 & 1 & 0.1 & 3.5 & 134 & $<0.01$ & 179 \\
\hline 6 & Iscar $360 \mathrm{~m}$ & 276 & 2 & 50 & 18 & 230 & 8.3 & 1 & 0.1 & 2.1 & 166 & 0.03 & 150 \\
\hline 7 & Iscar & 227 & 103 & 186 & 80 & 85 & 7.7 & 63 & 43.3 & 8.5 & 90 & $<0.01$ & 163 \\
\hline 8 & La Pedraja & 83 & 112 & 499 & 80 & 65 & 8.1 & 123 & 80.6 & 14.4 & 461 & $<0.01$ & 180 \\
\hline 9 & La Pedraja $7 \mathrm{~m}$ & 59 & 96 & 433 & 83 & 45 & 8.2 & 113 & 65.6 & 4 & 53 & $<0.01$ & 184 \\
\hline 10 & $\mathrm{LaPe}$ & 137 & 206 & 319 & 143 & 60 & 7.6 & 134 & 64.2 & 22.5 & 57 & $<0.01$ & 209 \\
\hline 11 & a $150 \mathrm{~m}$ & 166 & 1 & 31 & 18 & 115 & 8.2 & 1 & 0.2 & 4.5 & 70 & $<0.01$ & 191 \\
\hline 12 & Aldea S.M. 3 m & 114 & 60 & 104 & 17 & 90 & 7.6 & 61 & 16.7 & 13 & 11 & 0.03 & 184 \\
\hline 13 & Aldea S. M. $120 \mathrm{~m}$ & 248 & 2 & 58 & 14 & 110 & 8.6 & 1 & 0.6 & 1.6 & 166 & 0.02 & 151 \\
\hline 14 & S.M. $4 \mathrm{~m}$ & 149 & 85 & 180 & 25 & 55 & 7.7 & 70 & 19.8 & 45.2 & 239 & $<0.01$ & 301 \\
\hline 15 & Arrabal P. $140 \mathrm{~m}$ & 120 & 1 & 124 & 118 & 102 & 8.3 & 3 & 1.7 & 2.4 & 208 & 0.20 & 257 \\
\hline 16 & Arrabal P. $3 \mathrm{~m}$ & 149 & 11 & 801 & 42 & 60 & 7.9 & 215 & 86 & 7.7 & 58 & $<0.01$ & 168 \\
\hline 17 & P. $5 \mathrm{~m}$ & 167 & 58 & 800 & 49 & 45 & 7.8 & 180 & 116.1 & 8.8 & 56 & $<0.01$ & 174 \\
\hline 18 & $\mathrm{~s} 80 \mathrm{~m}$ & 378 & 1 & 118 & 169 & 180 & 8.6 & 7 & 2.5 & 2.1 & 289 & 0.31 & 198 \\
\hline 19 & Llano O. $210 \mathrm{~m}$ & 145 & 6 & 11 & 18 & 80 & 9.3 & 1 & 0.4 & 1.3 & 121 & $<0.01$ & 192 \\
\hline 20 & La Zarza $120 \mathrm{~m}$ & 201 & 17 & 14 & 35 & 100 & 8.3 & 3 & 0.5 & 0.4 & 137 & 0.02 & 202 \\
\hline 21 & Pozal G. $140 \mathrm{~m}$ & 177 & 56 & 16 & 30 & 41 & 8.3 & 23 & 13.7 & 2.4 & 58 & 0.01 & 151 \\
\hline 22 & Remondo $230 \mathrm{~m}$ & 144 & 23 & 24 & 18 & 40 & 8.9 & 3 & 3.2 & 1.2 & 125 & 0.01 & 150 \\
\hline 23 & Mata C. $300 \mathrm{~m}$ & 215 & 26 & 345 & 20 & 115 & 9.1 & 121 & 62.7 & 8.8 & 148 & 0.01 & 174 \\
\hline 24 & Mata C. $185 \mathrm{~m}$ & 65 & 1 & 4 & 3 & 20 & 9.4 & 1 & 0.1 & 0.4 & 59 & $<0.01$ & 245 \\
\hline 25 & Villaverde I. $30 \mathrm{n}$ & 140 & 11 & 12 & 9 & 38 & 8.4 & 15 & 5.1 & 3.6 & 36 & 0.03 & 246 \\
\hline 26 & Chañe $300 \mathrm{~m}$ & 145 & 2 & 10 & 6 & 30 & 9.5 & 1 & 0.1 & 0.3 & 110 & 0.01 & 320 \\
\hline 27 & Chañe $185 \mathrm{~m}$ & 201 & 29 & 26 & 15 & 37 & 8.4 & 19 & 8.1 & 2.2 & 83 & 0.01 & 243 \\
\hline 28 & Vallelado $70 \mathrm{r}$ & 164 & 2 & 92 & 7 & 83 & 9.5 & 1 & 0.3 & 1.3 & 149 & $<0.01$ & 400 \\
\hline
\end{tabular}




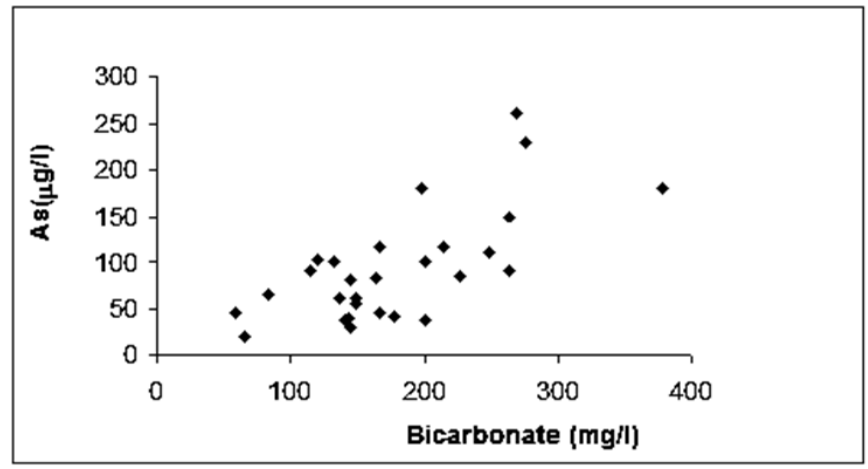

Figura 3. Relación As-bicarbonato As $=-10.20+0.58 \mathrm{HCO}_{3}{ }^{-}(\mathrm{R}=0.69 ; \mathrm{P}<0.01)$

El As, en los sedimentos detríticos del acuífero, podría estar incluido en los oxidróxidos de hierro $(\mathrm{FeOOH})$ que recubren las partículas minerales de arcosas rojas y de paleocanales de arenas y gravas (Nriagu, 1994; Smith et al., 1998). La disolución del hierro provocaría la liberación de As.

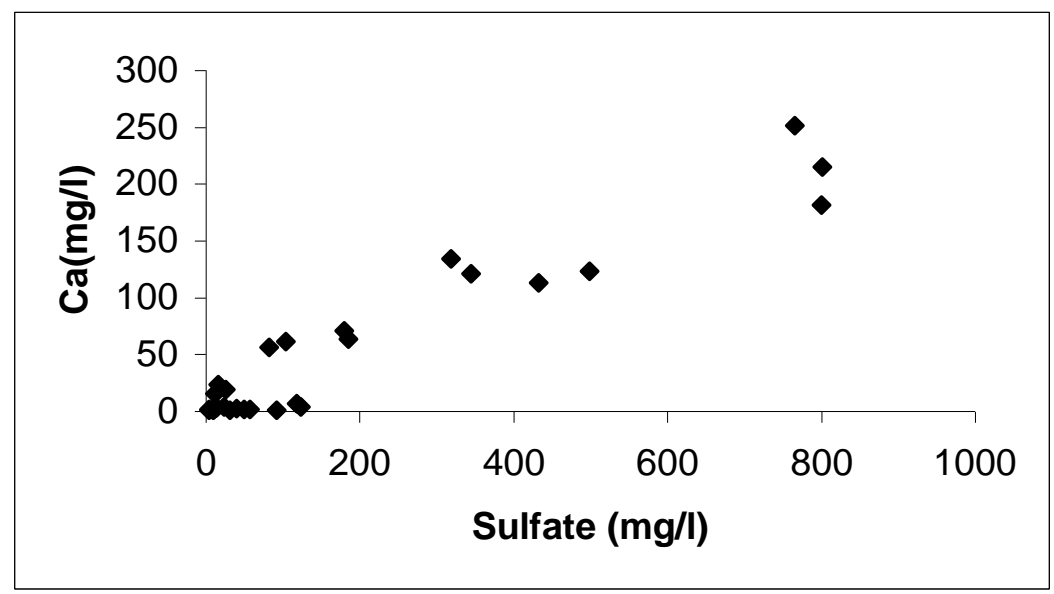

Figura 4. Relación calcio-sulfatos $\mathrm{Ca}^{++}=1.85+0.28 \mathrm{SO}_{4}{ }^{=}(\mathrm{R}=0.91 ; \mathrm{P}<0.01)$

En el caso de las aguas subterráneas estudiadas se observa que el rango de Eh varía de $150 \mathrm{mV}$ a $400 \mathrm{mV}$ (Tabla 1) y de acuerdo con el diagrama Eh-pH para el sistema Asagua la especie termodinámicamente estable es $\mathrm{HAsO}_{4}{ }^{2}$ (Masscheleyn et al., 1991). El hierro disuelto en las muestras de agua es bajo <0.01-0.38 mg/l (Tabla 1), considerando el hierro disuelto como el hierro total que pasa a través del filtro 0.45 micras, el cual puede incluir hierro inorgánico, orgánico y coloidal (adsorbido a arcillas, $\mathrm{FeOOH}$ y 
materia orgánica). A las condiciones señaladas anteriormente, hay que añadir que no hay correlación significativa entre Fe y As. Por lo tanto, se puede concluir que en este ambiente óxico y con baja concentración de hierro, los iones de bicarbonato podrían ser la causa principal de la movilización de As desde los sedimentos al agua subterránea. Van Geen et al., (1994) sugirieron que los aniones de carbonatos adsorbidos sobre la goethita reducen su capacidad de adsorción. Pantsar Kallio and Manninen (1997) constataron la habilidad del bicarbonato para extraer As de un suelo contaminado. Los resultados de Anawar et al., (2004) muestran que las soluciones de bicarbonato extraen el As adsorbido sobre arcillas, arenas y limos.

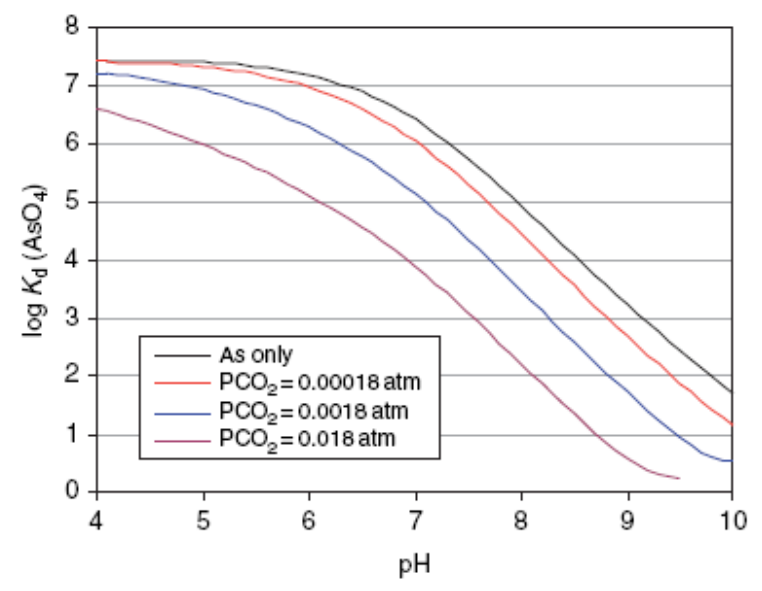

Figura 5. Modelo de competición de adsorción de arseniato y bicarbonato (Gustafsson, 2009)

La acción de los carbonatos en la adsorción sobre la superficie de los minerales, está asociada a reacciones de cambio de ligando con liberación de agua y/o $\mathrm{OH}^{-}$que incrementaría el $\mathrm{pH}$. A $\mathrm{pH}$ alto se ve favorecida la desorción de $\mathrm{HAsO}_{4}{ }^{=}$por la competencia con $\mathrm{HCO}_{3}{ }^{-}$y $\mathrm{OH}^{-}$. Por lo tanto un posible mecanismo de liberación del As sería: que en los acuíferos hay sedimentos que contienen cantidades altas de As adsorbido, cuando estos sedimentos entran en contacto con aguas con una gran cantidad de carbonato disuelto, el As puede ser movilizado por desplazamiento desde la superficie del mineral; este proceso estaría favorecido por concentraciones altas de $\mathrm{OH}^{-}$, en un área de pH elevado (Dzombak and Morel, 1990). A un pH de 8, la adsorción de la ferrihidrita a una presión de $\mathrm{CO}_{2}$ de 0.018 atm $(200 \mathrm{mg} / \mathrm{kg}$ de bicarbonato) es aproximadamente 500 veces menor que sin la presencia $\mathrm{CO}_{2}$ (Figura 5). Esto mismo ocurre con la presencia de otros iones competitivos como fosfatos o silicatos. Cuando la 
variable independiente es el $\mathrm{pH}$ se produce una desorción que crece exponencialmente en un ámbito cercano a 8.5 (Figura 6)

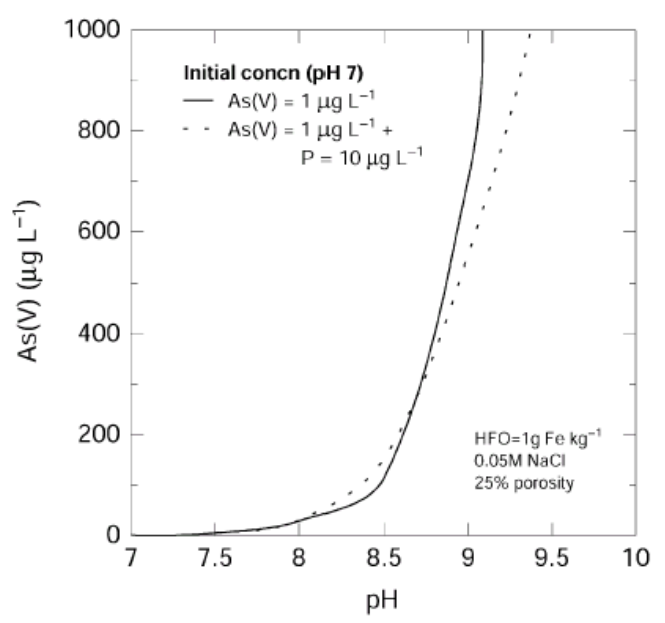

Figura 6. Desorción de As en FeOOH, con 0.1\% de Fe, con el aumento del pH. (Dzombak and Morel, 1990)

Los materiales de la Cuenca del Duero poseen contenidos de As que son relativamente bajos (Figura 7), por lo tanto el As procedería probablemente de la pirita y arsenopirita que podría estar esporádicamente en pegmatitas y filones de cuarzo, así como en otras rocas metamórficas como las pizarras negras y esquistos alterados hidrotermalmente en las áreas fuente, situadas en el Sistema Central. La cantidad de As disuelto estaría en principio en concentraciones muy bajas, de orden de microgramos litro; sin embargo, en un periodo de tiempo lo suficientemente largo podría promoverse una acumulación en los $\mathrm{FeOOH}$ de los sedimentos terciarios.

Otra posibilidad es que la liberación de As desde los sedimentos del acuífero al agua, se deba a la oxidación de la pirita y arsenopirita contenida en estos sedimentos. La excesiva extracción de agua podría haber hecho descender el nivel freático y promover la entrada de oxígeno atmosférico. En estas condiciones se podría haber realizado la oxidación de los sulfuros minerales y la disolución del As contenido en ellos. Sin embargo, esta explicación no es consistente con algunas observaciones. La oxidación de la pirita con oxígeno produce acidez; sin embargo, el pH es alcalino. El año 2001 fue muy lluvioso y por tanto subió el nivel freático; sin embargo, la cantidad de As no descendió. Por otra parte la interpretación de las columnas estratigráficas de la zona de estudio (IGME 1982, Armenteros, 1991) demuestra que no hay pirita ni arsenopirita en los sedimentos terciarios de la zona estudiada. La pirita no se encuentra como mineral 
detrítico y tiene que ocurrir un proceso diagenético en el cual se produzca una reducción del sulfato, posterior a la deposición, como parte de ese proceso de diagénesis. La presencia de pirita framboidal típica de este proceso no se ha encontrado. Incluso si hubiera habido una cantidad de pirita diagenética, probablemente no contendría As. Además, la oxidación de la arsenopirita produce la formación de escorodita $\left(\mathrm{FeAsO}_{4} \cdot 2 \mathrm{H}_{2} \mathrm{O}\right)$, que es muy insoluble. Además la hidrólisis de escorodita produce oxihidróxidos de hierro (goethita etc.) que tienen gran capacidad de adsorción del As liberado, esta adsorción impediría su movilización (Mok and Wai 1994, Joshi and Chaudhuvi, 1996, García Sánchez et al., 2002).

El arsénico contenido en las muestras de rocas y sedimentos de las columnas estratigráficas estudiadas (Figura 7) no es muy alto, con un rango entre 1.8 y 47.6 $\mathrm{mg} / \mathrm{kg}$. Los valores más altos (30.0-47.6 mg/kg) se encontraron en muestras de rocas opalinas con más de $3 \%$ de contenido $\mathrm{Fe}_{2} \mathrm{O}_{3}$, las cuales pertenecen al Paleógeno, en algunas arcosas rojas del Mioceno Medio (facies Villalba de Adaja) y margas orgánicas de color negro pertenecientes a la facies Zaratán (Sahún et al., 2004) con un contenido de As medio de 13-17 mg/kg, mientras que los valores más bajos fueron encontrados en las calizas (1.8-4.0 mg/kg del Mioceno Superior, facies Los Páramos).

La alta correlación entre $\mathrm{Ca}^{++}$y $\mathrm{SO}_{4}{ }^{2}$, observada en las aguas (Figura 4) indican dos procesos probables acerca del origen de los iones presente en el agua. En los pozos superficiales (< de $10 \mathrm{~m}$ ), situados en el estrato de la facies Las Cuestas, poseen abundante yeso debido a la disolución directa de este mineral. En cuanto a los pozos profundos, con bajos contenidos de ambas formas químicas, se producirían procesos de meteorización mineral y reacciones de intercambio iónico en margas o lutitas. Si el arsénico estuviera siendo liberado de las aguas subterráneas por oxidación de la pirita o arsenopirita, sería lógico encontrar una correlación significativa entre el As y el sulfato. Sin embargo, no existe tal correlación lo cual está de acuerdo con lo encontrado por Jain y Lepert (2000) que sostienen que el sulfato tiene poca influencia sobre la adsorción o movilización del As.

Los procesos de liberación de As también pueden ser coadyuvado por determinados microorganismos que disuelven los $\mathrm{FeOOH}$ reduciendo el $\mathrm{Fe}^{+++}$. Esta movilización de As ha sido propuesta por Langner y Inskeep (2000) en la reducción de Fe por Clostridium sp y por Cumming et al., (1999) con Shewanella algae Strain Bry. 


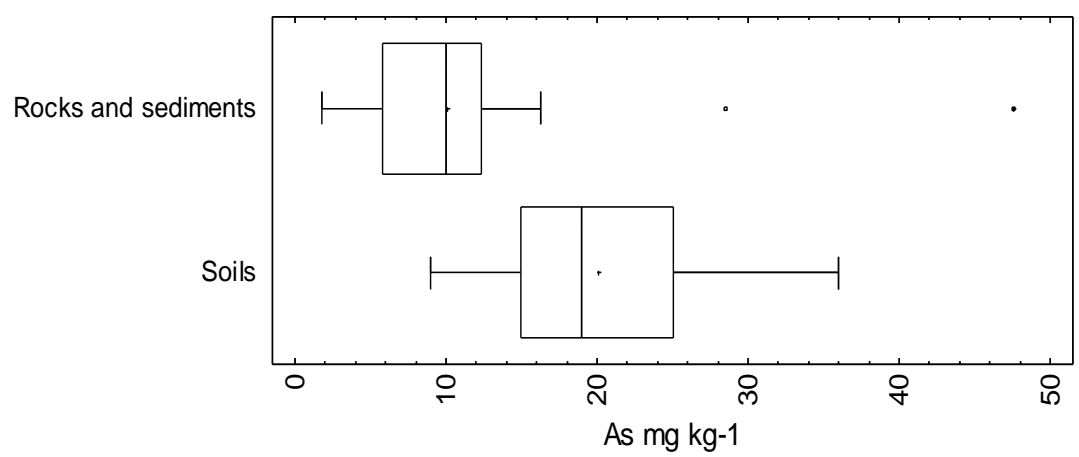

Figura 7. Box and whisker plots de la concentración de As en rocas y sedimentos de las columnas estratigráficas de la Cuenca del Duero y la concentración de As en los suelos agrícolas

Los resultados de los análisis microbiológicos muestran la presencia de colonias Gram $^{-}$ y oxidasa $^{+}$incluidas en el género Pseudomonas (Tabla 2). Estos microorganismos producen una serie de biomoléculas denominadas sideróforos que acomplejan fuertemente el Fe incrementando la disolución de los oxihidróxidos de Fe (Kalinowski et al., 2000; Maurice et al., 2000; Newman and Banfield 2002; Violante et al., 2003). Este proceso podría liberar el As adsorbido en los oxihidróxidos de Fe. Por consiguiente además del As liberado por el bicarbonato, otro mecanismo de movilización podría ser la liberación del As de los óxidos de Fe inducido por moléculas quelantes producidas por microorganismos (Pseudomonas).

Tabla 2. Resultados del análisis microbiológico

\begin{tabular}{|l|l|c|c|l|}
\hline $\begin{array}{c}\text { MUESTRAS } \\
\%\end{array}$ & MORFOLOGÍA & $\begin{array}{c}\text { TINCIÓN } \\
\text { DE GRAM }\end{array}$ & OXIDASA & IDENTIFICACIÓN \\
\hline $83 \%$ & Bacilos & - & + & Pseudomonas \\
\hline $33 \%$ & Bacilos & - & - & Enterobacterias \\
\hline $17 \%$ & Bacilos esporulados & + & - & Bacillus \\
\hline $33 \%$ & Cocos & + & $\mathrm{Nd}$ & Staphilococcus? \\
\hline
\end{tabular}

Nd: no determinado 
Por otra parte, cuando se analizaron muestras de aguas, suelos y tejidos vegetales, se observa que los valores de $\mathrm{pH}$ del suelo (Tabla 3), varían desde 6.22 hasta 8.86 con un valor medio de 7.82., la naturaleza calcárea del suelo se debe a la meteorización de margas y calizas de las facies "Las Cuestas" y "Los Páramos". El contenido de materia orgánica es bajo, oscila entre $0.23 \%$ y $2.30 \%$ con un valor medio de $1.16 \%$ y valores de CEC que están entre 2.84 y 16.25 meq/100g, con un valor medio de 8.94 meq/100g, el contenido en carbonatos es alto en algunas muestras, con un valor medio de $6.30 \%$. La presencia de yesos es común, la característica más importante de la mineralogía de los suelos arcillosos, es la presencia de yeso y calcita, heredada de los materiales parentales. Los contenidos de arsénico total en los suelos agrícolas estudiados, son generalmente, mayores de $10 \mathrm{mg} / \mathrm{kg}$, con un rango entre 8.0 y $36.0 \mathrm{mg} / \mathrm{kg}$, superando los contenidos de las áreas control (Olmedo-Tudela del Duero) y el fondo geoquímico regional (Figura 7). Este hecho sugiere que el riego con agua rica en arsénico (38-136 $\mu \mathrm{g} / \mathrm{l}),($

Figura 8), ha sido la causa del aumento de arsénico en los suelos agrícolas.

El arsénico soluble en agua, presenta un rango entre 0.030 y $0.961 \mathrm{mg} / \mathrm{kg}$,

Figura 8), superando el límite de $0.04 \mathrm{mg} / \mathrm{kg}$ recomendados para suelos agrícolas (Bohn et al., 1985) y computado como $0.41-2.50 \%$ del arsénico total, con un valor medio de $1.12 \%$, lo cual es relativamente más alto que algunos suelos de minas contaminados (Warren et al., 2003, Anawar et al., 2006) y más bajo que los valores descritos en suelos industriales contaminados. El arsénico soluble muestra una significativa correlación con el arsénico total $\mathrm{R}=0.78 \mathrm{P}<0.05$ y también con la materia orgánica $(\mathrm{MO}), \mathrm{R}=0.82 \mathrm{P}$ $<0.01$.

El alto pH de los suelos, puede favorecer la desorción de As de los coloides del suelo (Dzombak and Morel, 1990, Smedly and Kinniburg, 2002), incrementando la fracción disponible de arsénico en las soluciones del suelo. Además, la fracción orgánica soluble en el suelo (ácidos fúlvicos y húmicos) puede bloquear los sitios de adsorción disponibles y reducir la adsorción de arsénico, así como formar complejos acuosos de arsénico, en la solución del suelo, que incrementan su movilidad y disponibilidad (Carey et al., 1996, Casado et al., 2007, Lin et al., 2008). 
Tabla 3. Propiedades del suelo y concentración de As en el agua de riego

\begin{tabular}{|c|c|c|c|c|c|c|c|}
\hline & \multicolumn{6}{|c|}{ SUELO } & \multirow{2}{*}{\begin{tabular}{|r|} 
AGUA \\
As \\
$(\mu \mathrm{g} / 1)$
\end{tabular}} \\
\hline Muestra & $\begin{array}{l}\text { As Total } \\
(\mathrm{mg} / \mathrm{kg})\end{array}$ & $\begin{array}{c}\text { As Soluble } \\
(\mathrm{mg} / \mathrm{kg})\end{array}$ & $\mathrm{pH}$ & $\begin{array}{c}\mathrm{CaCO}_{3} \\
(\%)\end{array}$ & $\mathrm{MO}(\%)$ & $\begin{array}{c}\text { CEC } \\
(\mathrm{meq} / 100 \mathrm{~g})\end{array}$ & \\
\hline Arrabal de Portillo-1 & 32 & 0.527 & 7.70 & 5.60 & 1.28 & 10.78 & 125 \\
\hline Arrabal de Portillo-2 & 36 & 0.961 & 7.76 & 8.40 & 2.06 & 6.09 & 79 \\
\hline Arrabal de Portillo-3 & 18 & 0.098 & 7.90 & 6.61 & 0.56 & 3.01 & 79 \\
\hline Arrabal de Portillo-4 & 15 & 0.172 & 7.83 & 3.90 & 2.02 & 3.10 & 125 \\
\hline Arrabal de Portillo-5 & 10 & 0.321 & 7.98 & 35.60 & 1.86 & 6.80 & 125 \\
\hline Mojados-1 & 35 & 0.444 & 7.82 & 9.90 & 1.51 & 16.25 & 136 \\
\hline Mojados-2 & 24 & 0.196 & 8.01 & 8.33 & 1.80 & 14.05 & 105 \\
\hline Mojados-3 & 27 & 0.318 & 7.98 & 7.65 & 1.95 & 12.35 & 120 \\
\hline Hornillos-1 & 22 & 0.061 & 6.22 & 0.30 & 0.26 & 2.84 & 91 \\
\hline Hornillos-2 & 18 & 0.090 & 6.75 & 0.45 & 0.52 & 4.20 & 85 \\
\hline Pozal-1 & 21 & 0.030 & 7.84 & 0.70 & 0.23 & 4.25 & 65 \\
\hline Pozal-2 & 16 & 0.080 & 7.91 & 0.95 & 0.40 & 6.23 & 70 \\
\hline Iscar-1 & 12 & 0.204 & 7.80 & 6.31 & 2.30 & 10.09 & 48 \\
\hline Iscar-2 & 14 & 0.240 & 8.18 & 5.46 & 2.05 & 9.95 & 53 \\
\hline Chañe-1 & 10 & 0.107 & 8.24 & 3.15 & 0.70 & 8.25 & 38 \\
\hline Chañe-2 & 9 & 0.078 & 8.41 & 1.24 & 0.90 & 8.15 & 38 \\
\hline Chañe-3 & 11 & 0.065 & 8.14 & 2.18 & 0.79 & 9.24 & 42 \\
\hline Megeces-1 & 15 & 0.090 & 7.60 & 3.16 & 1.20 & 7.95 & 83 \\
\hline Megeces-2 & 13 & 0.110 & 7.53 & 4.20 & 1.16 & 6.82 & 83 \\
\hline Remondo-1 & 20 & 0.220 & 7.80 & 0.80 & 2.05 & 12.45 & 66 \\
\hline Remondo-2 & 16 & 0.165 & 7.65 & 0.92 & 1.63 & 10.93 & 68 \\
\hline Pedrajas-1 & 19 & 0.080 & 7.48 & 5.80 & 1.05 & 8.60 & 58 \\
\hline Pedrajas-2 & 17 & 0.065 & 7.71 & 4.32 & 1.32 & 7.41 & 55 \\
\hline Olmedo-control & $<10$ & $<0.001$ & 8.86 & 8.25 & 0.90 & 12.40 & 5 \\
\hline Tudela-control-1 & $<10$ & $<0.001$ & 8.41 & 8.10 & 0.88 & 10.85 & 4 \\
\hline Tudela-control-2 & $<10$ & $<0.001$ & 8.28 & 5.90 & 0.92 & 10.40 & 4 \\
\hline
\end{tabular}




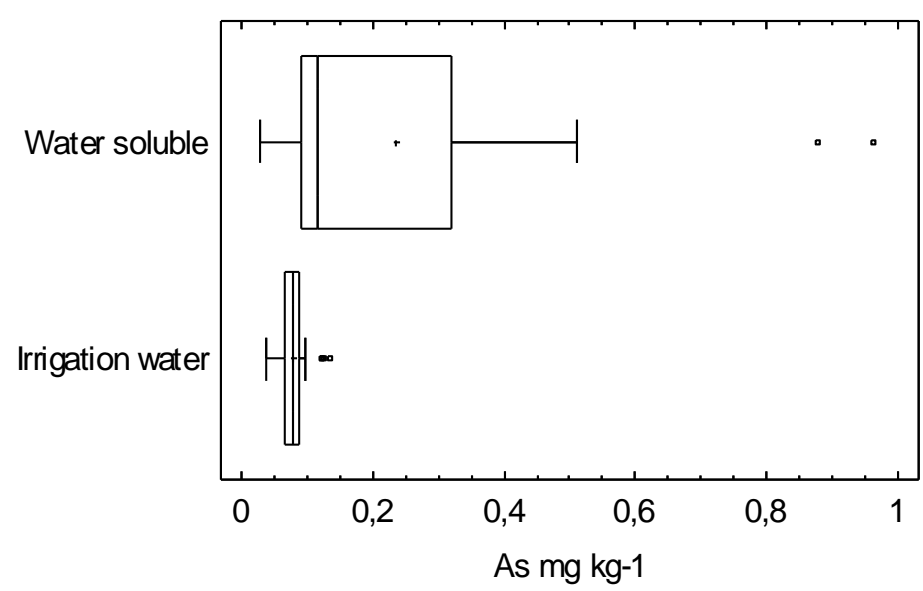

Figura 8. Box and whisker plots de la concentración de As el en agua de riego y la concentración de As soluble en el suelo.

El arsénico contenido en las muestras vegetales (Figura 9) es más alto que el nivel de referencia global de (0.01-1 mg/kg peso seco) (Kabata-Pendias and Pendias, 1992). Algunas de las muestras de plantas exceden los límites de $0.5-1 \mathrm{mg} / \mathrm{kg}$ peso seco para la alimentación establecidas en la normativa vigente de muchos países, tales como Alemania, Reino Unido, India y Países Bajos (FAC, 1975, WHO, 1989, ANFA, 1993, Norra et al., 2005). Además, estos valores superan el contenido de arsénico de las áreas control, las cuales tienen suelos y características climáticas similares, lo cual evidencia el impacto del riego con agua de concentración de arsénico elevada.

\section{Box-and-Whisker Plot}

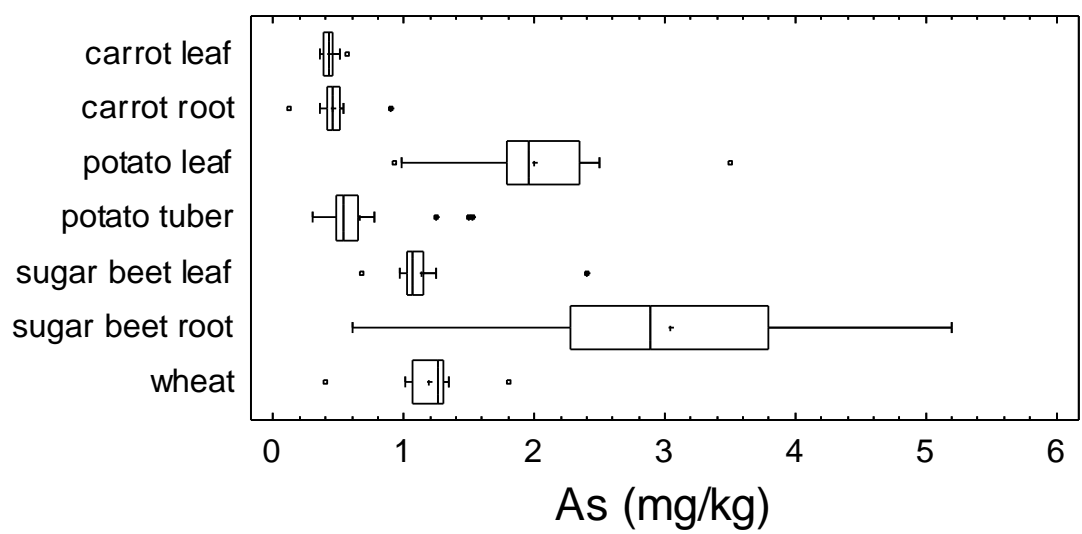

Figura 9. Box and whisker plots del arsénico contenido en las muestras vegetales estudiadas. 
En comparación con algunos datos publicados se evidencia que el contenido de As de los vegetales en el área de estudio es mayor que la de los vegetales de la "cesta de la compra” en España (Llobet et al., 2003), en vegetales de Salamanca (España) (Gómez et al., 1980), en vegetales de una región minera (Cornwal) el Reino Unido (Xu and Thornton 1985) y similar a los vegetales de un área chilena con contaminación geogénica (Lara et al., 2006), en Bangladesh (Goessler and Kuehnelt 2002, Das et al., 2004) y en zanahorias que han crecido en parcelas experimentales en suelos contaminados con arsénico (Helgensen and Larsen 1998, Grant and Dobbs, 1977). Por otra parte el contenido de arsénico encontrado en los vegetales de este estudio es más bajo que aquellos que han crecido cultivados en suelos con concentraciones arsénico disponibles mayores de $1 \mathrm{mg} / \mathrm{kg}$. (Cao and Ma, 2004).

El elevado contenido de arsénico en el trigo (Figura 9), presentaría un riesgo para la salud, ya que es mayor que el valor crítico de $1 \mathrm{mg} / \mathrm{kg}$ peso seco, en vigor en la normativa de muchos países (Norra et al., 2005). Además las concentraciones son más elevadas que las que se han descrito en Bengala, en los cultivos que fueron y regados con aguas subterráneas de alto contenido en arsénico (Norra et al., 2005).

El coeficiente de transferencia oscila entre 0.02 y 0.12 y el factor de bioacumulación es de 1.1 a 15.4 , estos resultados son mayores que los coeficientes de transferencia 0.010.05 y de bioacumulación 1-10 descritos en la literatura (Helgensen and Larsen, 1998, Warren et al., 2003). Estos valores encontrados, especialmente los factores de bioacumulación, muestran una elevada cantidad de arsénico disponible en el área de estudio y por consiguiente un riesgo de introducción en la cadena trófica.

Desde el punto de vista de las implicaciones en materia de salud, el límite de ingesta semanal tolerable para arsénico inorgánico propuesta por la Organización Mundial de la Salud (WHO, 1989) es de $15 \mu \mathrm{g} / \mathrm{kg}$ de peso corporal. Para un adulto que pese $65 \mathrm{kilos}$, la cantidad de ingesta semanal tolerable serían $975 \mu \mathrm{g}$. Teniendo en cuenta que el consumo de vegetales diario recomendado es de 200 g por día y aun suponiendo que se consuman zanahorias o patatas del área de estudio, la cantidad ingerida sería menor de $925 \mu \mathrm{g}$. Por consiguiente la población que consume vegetales esta área no tiene peligro de arsenicosis. Esto no sería igual cuando la población consumiera 400 g de trigo por día), la cantidad ingerida sería de $3550 \mu \mathrm{g}$ de arsénico (basándonos en la media de contenido de trigo) indicando un riesgo para la salud. Por consiguiente el consumo de trigo combinado con vegetales estas áreas podría representar un riesgo para la salud humana. 
Para alcanzar el tercer objetivo se analizaron una serie de parámetros físico-químicos a las muestras de aguas (Tabla 4). El diagrama de Piper (Figura 10), muestra que los procesos geoquímicos fundamentales que se producen en el acuífero (hidrólisis de silicatos y carbonatos, intercambio iónico, precipitación) conducen a una tendencia evolutiva de las aguas subterráneas hacia el tipo de $\mathrm{Na}^{-} \mathrm{HCO}_{3}{ }^{-}$con un $\mathrm{pH}$ alto (8.0-9.0) en un entorno general de procesos aeróbicos. La captación de protones por la meteorización de minerales y el intercambio iónico durante la evolución de las aguas subterráneas, puede ser la razón de la relativamente alta concentración de $\mathrm{OH}^{-}$.

Como se ha indicado anteriormente, la movilidad de arsénico en aguas subterráneas es una función del pH, Eh, el tipo y la abundancia de sitios de absorción en las superficies minerales del acuífero y los iones que compiten por los sitios de adsorción, así como la población microbiana.

La desorción a un pH elevado es un probable mecanismo para la liberación de As en el agua subterránea ya que la alta concentración de $\mathrm{OH}^{-}$así como la presencia de bicarbonatos pueden promover la desorción de arseniato de los sitios de adsorción (Mc Bride, 1994).

El bicarbonato, puede competir con el arseniato por los sitios de adsorción de las superficies minerales, principalmente en los $\mathrm{FeOOH}$, reduciendo así la cantidad de arsénico adsorbido. El papel de bicarbonato en la desorción de arsénico es muy importante a pH alto (Wilkie y Hering, 1996). Anawar et al., (2004) demostraron que las soluciones de bicarbonato puede extraer el arsénico de arenas limos y arcillas de forma eficiente. 
Tabla 4. Resumen estadístico de las propiedades de las aguas

\begin{tabular}{|c|c|c|c|c|}
\hline Propiedad & Año & Rango & Media & Desviación típica \\
\hline \multirow[t]{3}{*}{ As $(\mu \mathrm{g} / \mathrm{l})$} & 1 & $20-260$ & 93 & 60 \\
\hline & 2 & $3-187$ & 48 & 45 \\
\hline & 3 & $5-51$ & 15 & 10 \\
\hline \multirow{3}{*}{$\mathrm{Fe}(\mathrm{mg} / \mathrm{l})$} & 1 & $0.005-0.310$ & 0.03 & 0.066 \\
\hline & 2 & $0.005-0.300$ & 0.03 & 0.050 \\
\hline & 3 & $0.005-0.099$ & 0.02 & 0.023 \\
\hline \multirow{3}{*}{$\mathrm{O}_{2}(\mathrm{mg} / \mathrm{l})$} & 1 & $2.29-8.18$ & 5.71 & 1.90 \\
\hline & 2 & $2.29-8.80$ & 7.47 & 1.68 \\
\hline & 3 & $2.29-8.18$ & 5.66 & 1.82 \\
\hline \multirow[t]{3}{*}{$\mathrm{pH}$} & 1 & $7.7-9.3$ & 8.6 & 0.5 \\
\hline & 2 & $7.2-9.5$ & 8.3 & 0.7 \\
\hline & 3 & $7.1-9.0$ & 8.1 & 0.5 \\
\hline \multirow{3}{*}{$\mathrm{CE}\left(\mu \mathrm{Scm}^{-1}\right)$} & 1 & $202-2980$ & 917 & 732 \\
\hline & 2 & $215-3760$ & 1182 & 837 \\
\hline & 3 & $228-1934$ & 885 & 412 \\
\hline \multirow[t]{3}{*}{$\mathrm{Eh}(\mathrm{mV})$} & 1 & $135-281$ & 198.7 & 38.3 \\
\hline & 2 & $217-668$ & 332.9 & 96.3 \\
\hline & 3 & $144-241$ & 201.8 & 22.8 \\
\hline \multirow[t]{3}{*}{$\mathrm{HCO}_{3}^{-}(\mathrm{mg} / \mathrm{l})$} & 1 & $59.0-378.0$ & 178.4 & 71.1 \\
\hline & 2 & $92.0-413.0$ & 202.2 & 59.8 \\
\hline & 3 & $6.5-386.0$ & 177.5 & 94.7 \\
\hline \multirow{3}{*}{$\mathrm{NO}_{3}^{-}(\mathrm{mg} / \mathrm{l})$} & 1 & $1.0-218.0$ & 41.0 & 59.4 \\
\hline & 2 & $0.3-187.0$ & 37.0 & 44.8 \\
\hline & 3 & $7.0-423.0$ & 81.9 & 93.8 \\
\hline \multirow{3}{*}{$\mathrm{Cl}^{-}(\mathrm{mg} / \mathrm{l})$} & 1 & $2.0-69.0$ & 23.2 & 16.1 \\
\hline & 2 & $3.0-71.0$ & 32.4 & 9.0 \\
\hline & 3 & $3.0-80.0$ & 26.4 & 24.7 \\
\hline \multirow{3}{*}{$\mathrm{CO}_{3}^{-2}(\mathrm{mg} / \mathrm{l})$} & 1 & $0.2-32.2$ & 5.9 & 5.1 \\
\hline & 2 & $0.11-26.5$ & 4.8 & 7.2 \\
\hline & 3 & $0.03-9.7$ & 1.5 & 2.0 \\
\hline \multirow[t]{3}{*}{$\mathrm{SO} 4^{2-}(\mathrm{mg} / \mathrm{l})$} & 1 & $4.0-92.0$ & 41.6 & 27.8 \\
\hline & 2 & $5.0-81.0$ & 34.4 & 23.1 \\
\hline & 3 & $4.0-80.2$ & 38.2 & 23.5 \\
\hline \multirow{3}{*}{$\mathrm{Ca}^{++}(\mathrm{mg} / \mathrm{l})$} & 1 & $0.4-251.1$ & 51.2 & 72.9 \\
\hline & 2 & $1.0-369.9$ & 97.0 & 109.5 \\
\hline & 3 & $0.4-292.0$ & 103.6 & 92.2 \\
\hline \multirow{3}{*}{$\mathrm{K}^{+}(\mathrm{mg} / \mathrm{l})$} & 1 & $0.3-45.2$ & 6.8 & 9.2 \\
\hline & 2 & $0.4-14.0$ & 3.6 & 3.3 \\
\hline & 3 & $0.5-21.0$ & 5.6 & 4.6 \\
\hline \multirow[t]{3}{*}{$\mathrm{Mg}^{++}(\mathrm{mg} / \mathrm{l})$} & 1 & $0.1-117.0$ & 25.5 & 37.5 \\
\hline & 2 & $0.1-158.0$ & 43.9 & 52.8 \\
\hline & 3 & $0.2-163.0$ & 57.9 & 53.7 \\
\hline \multirow[t]{3}{*}{$\mathrm{Na}^{+}(\mathrm{mg} / \mathrm{l})$} & 1 & $10.8-289.2$ & 109.0 & 67.2 \\
\hline & 2 & $3.1-200.0$ & 72.9 & 51.7 \\
\hline & 3 & $6.0-201.0$ & 70.8 & 42.3 \\
\hline \multirow[t]{3}{*}{ Profundidad (m) } & 1 & $120-300$ & 185.0 & 78.5 \\
\hline & 2 & $116-300$ & 216.5 & 97.4 \\
\hline & 3 & $116-380$ & 181.2 & 77.8 \\
\hline
\end{tabular}




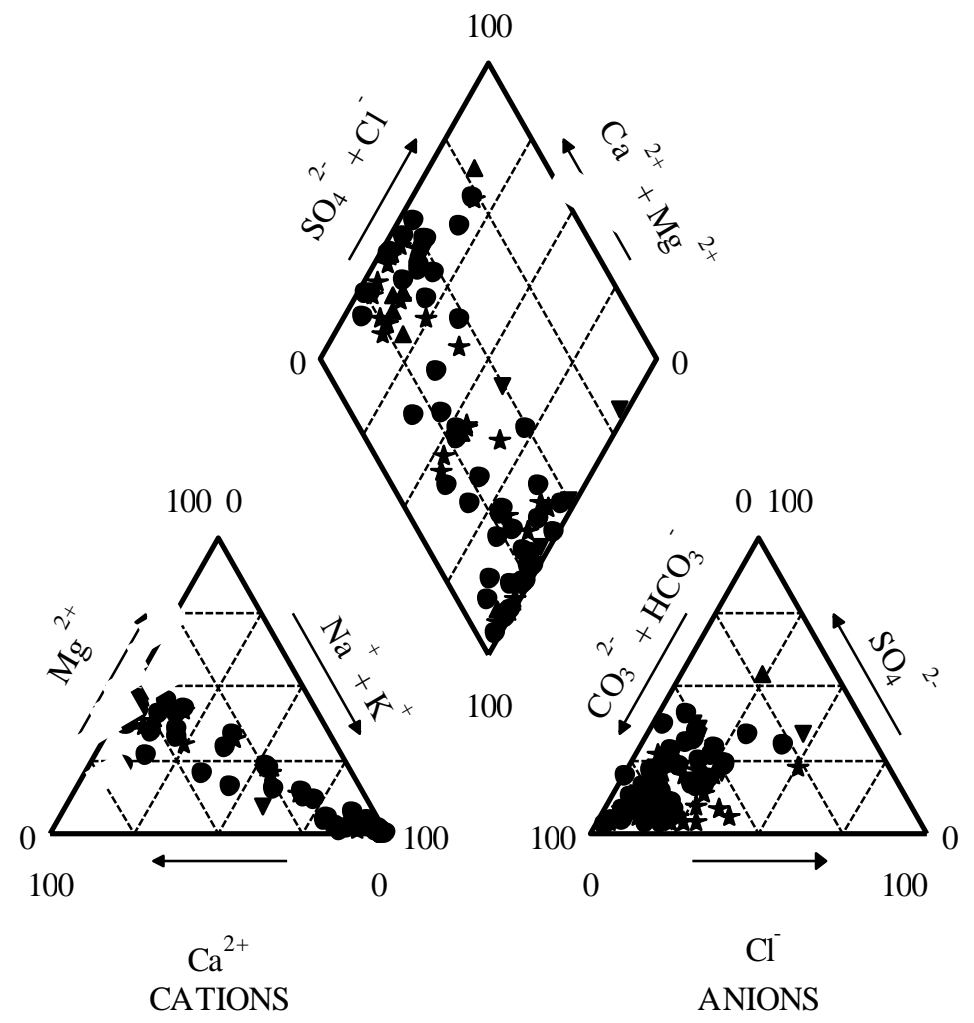

Figura 10. Diagrama de Piper

En relación a lo citado anteriormente, los resultados analíticos de las aguas de este área, muestran que el $\mathrm{pH}$ es alcalino (Tabla 4), habiendo una correlación significativa entre el pH y el contenido de arsénico en el agua (Figura 11); además también existe una importante correlación significativa entre el arsénico y el contenido de bicarbonato en las muestras de agua recogidas a lo largo de primer año estudiado (García-Sánchez et al., 2005), datos coherentes con los resultados obtenidos en otros países (Pantsar-Kallio y Manninen 1997). 


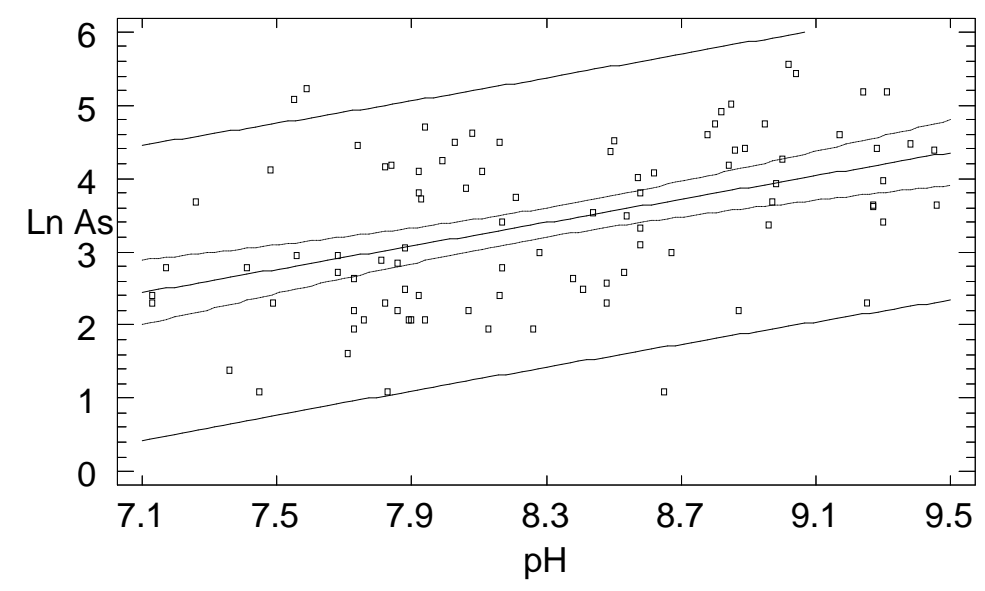

Figura 11. Relación entre pH y Ln As (para la normalización de los datos) $(R=$ $0.54 ; \mathrm{P}<0.01)$

A medida que sube el $\mathrm{pH}$ se libera el arseniato adsorbido, especialmente por encima de pH 8.5. Es posible demostrar este efecto con algunos cálculos en modelos (Figura 6), como el modelo de doble capa difusa (DLM), propuesto por Dzombak y Morel (1990). Además, el modelo confirma que la adsorción de bicarbonato reduce la adsorción de As en los FeOOH, (Gustafsson and Bhattacharya, 2007). Cuando las concentraciones de bicarbonato alcanzan valores de alrededor de $200 \mathrm{mg} / \mathrm{kg}$, (concentración similar a la de nuestro estudio), se produce una disminución de la capacidad de adsorción del As en los FeOOH de alrededor de 500 veces con respecto a la producida en ausencia de este anión. Por lo tanto, bajo estas condiciones de alcalinidad, con concentración de bicarbonato alta, se podría desplazar el arsénico desde los $\mathrm{FeOOH}$ y liberarse en el agua.

Es necesario señalar la correlación negativa entre el arsénico y el contenido de nitrato en el agua, y el aumento de los valores del coeficiente de correlación a lo largo de los tres años sucesivos de estudios, llegando a un valor de $\mathrm{R}=-0,51$ durante el tercer año (Figura 12), lo que explicaría la evolución temporal del contenido de arsénico a lo largo de los tres años estudiados. 


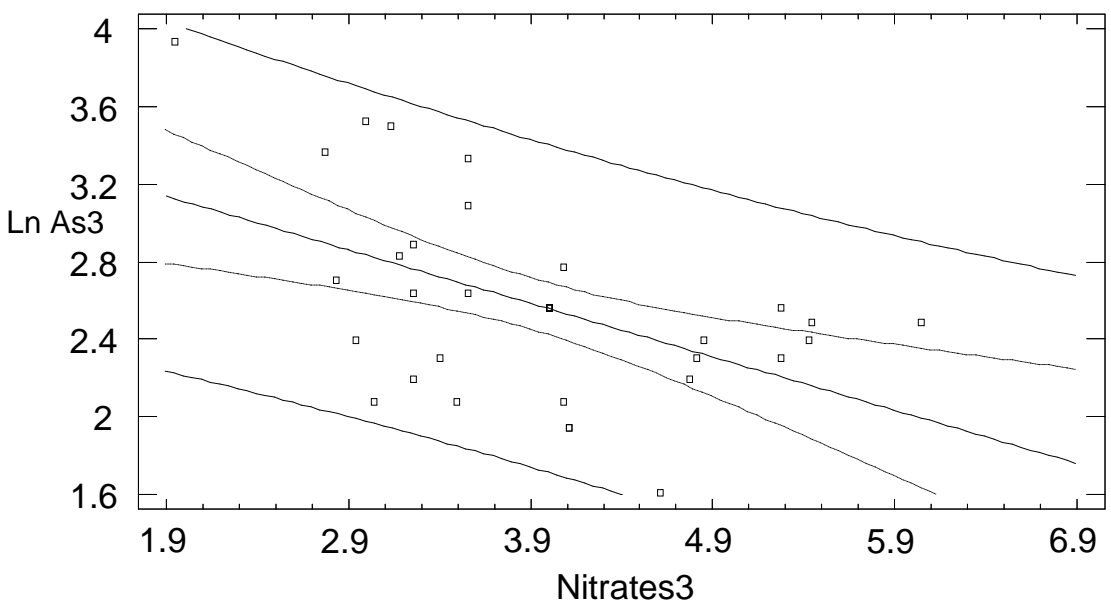

Figura 12. Relación entre Ln As (para la normalización de los datos) con Ln nitratos (para la normalización de los datos) durante el tercer año, $(R=-\mathbf{0 . 5 1} ; \mathbf{P}<$ 0.01)

El arsénico adsorbido en los coloides del suelo aumenta en presencia de nitratos, esto puede ser propiciado porque la oxidación (química o microbiológica) del $\mathrm{Fe}$ (II) favorece la aparición de $\mathrm{FeOOH}$, que son los compuestos más importantes en la adsorción de este elemento (Álvarez-Benedi et al., 2003, Weber et al., 2001, Smedley and Kinninburg, 2002, Senn and Hemond, 2002, Hoeft et al., 2002, Rhine et al., 2007, Sun et al., 2008).

Por otro lado, como se ha citado anteriormente, el contenido de hierro del agua varía entre 0.01 y $0.31 \mathrm{mg} / \mathrm{l}$, este hierro es en realidad el total de Fe que pasa por un filtro de 0.45 micras y que puede incluir el Fe (III) y/o Fe (II) formando compuestos inorgánicos, orgánicos y coloidales (Bauer and Blodau, 2009). Esto podría representar una cantidad suficiente de hierro para adsorber las concentraciones de arsénico en el agua (Tabla 3). Sobre la evolución temporal del contenido de arsénico, se observan diferencias significativas a lo largo de los tres años estudiados (Figura 13). Los datos muestran una disminución del contenido de arsénico en el tercer año. Por otra parte, se observó un aumento del contenido de nitratos en el mismo periodo de tiempo (Figura 14). 


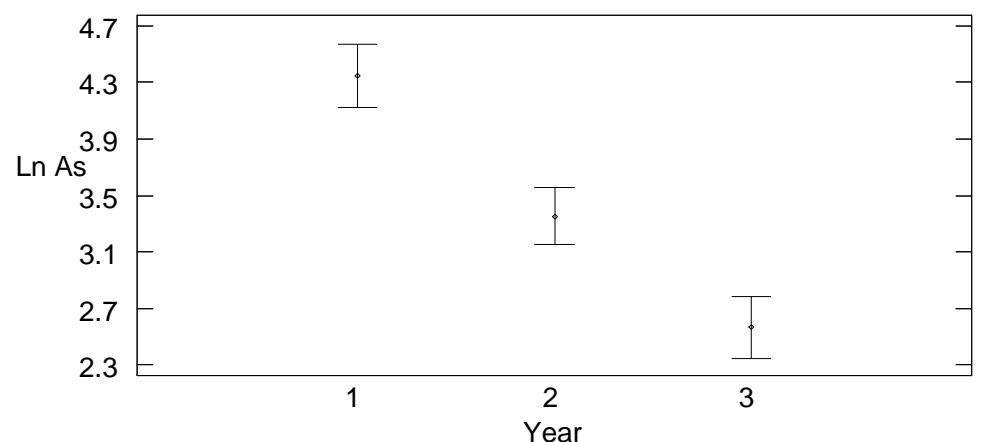

Figura 13. Medias con intervalos LSD al 95\%, de la concentración de As (expresada como Ln para la normalización de los datos) en los tres años de muestreos: $1=2001,2=2003$ y $3=2007$

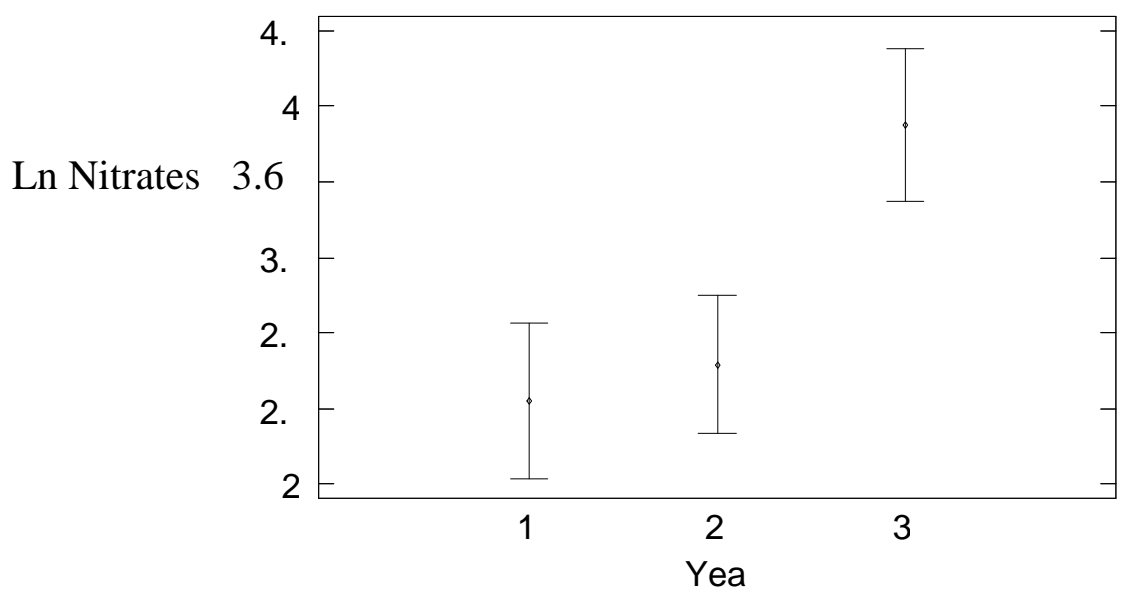

Figura 14. Gráfico de medias y $95 \%$ Fisher LSD, (concentración expresada Ln $\mathrm{NO}_{3}{ }^{-}$para la normalización de los datos) en los tres años de muestreos: 1: 2001, 2: 2003 y 3: 2007

En el área de estudio, la superficie agrícola bajo riego se ha incrementado alrededor del 20\% (AEDCYL, 2004, 2008), esto ha supuesto que la aplicación de nitrato, debido al uso generalizado e intensivo de fertilizantes nitrogenados, también se haya incrementado.

Se ha demostrado que el nitrato, actúa como aceptor terminal de electrones en los sistemas acuáticos y promueve la formación de As (V) y Fe (III), incluso bajo 
condiciones de anoxia (Senn and Hemond, 2002). Según Höhn et al., 2006, en un estudio sobre el transporte de arsénico en un acuífero en el Cabo Cod Massachusetts (EE.UU.), la inyección de nitratos y oxígeno oxida al hierro, y el arsénico (V) se unió a los oxihidróxidos de hierro recién formados. En una prueba en Bangladesh, donde se inyectaron nitratos en un acuífero, se demostró que los niveles de arsénico disuelto se habían reducido, probablemente como resultado de la adsorción en los FeOOH (Harvey et al., 2002).

Estudios de laboratorio han identificado bacterias que pueden realizar la oxidación de Fe (II) mediante la reducción de NO3- (Senn and Hemond, 2002), y pruebas de campo indican que el $\mathrm{NO}^{-}$pueden influir en el ciclo $\mathrm{Fe}$, la reacción es catalizada en la superficie del $\mathrm{FeOOH}$ recientemente precipitado (Postma et al., 1991).

El incremento de nitratos en aguas subterráneas (Branson et al., 1975), podría haber favorecido la precipitación de los oxihidróxidos de hierro, donde el arsénico puede ser adsorbido. Además, el nitrato puede inhibir la reducción Fe (III) en los sedimentos de los acuíferos, evitando la disolución los $\mathrm{FeOOH}$ y así promover la inmovilización del arsénico.

El suelo seleccionado para el ensayo de invernadero, es pobre en materia orgánica, $\mathrm{P}$ biodisponible, y presenta pH cercano a la neutralidad (Tabla 5).

Tabla 5. Características fisicoquímicas del suelo

\begin{tabular}{|l|c|c|c|c|c|c|c|c|}
\hline $\mathrm{pH}$ & $\mathrm{CO}(\%)$ & $\mathrm{M} \mathrm{O}(\%)$ & $\begin{array}{c}\mathrm{N} \\
(\%)\end{array}$ & $\begin{array}{c}\mathrm{P}(\text { Olsen }) \\
(\mathrm{mg} / \mathrm{kg})\end{array}$ & $\begin{array}{c}\text { Arcilla } \\
(\%)\end{array}$ & $\begin{array}{c}\text { limo } \\
(\%)\end{array}$ & $\begin{array}{c}\text { arena } \\
(\%)\end{array}$ & $\begin{array}{c}\mathrm{CIC} \\
(\mathrm{meq} / 100 \mathrm{~g})\end{array}$ \\
\hline 7.2 & 0.45 & 0.77 & 0.038 & 8.3 & 3.3 & 3.1 & 93.6 & 1.76 \\
\hline
\end{tabular}

El análisis granulométrico del suelo, indica textura arenosa, ya que la roca madre son arenas eólicas del Cuaternario y en consecuencia, la capacidad de intercambio catiónico (CIC) es muy baja, 1.76 meq/100 g. El As soluble del suelo después de los ensayos, presentó variaciones dependiendo de su concentración en el agua de riego con valores de $28,44,130,170$ y $196 \mu \mathrm{g} / \mathrm{kg}$ para los tratamientos con concentraciones en el agua de riego de $0,20,50,100$ y $150 \mu \mathrm{g} / 1$, respectivamente.

El contenido de arsénico de las muestras de raíces de zanahoria (Figura 16), regadas con agua con concentraciones de As de 100 y $150 \mu \mathrm{g} / \mathrm{l}$, mostró resultados más elevados que 
los valores de referencia en vegetales (0.01-1 mg/kg de peso seco), (Kabata-Pendias and Pendias, 1992), superando los límites establecidos para los productos alimenticios (0.5 a $1 \mathrm{mg} / \mathrm{kg}$ de peso seco), estipulado por la legislación de muchos países, por ejemplo, Alemania, Reino Unido, India y los Países Bajos. A pesar de los niveles altos de As encontrados en la raíz de zanahoria, son menores que los reseñados en zanahorias cultivadas en suelos contaminados con As (Grant y Dobbs, 1977; Helgesen and Larsen, 1998; Vela et al., 2001; Pizarro et al., 2003; Pendergrass and Butcher, 2006).

Los contenidos de arsénico en las muestras de zanahoria, mostraron diferencias significativas en los distintos tratamientos con concentraciones crecientes de As en el agua de riego en cuanto a la concentración de arsénico tanto en las hojas (Figura 15) como en la raíz, (Figura 16).

No se encontraron alteraciones en el crecimiento o síntomas de toxicidad como decoloraciones o necrosis en las hojas.

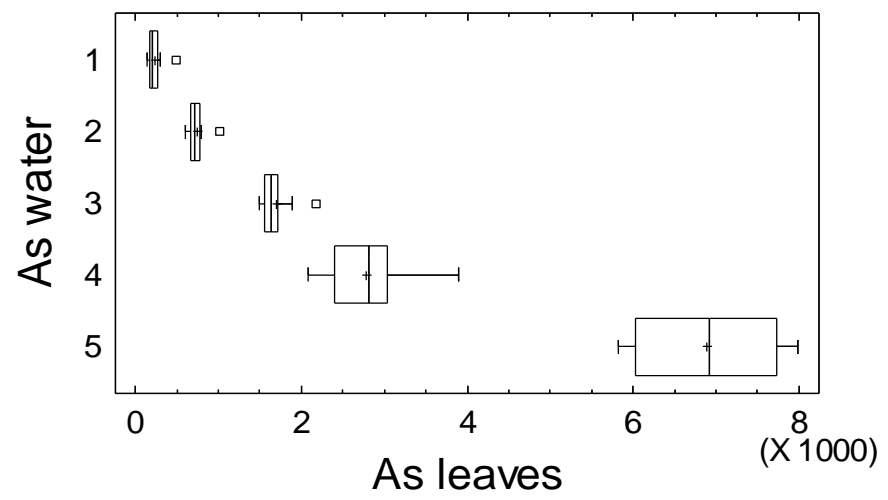

Figura 15. Box and whisker plots de As en hojas (peso seco), regadas con concentraciones de As crecientes. 1: $0 \mu \mathrm{g} / \mathrm{l} ; 2: 20 \mu \mathrm{g} / \mathrm{l} ; 3: 50 \mu \mathrm{g} / \mathrm{l} ; 4: 100 \mu \mathrm{g} / \mathrm{l} ; 5: 150$ $\mu \mathrm{g} / \mathrm{l}$. Intervalo de confianza $95 \%$ 


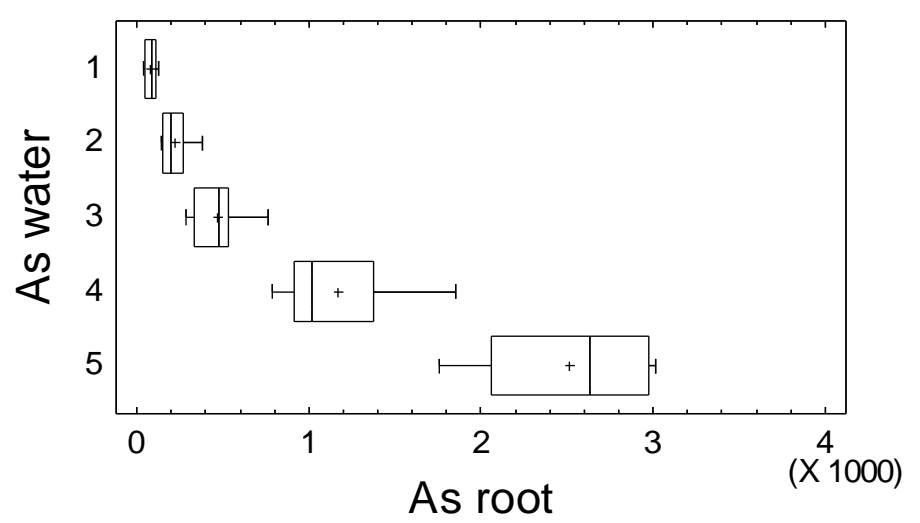

Figura 16. Box and whisker plots de As en raíces (peso seco). Regadas con concentraciones de As crecientes 1: $0 \mu \mathrm{g} / \mathrm{l} ; 2: 20 \mu \mathrm{g} / \mathrm{l} ; 3: 50 \mu \mathrm{g} / \mathrm{l} ; 4: 100 \mu \mathrm{g} / \mathrm{l} ; 5: 150$ $\mu \mathrm{g} / \mathrm{l}$. Intervalo de confianza $95 \%$.

La relación entre los factores de bioacumulación (As tejido/As soluble en suelo) y el contenido de arsénico en el agua de riego muestra, en general, que el almacenamiento de arsénico en las hojas y las raíces es mayor cuando la concentración de arsénico en el agua de riego es más alto. Las concentraciones de As en las plantas de zanahoria estudiadas, se corresponden con cultivos en condiciones aeróbicas, datos representados en la Figura 15 y Figura 16.

La relación entre el factor de bioacumulación y la concentración de arsénico en el agua de riego en las raíces (Figura 17) y en las hojas (Figura 18), muestra que ambos órganos presentan una acumulación muy eficiente de arsénico en el caso de tratamiento número $2(20 \mu \mathrm{g} / 1$ de arsénico, la concentración más baja de tratamiento de arsénico) y/o una baja acumulación en el tratamiento de $3(50 \mu \mathrm{g} / \mathrm{l})$ As en el agua de riego. La absorción de As en zanahorias presenta una cinética similar a la absorción del Pi (Fósforo inorgánico) con un sistema de transporte de alta afinidad que opera a bajas concentraciones en la solución del suelo, y un sistema de baja afinidad a altas concentraciones (Clarkson, 1984; Ullrich-Eberius et al., 1984; Mc Pharlin and Bieleski, 1987, Ullrich-Eberius et al., 1989; Meharg and MacNair, 1992; Furihata et al., 1992). 
La concentración de P disponible en el suelo utilizado es de $8.3 \mathrm{mg} / \mathrm{kg}$, si se estima que aproximadamente un $10 \%$ del $\mathrm{Pi}$ disponible esta en la solución del suelo, la concentración de Pi en solución podría ser $<10 \mu \mathrm{g} / 1$ (Bushman et al., 2009; Mengel , 2001). Por lo tanto, podría ser que la absorción haya sido llevada a cabo por los transportadores de alta afinidad.

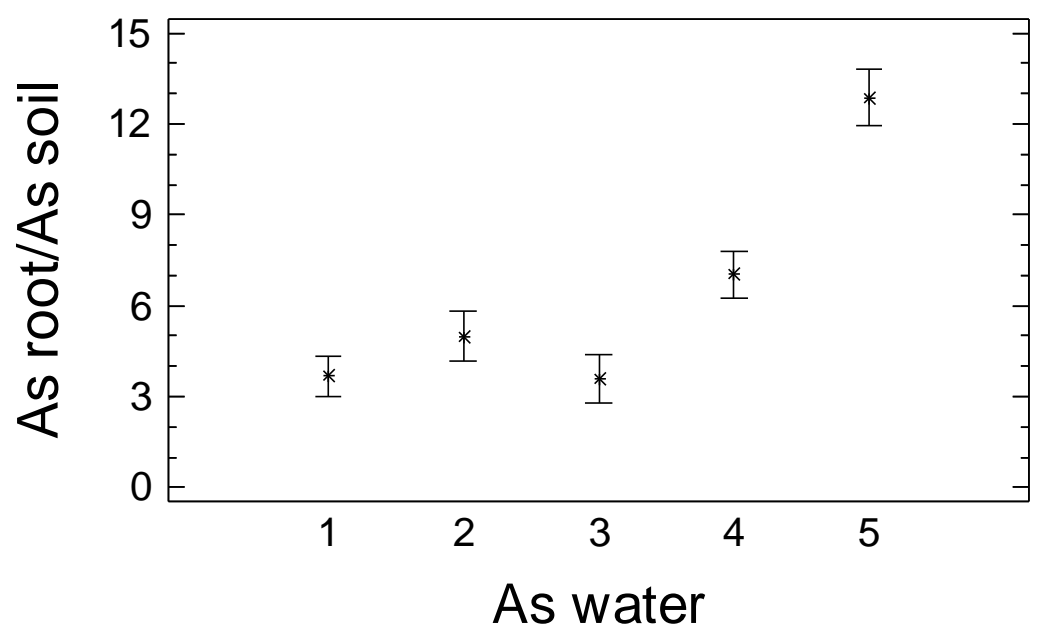

Figura 17. Medias con intervalos LSD al 95\%, del coeficiente de bioacumulación en las raíces. Concentración de As en agua en $\mu \mathrm{g} / \mathrm{l}$; $1: 0 ; 2: 20 ; 3: 50 ; 4: 100 ; 5: 150$.

Las concentraciones de As en la solución del suelo en el tratamiento $2(20 \mu \mathrm{g} / 1$ As en el agua de riego) son muy bajas con una media de $41 \mu \mathrm{g} / 1$ presumiblemente cercana a la gama de transportadores de alta afinidad. Por el contrario, en el suelo del tratamiento 3 (50 $\mu \mathrm{g} / 1$ de As en el agua de riego), tiene un valor medio de As más elevado de $131 \mu \mathrm{g} / \mathrm{l}$, que podría estar más cercana al rango de concentración para los transportadores de baja afinidad, lo que podría explicar la menor eficiencia en la absorción. A pesar de que el fosfato inhibe la absorción de arsénico por las plantas debido a la competencia entre ellos (Meharg et al., 1994; Cox et al., 1996. Pickering et al., 2000), su influencia puede ser despreciable debido a la muy baja concentración de P respecto al As. 


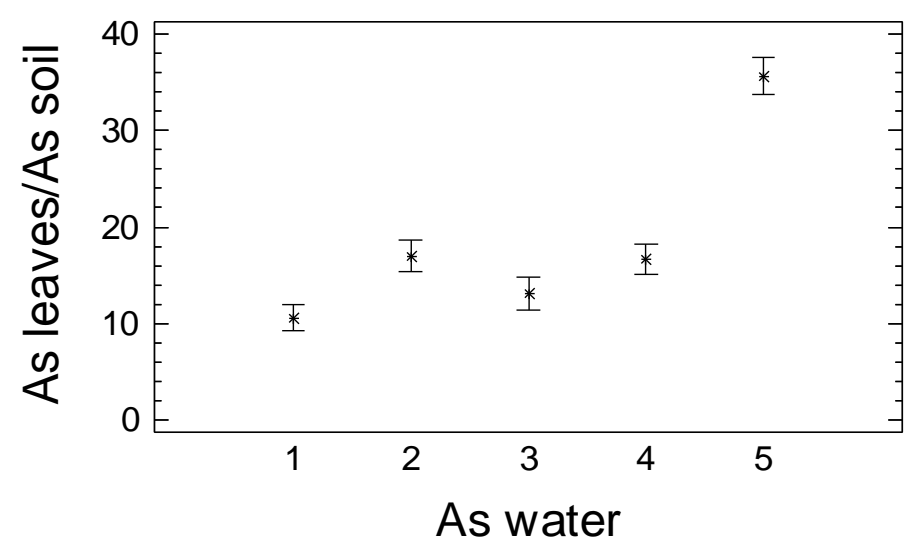

Figura 18. Medias con intervalos LSD al 95\%, del coeficiente de bioacumulación en las hojas. Concentración de As en agua en $\mu \mathrm{g} / \mathrm{l} ; 1:$; 2:20; 3:50; 4:100; 5:150.

En cuanto a la bioacumulación y reparto del arsénico en los diferentes órganos de la zanahoria, existe considerable evidencia de que una parte de arsénico total acumulado por las plantas es acomplejado con el glutatión y las fitoquelatinas, siendo secuestrado en las vacuolas posteriormente, en un mecanismo de detoxificación (Gupta et al., 2008). En este proceso, el arseniato se reduce a arsenito antes de la formación de As-GSH o complejos de As-PC. Sin embargo, la ubicación de los complejos de As en los tejidos vegetales todavía es discutible y no se sabe con claridad, pero se ha observado que estos compuestos son estables en las vacuolas en condiciones ácidas (Gupta et al., 2004, Raab et al., 2004). En este estudio, la relación de concentraciones de As raíz/As hojas no mostró diferencias estadísticamente significativas con los diferentes tratamientos, siendo el valor medio de 0.36 (Figura 19), Smith et al., (2008) también mostraron una proporción muy similar, de 0.35 entre As raíz/As tallo+hojas.

El análisis estadístico entre arsénico en las hojas o las raíces de la zanahoria y el As soluble en el suelo, mostró que no había una relación lineal (modelo de constante de reparto), ni una curva en meseta (modelo de saturación), pero se puede establecer una relación lineal entre el As de raíces y hojas y el factor de bioacumulación 


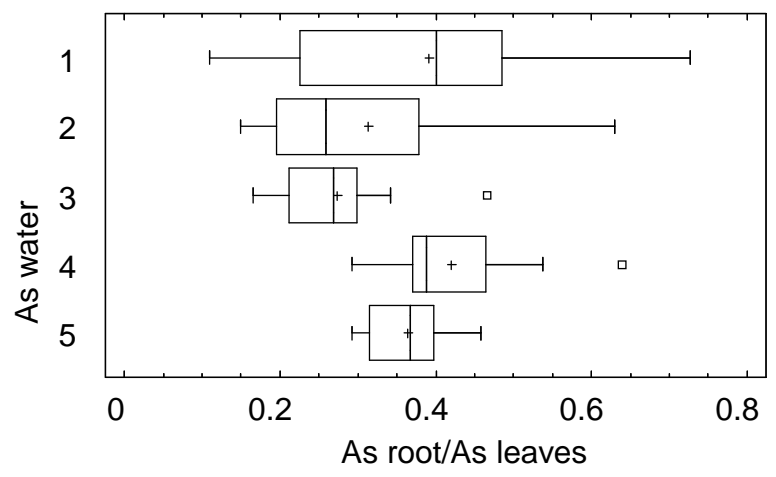

Figura 19. Box and whisker plots de la relación As raíz/As hojas. Concentración de As en agua en $\mu \mathrm{g} / \mathrm{l} ; 1: 0 ; 2: 20 ; 3: 50 ; 4: 100 ; 5: 150$. Intervalo de confianza 95\%.

En esta relación lineal (Figura 20 y Figura 21), donde el factor de bioacumulación (As tejido vegetal /As soluble suelo) se representa en el eje de ordenadas y As en raíces y hojas se representa en abscisas. Las ecuaciones de regresión fueron siguientes:

$\mathrm{As}_{\text {raíz }} / \mathrm{As}_{\text {soluble suelo }}=2.9731+0.00388066 * \mathrm{As}_{\text {raíz }}$

$\mathrm{As}_{\text {hojas }} / \mathrm{As}_{\text {soluble suelo }}=9.72497+0.00352939 * \mathrm{As}_{\text {hojas }}$

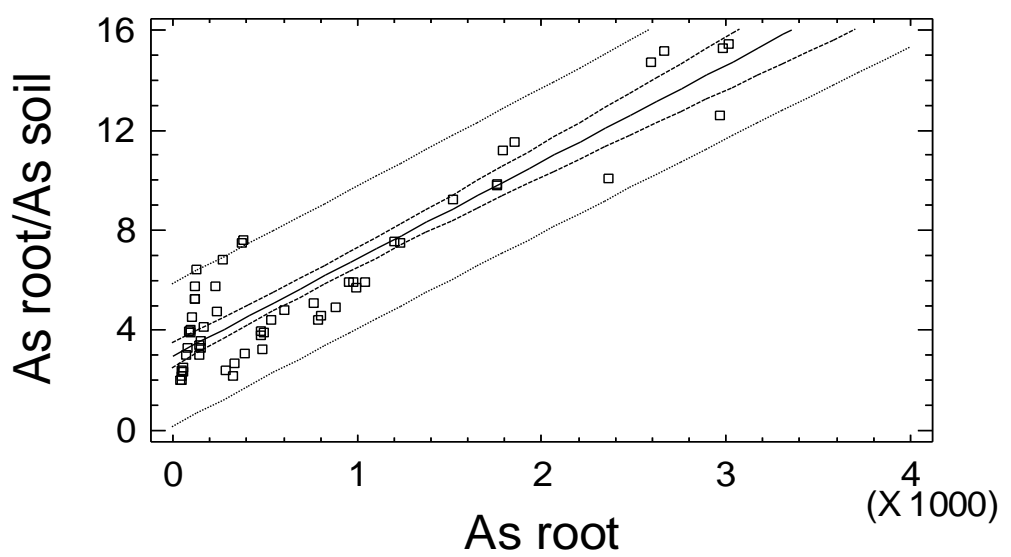

Figura 20. Ecuación lineal de la relación As en raíz/coeficiente de bioacumulación en raíz. As en agua: $1: 0 ; 2: 20 ; 3: 50 ; 4: 100 ; 5: 150 . R=0.89 ; P<0.01$ ) 


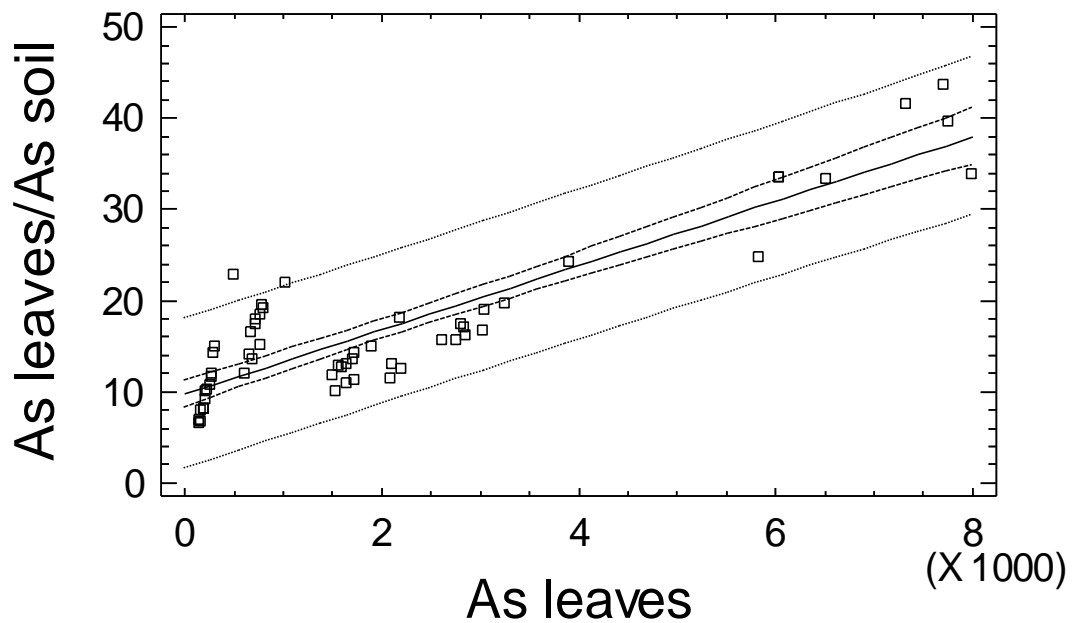

Figura 21. Ecuación lineal de la relación As en hojas/coeficiente de bioacumulación en hojas. As en agua: $1: 0 ; 2: 20 ; 3: 50 ; 4: 100 ; 5: 150 . R=0.89 ; P<0.01)$

Los resultados de los análisis de regresión anteriores, demuestran que las hojas de las zanahorias tienen una mayor afinidad por el As que las raíces 


\section{Conclusiones}

1. Los sedimentos de la Cuenca Terciaria del Duero contienen concentraciones normales de arsénico, con ligera anomalía en rocas opalinas rojas y margas negras.

2. Las aguas subterráneas presentas concentraciones de As anómalas que superan $\operatorname{los} 10 \mu \mathrm{g} / \mathrm{l}$.

3. El agua tiene un alto contenido de bicarbonato disuelto que pueden movilizar el As por desplazamiento de las superficies minerales, ya que el bicarbonato pueden competir con el arseniato por los sitios de absorción en los $\mathrm{FeOOH}$ presentes en el acuífero.

4. La desorción del arseniato está favorecida a $\mathrm{pH}$ alto y coadyuvada por las presencia de determinados microorganismos.

5. En la evolución temporal se observa que un alto contenido de nitratos en el agua subterránea, puede dar lugar a la oxidación de $\mathrm{Fe}$ (II), que conduce a la formación de $\mathrm{FeOOH}$, que pueden adsorber el arsénico disuelto, lo que puede causar una disminución del contenido de As en el agua paralelamente al aumento de la concentración de nitratos.

6. La variación temporal del contenido de As en el agua subterránea puede ser el resultado del cambio de la concentración de nitratos a lo largo del tiempo y en la variación de la proporción de bicarbonato.

7. Entre las dos variables consideradas, la concentración de nitratos es la que ha experimentado los incrementos más importantes y se asocia a que en el área de estudio ha habido un $20 \%$ de aumento de la superficie de suelo cultivado para agricultura de regadío, con el consiguiente incremento del uso de fertilizantes nitrogenados y estiércol y purines.

8. El contenido de fondo de As en el suelo de la zona es bajo. Por consiguiente la elevada concentración de arsénico en suelos agrícolas es debida al riego con agua contaminada por arsénico.

9. En los suelos la cantidad de As soluble en agua es el 0.4-2.50\% del total de arsénico (con un valor medio de 1.12\%), lo cual es mayor que el encontrado en 
algunos suelos contaminados de minas y muestra una significativa correlación con el arsénico total y la materia orgánica.

10. El pH elevado del suelo, así como la materia orgánica disuelta pueden favorecer la desorción de As desde los coloides del suelo y dar como resultado una fracción alta de As asimilable para las plantas.

11. El arsénico contenido en hortalizas y trigo es mayor que el de las áreas control y supera los valores encontrados en otros estudios realizados en diferentes países,

12. Los valores encontrados en algunas hortalizas y trigo superan los límites establecidos para alimentos, lo cual podría representar un riesgo para la salud.

13. Las altas concentraciones de arsénico en las raíces de zanahoria cultivadas en invernadero y regadas con aguas que contienen concentraciones de As equivalente a las aguas subterráneas del área de estudio, indican riesgo potencial para la salud por su consumo.

14. Del ensayo realizado en invernadero con los diferentes tratamientos de riego, no se encontraron diferencias en el crecimiento o síntomas de toxicidad tales como cambios de color de las hojas o necrosis.

15. La relación entre los factores de bioacumulación y la concentración de As en el agua de riego, tiene un comportamiento general caracterizado porque el As almacenado en hojas y raíces es mayor cuando la concentración medida en el agua de riego es más alto.

16. La raíz y las hojas de zanahoria mostraron una muy eficiente acumulación de As en el tratamiento (2) de $20 \mu \mathrm{g} / \mathrm{l}$ en el agua de riego, con un contenido medio de $41 \mu \mathrm{g} / 1$ en la solución del suelo, mientras que una menor eficiencia en la acumulación se encontró en el tratamiento de (3) con $50 \mu \mathrm{g} / \mathrm{l}$ en el agua de riego y un contenido medio de $131 \mu \mathrm{g} / 1$ de As soluble en suelo.

17. En las proporciones de As raíz/As hojas no se observaron diferencias estadísticamente significativas para los distintos tratamientos de riego, teniendo un valor medio 0.36 , esto indica la magnitud y velocidad de desplazamiento del As desde las raíces hasta las hojas de las plantas.

18. Se puede establecer una relación lineal entre el As de raíces y hojas y el factor de bioacumulación. Los resultados estos análisis de regresión, muestran que las hojas de las zanahorias tienen una mayor afinidad por el As que las raíces. 


\section{Bibliografía}

Abedin, M. J., Cotter-Howells, J., Meharg, A. A. 2002. Arsenic uptake and accumulation in rice (Oryza sativa L.) irrigated with contaminated water. Plant Soil, 240, 311-319.

Adriano D. C. 2001. Trace Elements in Terrestrial Environment. Biogeochemistry, bioavailability, and risks of metals. New York.

AEDCYL. Consejería de Agricultura y Ganadería, Junta de Castilla y León 2004. Anuario de Estadística Agraria de Castilla y León. Consejería de Agricultura y Ganadería-Junta de Castilla y León. Valladolid.

AEDCYL. Consejería de Agricultura y Ganadería, Junta de Castilla y León 2008. Anuario de Estadística Agraria de Castilla y León. Consejería de Agricultura y Ganadería-Junta de Castilla y León. Valladolid.

Ahmann D., Krumholz L. R., Hemond H. F., Lovley D. R., Morel F. M. M. 1997. Microbial mobilization of arsenic from sediments of the Aberjona watershed. Environmental Science Technology 31: 2923-2930.

Alam, M. G. M., Snow, E. T., Tanaka, A. 2003. Arsenic and heavy metal contamination of vegetables grown in Samta Village, Bangladesh. Science of the Total Environment. 308. 883-896.

Álvarez-Benedí, J., Bolado Rodríguez, S., Cancillo Carro, I. and Calvo Revuelta, C. 2003. Dinámica de adsorción- desorción de arsénico (V) en suelos de cultivo en Castilla y León. Estudios de la Zona no Saturada del Suelo Vol. VI. 331-338.

Anawar, H. M., Akai, J, Sakugawa, H. 2004. Mobilization of arsenic from subsurface Sediments by effect of bicarbonate ions in groundwater. Chemosphere 54: 753762.

Anawar, H. M., García-Sánchez, A., Murciego, A., Buyolo, T. 2006. Exposure and bioavailability of arsenic in contaminated soils from the La Parrilla mine, Spain. Environ. Geol., 50, 170-179.

Anawar, H. M., García-Sánchez, A., Santa Regina, I. 2008. Evaluation of various chemical extraction methods to estimate plant-available arsenic in mine soils. Chemosphere, 70, 1459-1467.

ANFA: Australian National Food Authority 1993. Australian Food Standart Code, Canberra. 
Anke, M. 2001. Arsenic in plants, soils and some foodstuffs, in trace and ultratrace elements in plants and soil, Boston, pp. 148-169.

Appelo, C. A. J., Van der Weiden M. J. J., Tournassat, C., Charlet, L. 2002. Surface complexation of ferrous iron and carbonate on ferrhydrite and the mobilization of arsenic. Environmental Science Technology 36: 3096-3103.

Armenteros, I. 1991 Contribución al conocimiento del Mioceno lacustre de la Cuenca Terciaria del Duero. Sector centro-oriental, Valladolid-Peñafiel-SacramenciaCuellar. (Contribution to the knowledge of the lake Miocene of the Tertiary Duero Basin. East and central sector, Valladolid- Peñafiel-Sacramencia-Cuellar). Acta Geol Hispánica. 26: 97-131.

Baur, W. H. and Onishi, H. 1978. Arsenic. In: Wedepoohl KH (ed). Handbook of Geochemistry. Springer, Berlin. Heidelberg. New York.

Bauer, M. and Blodau, C. 2009. Arsenic distribution in the dissolved colloidal and particulate size fraction of experimental solutions rich in dissolved organic matter and ferric iron. Geochem. Cosmochim. Acta, 73, 529-542.

Benz, M., Brune, A., Schink, B. 1998. Anaerobic and aerobic oxidation of ferrous iron at neutral $\mathrm{pH}$ by chemoherotrophic nitrate reducing bacteria. Archives Microbial., $169,159-165$.

Bohn, H. L., McNeal, B. L. and O'Connor, G. A.1985. Soil chemistry, New York.

Branson, R. L., Pratt, P. F., Rhoades, J. D. and Oster, J. D. 1975. Water quality in irrigated watersheds. J. Environ. Qual. 4, 33-40.

Bushman, L., Lamb, J., Randall, G., Rehm, G., Schmitt, M. 2009. The nature of phosphorous in soils. Phosphorous in agriculture environment. University of Minnesota.

Brown, V. I., Lowbury, E. J. L. 1965. Use of improved cetrimide agar medium and other culture methods for Pseudomonas aeruginosa. J. Clin. Pathol. 18, 725-756.

Cao, X. and Ma, L. 2004. Mechanisms of Lead, Copper, and Zinc Immobilization by Phosphate Rock. Environ. Pollut., 132, 435-442.

Carbonell-Barrachina, A. A., Signes-Pastor, A. J., Vazquez-Araffljo, L., Burlo, F., Sen Gupta, B. 2009. Presence of arsenic in agricultural products from arsenic-endemic areas and strategies to reduce arsenic intake in rural villages, Molecular Nutrition and Food Research 53, 531- 541. 
Carey, P.L., McLaren, R. G., Adams, J. A. 1996. Sorption of cupric, dichromate and arsenate ions in some New Zealand soils. Water Air and Soil Pollution J. 87, 189203.

Casado, M., Anawar, M. H. García-Sánchez, A., Santa Regina, I. 2007. Bull. Environ. Contam. Toxicol. 79, 29-35.

Chapman, H. D.1965. Cation exchange capacity, in Methods of soil analysis. Soil Sci. Soc. Am, Madison, USA.

Chen, T. B., Wei, C. Y., Huang, Z. C., Huang, Q. F., Lu, Q. G., Fan, Z. L. 2002a. Arsenic hyperaccumulator Pteris vittata L. and its arsenic accumulation. Chin. Sci. Bull.47, 902-905.

Clarkson, D. T, 1984. Calcium Transport between tissues and its distribution in the plant. Plant Cell Environ. 7, 449-456.

Cox, M. S., Bell, P. F., Kovar, J. L. 1996. Differential tolerance of canola to arsenic when grown hydroponically or in soil. J Plant Nutr. 19, 1599-1610.

Cumming, D. E., Caccabo, F., Fendorf, S., Rosenzweig, R. F. 1999. Arsenic mobilization by the dissimilatory Fe III- reducing bacterium Sewanella alga BrY. Environmental Science Technology 33, 723-729.

Das, H., Mitra, A., Sengupta, P., Hossain, A., Islam, F. and Rabbani, G. 2004. Environ. Int., 30, 383-87.

De Koe, T.1994. Sci. Agrostis castellana and Agrostis delicatula on heavy metal and arsenic enriched sites in NE Portugal. Total Environ. 145, 103-09.

De la Fuente, C., Clemente, R., Alburquerque, J. A., Vélez, D., Bernal. M. P. 2010. Implications of the use of As-rich groundwater for agricultural purposes and the effects of soil amendments on As solubility. Environ. Sci. Technol. 44 (24), 94639469.

Deuel, L. E. and Swoboda, A. R. 1972. Arsenic solubility in a reduced environment. Soil Sci. Soc. Am. Proc. 36, 276-78.

Dudas, M. J. Soil Sci. Soc. Am. J., 1984. Enriched levels of arsenic in post-active acid sulfate soils in Alberta. 48, 1451-452.

Dzombak, D. A. and Morel, F. M. M. 1990. Surface complexation modelling. Hydrous ferric oxide. John Wiley, New York.

Elkhatib, E. A., Bennett, O. L., Wright, R. J. 1984. Kinetics of arsenite sorption in soils. Soil Sci. Soc. Am. 48, 758-762.

FAC, Feed Additive Compendium1975. Vol. 13. Minneapolis, USA. 
Farooqi, A., Masuda, H., Firdous, N. 2007. Toxic fluoride and arsenic contaminated water in Lahore and Kasur districts, Punjab, Pakistan and possible contaminant sources.

Fendorf, S., Eick, M. J., Grossl, P., Sparks, D. L. 1997. Arsenate and chromate retention mechanism on goethite. 1. Surface structure. Environmental Science Technology $31,315-320$.

Francesconi, K. and Kuehnelt, D. 2002. Arsenic compounds in the environment, in Environmental chemistry of arsenic, New York.

Francesconi, K., Visoottiviseth, P., Sridokchan W. and Goessler, W. 2002. Sci. Total Environ. 284, 27- 35.

Furihata, T., Suzuki, M., Sakurai, H. 1992. Kinetic characterization of two phosphate uptake systems with different affinities in suspension-cultured Catharanthus roseus protoplasts. Plant Cell Physiol. 33, 1151-1157.

García-Sánchez, A., Santa Regina, I., Jiménez, O. 1996. Arsenic environmental impact on mining areas (Salamanca, Spain) Toxicol. Environ. Chem. 53, 137-141.

García Sánchez, A., Álvarez-Ayuso. E., Rodríguez, F. 2002. Sorption of As (V) by some oxyhydroxides and clay minerals. Application to its immobilization in two polluted mining soils. Clay Minerals 37, 187-194.

García Sánchez, A., Álvarez-Ayuso, E. 2003. Arsenic in soils and waters and its relation to geology and mining activities (Salamanca Province, Spain). J. Geochemical Exploration 80, 69-79.

García-Sánchez, A., Moyano, A. and Mayorga, P. 2005. High arsenic contents in groundwater of central Spain. Environmental Geology 47, 847-854.

Goessler, W. and Kuehnelt, D. 2002. Analytical methods for the determination of arsenic and arsenic compounds in the environment, in Environmental chemistry of arsenic, New York,

Gómez, M., Gómez, M. A. and Marine, A.1980. Las Ciencias (in spanish) 45, 171-176.

Grant, C. and Dobbs, A. J. 1977. The Growth and Metal Content of Plants Grown in Soil Contaminated by a Copper/Chrome/Arsenic Wood Preservative. Environ. Pollut. 14, 213-226.

Gupta D. K., Tohoyama, H., Joho, M., Inouhe, M. 2004. Changes in the levels of phytochelatins and related metal-binding peptides in chickpea seedlings exposed to arsenic and different heavy metal ions. J. Plant. Res. 117, 253-256. 
Gupta, D. K., Tripathi, R. D., Mishra, S., Srivastava, S., Dwived, S., Rai, U.N., Yang, X. E., Huanj, H., Inouhe, M. 2008. Arsenic accumulation in root and shoot vis-avis its effects on growth and level of phytochelatins in seedlings of Cicer arietinum L. Journal of Environmental Biology 29(3), 281-286.

Gustafsson, J. P. and Jacks, G. 1995 Arsenic geochemistry in forest soil profiles as revealed by soil-phase studies. Applied Geochemistry 10, 307-315.

Gustafsson, J. P. and Bhattacharya, P. 2007. Geochemical modeling of arsenic adsorption to oxide surfaces. In Bhattacharya, P., Mukherjee, A. B., Bunsdchuh, J., Zevenhoven, R. and Loeppert, R. H. Eds. Arsenic in soil and groundwater environment, 159-206. Elsevier, New York.

Gustafsson, J. P. 2009. Modelling metal sorption in soils. In: Modelling of pollutants in complex environmental systems, Vol. 1 (ed. G. Hanrahan).145-176. ILM Publications, St. Albans, UK.

Haas J. R., Dichristina T. J. 2002 Effects of Fe(III) chemical speciation on dissimilatory Fe(III) reduction by Shewanella putrefaciens. Environmental Science Technology 36, 373-380.

Hammel, W., Debus, R. and Steubing, L. Mobility of antimony in soil and its availability to plants. Chemosphere, 2000, 41, 1791-1798.

Hartley-Whitaker, J., Ainsworth, G., Vooijs, R., Ten Bookum, W., Schat, H., Meharg, A. A. 2001. Phytochelatins are involved in differential arsenate tolerance in Holcus lanatus. Plant Physiol. 126, 299-306.

Harvey, C. F., Swartz, C. H., Badruzzaman, A. B. M.; Keon-Blute, N., Yu, W., Ali, M. A., Jay, J., Beckie, R., Niedan, V., Brabander, D., Oates, P. M., Ashfaque, K. N., Islam, S., Hemond, H. F. and Ahmed, M. F. 2002. Arsenic mobility and groundwater extraction in Bangladesh. Science 298 (5598), 1602-1606.

Haswell, S. J., O`Neill, P., Bancroft, K. K. H. 1985. Arsenic speciation in soil-pore waters from mineralized and unmineralized areas of South-West England. Talanta $32,69-72$

Helgesen, H. and Larsen, E. H. 1998. Bioavailability and speciation of arsenic in carrots grown in contaminated soil, Analyst (London), 123/5, 791-796.

Hemond, H. F. and Ahmed, M. F. 2002. Arsenic mobility and groundwater extraction in Bangladesh. Science 298 (5598), 1602-1606. 
Hoeft. S. E., Lucas. F., Hollibaugh. J. T. and Oremland. R. S. 2002. Characterization of microbial arsenate reduction in anoxic bottom waters of Mono Lake. California. Geomicrobiology Journal 19, 23-40.

Höhn, R., Isenbeck-SchröterR., Kent, D. B., Davis, J. A., Jakobsen, R., Jann, S. Niedan, V., Scholz, C., Staler, S. A. and Tracer, A. 2006. Test with As (V) under variable redox conditions controlling arsenic transport in the presence of elevated ferrous iron concentrations. Journal of Contaminant Hydrology 88 (1-2), 36-54.

Hossain, M. F., 2006. Arsenic contamination in Bangladesh. An overview. Agric. Ecosyst. Environ. 113, 1-16.

IGME, 1980. Investigación Geología de la Cuenca del Duero. Sistema No 8 y 12. (Duero Basin Geological Investigation. System $N^{\circ} 8$ and 12). Grafic. Ibergesa, Madrid.

IGME, 1982 Mapa Geológico de España, E. 1:50.000. Hoja 400 (Geological Map of Spain, E. 1:50.000. Nº0). Portillo.

Jain, A. and Loeppert, R. H. 2000. Effects of competing anions on the adsorption of arsenate and arsenite by ferrihydrite. J. Environ. Qual. 29, 1422-1430.

Jiménez, O., Rodríguez, N., García-Sánchez, A. 1996. Determination of total arsenic and selenium in soils and plants by AAS with HG and FIA coupled techniques. J. Of AOAC International 79, 764-768.

Jones, C.A, Langner H. W., Anderson, K., McDermott, T. R., Inskeep, W. P. 2000. Rates of microbial mediated arsenate reduction and solubilization. Soil Sci. Soc. Am. J. 64, 600-608.

Joshi, A. and Chaudhuvi, M., 1996. Removal of As from ground water by iron oxidecoated sand. J. Environ. Engineering 122, 769-771.

Junta de Castilla y León. Mapa de los suelos de Castilla y León. 1988.

Kabata-Pendias, A. and Pendias, H. 1992. Trace elements in soils and plants., 2nd edn. Boca Raton, FL, USA: CRC Press.

Kabata-Pendias, A. 2004. Soil-plant transfer of trace elements: an environmental issue. Geoderma. 123, 143-149.

Kahlown, M. A., Majeed, A., Tahir, M. A., 2002. Water Quality Status in Pakistan. Pakistan Council of Research in Water Resources (PCRWR), Ministry of Science \& Technology, Government of Pakistan. 
Kalinowski, B. E., Lierman, L. J., Givens, S., Brantley, S. L. 2000. Rates of bacteria promoted solubilization of Fe from minerals: review of problems and approaches. Chemical Geology 169, 357-370.

Kneebone, P. E, O`Day, P. A, Jones, N., Hering, J. G. 2002. Deposition and fate of arsenic in arsenic-enriched reservoir sediment. Environmental. Science Technology 36: 381-386.

Kumpiene, J., Montesinos, I., Lagerkvist, A., Maurice C. 2007. Evaluation of the critical factors controlling stability of chromium, copper, arsenic and zinc in irontreated soil. Chemosphere 67, 410-417.

Langner, H. W. and Inskeep, W. P. 2000. Microbial reduction of arsenate in the presence of ferrihydrite. Environmental. Science Technology 34, 3131-3136.

Lara, F., Cornejo, L., Yañez, J., Freer, J. and Mansilla, H. J. 2006. Solar-light assisted removal of arsenic from natural waters: effect of iron and citrate concentration Chem. Technol. Biotechnol. 81, 1282-1287.

Liebig, G. F. 1966. Arsenic in H D Chapman ed. Diagnostic Criteria for Plant and Soil, Riverside, CA, pp. 13-23.

Lin, H., Wang, M., Seshaiah, K. 2008. Mobility of adsorbed arsenic in two calcareous soils as influenced by water extract of compost. Chemosphere, 71, 742-749.

Llobet, J., Falcoa, G., Casas, C., Teixido, P., Domingo, J. J. 2003. Human exposure to dioxins through the diet in Catalonia, Spain Agric. Food Chem. 51, 838-842.

Lu, Y., Adomako, E. E., Solaiman, A. R. M., Islam, M. R., Deacon, C.,Williams, P. N., Rahman,G. K. M. M., Meharg, A. A. 2009. Baseline soil variation is a major factor in arsenic accumulation in Bengal delta paddy rice. Environ. Sci. Technol., 43 (6), 1724-1729.

Ma, L. Q., Komar, K. M., Tu, C., Zhang, W., Cai, Y. 2001. A fern that hyperaccumulates arsenic.Nature, 2001, 409, 579.

Marin, A. R. 1995. Effect of soil redox potential and $\mathrm{pH}$ on nutrient uptake by rice with special reference of arsenic forms and uptake. Ph. D. Dissertation, Louisiana State University, Baton Rouge, LA, Louisiana.

Masscheleyn, P. H., Delaune, R. D., Patrick, W. H. Jr 1991. Effect of redox potential and $\mathrm{pH}$ on arsenic speciation and solubility in a contaminated soil. Environmental Science Technology 25, 1414-1419. 
Matisoff, G., Khourey, C. J., Hall, J. F., Varnes, A. W., Strai, W. H. 1983. The nature and source of arsenic in northeastern Ohio ground water. Ground Water 20, 446456.

Maurice, P. A., Lee, Y. J., Hersman, L. E. 2000. Dissolution of Al-substituted goethites by an aerobic Pseudomonas mendocina var. bacterium. Environmental Science Technology 34, 1363-1374.

Mayorga, P., Moyano, A., García-Sánchez, A., Anawar, H. M., Rate, A. W., Rengel, Z. 2012. Temporal variation of arsenic and nitrate content in groundwater of the Duero River Basin (Spain), en trámite de publicación.

Mayorga, P., Moyano, A., Anawar, H. M., García-Sánchez, A. 2012. Uptake and accumulation of arsenic in different organs of carrot irrigated with As-rich water. Clean - Soil, Air, Water, en trámite de publicación.

McArthur, J. M., Ravenscroft, P., Safiullah, S., Thirlwall, M. F. 2001. Arsenic in groundwater: Testing pollution mechanisms for sedimentary aquifers in Bangladesh. Water Research 37, 109-117.

McBride, M. B. 1994. Environmental chemistry of soils. Oxford University Press, Oxford New York.

McPharlin, I. R., and Bieleski, R. C. 1987. Phosphate uptake by Spirodela and Lemna during early stages of phosphate deficiency. Aust J Plant Physiol. 14, 561-572.

Markert, M. B. 1997. Instrumental element and multi-element analysis of plant samples, New York.

Meharg, A. A. 1994. Integrated tolerance mechanisms constitutive and adaptive plant responses to elevated metal concentrations in the environment. Plant Cell Environ 17, 989-993.

Meharg A. A., Naylor J, Macnair M. R. 1994. Phosphorus nutrition of arsenate-tolerant and nontolerant phenotypes of velvetgrass. J. Environ. Qual. 23, 234-238.

Meharg, A. A. and Hartley-Whitaker, J. 2002. Arsenic uptake and metabolism in arsenic resistant and non-resistant plant species. New Phytol. 154, 29-43.

Meharg, A. A. 2004. Arsenic in rice understanding a new disaster for South East Asia. Trends Plant Sci. 9, 415-417.

Meharg, A. A. and Macnair M. R. 1992. Suppression of the high-affinity phosphate uptake system: a mechanism of arsenate tolerance in Holcus lanatus L. J Exp Bot 43, 519-524. 
Mengel, K., Kirkby, E. A., Kosegarten, H., Appel, T. 2001. Principles of Plant Nutrition, 5th edition, Kluwer Academic Publishers.

Miller, J. H. 1972. Experiments in molecular genetic. Cold Spring Harbor, New York.

Mok, W. M. and Wai, C. M. 1994. Mobilization of As in contaminated river water. In: Nriagu, J.D. (ed). Arsenic in the Environment. John Wiley, New York.

Moyano, A., García-Sánchez, A., Mayorga, P., Anawar H. M., Álvarez-Ayuso, E. 2009. Impact of irrigation with arsenic-rich groundwater on soil sand crops. J. Environ. Monit., 11, 498-502.

Mukherjee, A., Sengupta, M. K., Hossain, M. A., Ahamed, S., Lodh, D., Das, B., Nayak, B., Saha, K. C., Mukherjee, S. C., Pati, S., Dutta, R. N., Chatterjee, G., Chakraborti, D. 2005. Are some animals more equal than others? Toxicology. 208(1), 165-169.

Newman, D. K. and Banfield, J. F. 2002. Geomicrobiology: how molecular-scale interactions underpin biogeochemical systems. Science 296, 1071-1077.

Neumann, R. B., St Vincent, A. P., Roberts, L. C., Badruzzaman, A. B. M., Ali, M. A., Harvey, C. F. 2011. Rice field geochemistry and hydrology: an explanation for why groundwater irrigated fields in Bangladesh are net sinks of arsenic from groundwater. Environ Sci. Technol. 45, 2072-2078

Nickson, R., McArthur, J., Burgess, W., Ahmed, K. M., Ravencroft, P., Rahman, M. 1998. Arsenic poisoning of Bangladesh groundwater. Nature 395, 338.

Nickson, R. T., McArthur, J. M., Ravenscroft, P., Burgess, W. G., Ahmed, K. M. 2000. Mechanism of arsenic release to groundwater, Bangladesh and west Bengal. Applied Geochemistry 15, 403-413.

Nordstrum, D. K. 2002.Worldwide occurrences of arsenic in groundwater. Science 296, 2143-2145.

Norra, S., Berner, Z., Agarwala, P., Wagner, F., Chandrasekhara, D. and Stuben, D. 2005. Impact of irrigation with As rich groundwater on soil and crops: a geochemical case study in Maldah District, West Bengal. Appl. Geochem. 20, 1890-1906.

Nriagu, J. O. 1994. Arsenic in the environment (J. O. Nriagu, Editor), John Wiley \& Sons, New York.

Olsen, R. S., Cole, V.C., Watanabe, F. S., Dean, L. A. 1954. Estimation of available phosphorus in soils by extraction with sodium bicarbonate. USDA. Washington, D.C. Circular 939. 
O’Neill, P. 1995. Arsenic. In Heavy Metals in Soils (B. J. Alloway, Ed.). Blackie Academic \& Professional, London.

Pandey, P. K., Yadav, S., Nair, S., and Bhui, A. 2002. Arsenic contamination of the environment. A new perspective from central-east India. Environ. Int. 905 28, 235-245.

Pantsar-Kallio, M., Manninen, P. K. G. 1997. Speciation of mobile arsenic in soil samples as a function of pH. Science of Total Environment 204, 193-200.

Pendergrass, A. and Butcher, D. J. 2006. Uptake of lead and arsenic in food plants grown in contaminated soil from Barber Orchard, NC. Microchemical Journal 83, 14-16.

Peterson, P. J., Girling, C. A., Benson, L. M., Zieve, R., 1981. Metalloids. In: Lepp, N.W. (Ed.), Effect of Heavy Metal Pollution on Plants, vol. 1. Applied Science, London, 299-322.

Pickering, I. J., Prince, R. C., George, M. J., Smith, R. D., George, G. N., Salt, D. E., 2000. Reduction and coordination of arsenic in indian mustard. Plant Physiol. 122, 1171-1178.

Pierce, M. L., Moore, C. B. 1982. Adsorption of arsenite and arsenate on amorphous iron oxyhydroxides. Water Research 16: 1247-1253.

Pizarro, I., Gómez, M. M., Cámara, C., Palacios, M. A. 2003. Distribution of arsenic species in environmental samples collected in Northern Chile International Journal of Environmental Analytical Chemistry, Volume 83, Issue 10, 879 - 890.

Porter, E. K. and Peterson, P. Arsenic accumulation by plants on mine waste (United Kingdom)J. Sci. Total Environ., 1975, 4, 365-371.

Postma, D., Boesen, C., Kristiansen, H. and Larsen, F. 1991. Nitrate reduction in an unconfined sandy aquifer: water chemistry, reduction processes, and geochemical modeling. Water Resour. Res. 27, 2027-2045.

Raab, A, Meharg, A. A., Jaspars, M., Genney, R., Feldmann, J. 2004. Arsenic glutathione complexes: their solubility in solution and during separation by different HPLC modes. J Anal At Spectrom. 19, 183-90.

Redman, A.D., Macalady, D.L., Ahmann, D. 2002. Natural organic matter affects arsenic speciation and adsorption onto hematite, Environmental Science and Technology 36, 2889-2896. 
Rhine, E. D., Chadhain, S. M. Ní, Zylstra, G. J., Young, L. Y. 2007. The arsenite oxidase genes (aroAB) in novel chemoautotrophic arsenite oxidizers. Biochemical and Biophysical Research Communications 354, 662-667.

Roberts, L. C., Hug,S. J., Dittmar,J., Voegelin, A., Saha,G. C., Ali, M. A., Badruzzaman,A. B. M., Kretzschmar, R. 2007. Spatial distribution and temporal variability of arsenic in irrigated rice fields in Bangladesh. 1. Irrigation water. Environ. Sci. Technol. 41 (17), 5960-5966.

Sadiq, M., Zaida, T. H., Mian, A. A. 1983. Environmental behaviour of arsenic in soils. Water Air and Soil Pollution 20, 369-377.

Sadiq, M. Plant Soil, 1986, Solubility relationships of arsenic in calcareous soils and its uptake by corn. 91, 241-247.

Sahún, B., Gómez, J. J., Lillo, J., Del Olmo, P. 2004. Arsénico en aguas subterráneas e interacción agua-roca: un ejemplo en la Cuenca Terciaria del Duero (Castilla y León, España). Rev. Soc. Geol. De España, 17, 137-155.

Schmöger, M. E. V., Oven, M., Grill, E., 2000. Detoxification of arsenic by phytochelatins in plants. Plant Physiol. 122, 793-801.

Smedley P. L. and Kinniburgh D. G. 2002. A review of the source, behaviour and distribution of arsenic in natural waters. Applied Geochemistry 17, 517-568.

Smith, E., Naidu, R., Alston, A. M. 1998. Arsenic in the soil environment. Advances in Agronomy 64, 149-195.

Smith, N. M., Lee, R., Heitkemper, D. T., DeNicola Cafferky, K., Haque, A. and Henderson, A. 2006. Inorganic arsenic in cooked rice and vegetables from Bangladeshi households. Sci. Total Environ. 370, 294-301.

Smith, P. G., Koch, I., Kenneth, J. Reimer, K. J. 2008. Uptake, transport and transformation of arsenate in radishes (Raphanus sativus). Environmental Sciences Group, Royal Military College, P.O. Box 17000 Station Forces, Kingston, ON, Canada. K7K7B4 Science of the total environment 390, 188 -197.

Senn, D. B. and Hemond, H. F. 2002. Nitrate controls on Iron and Arsenic in urban lake. Science, 296, 2373-2376.

Sun, W., Sierra, R., Field, J. A. 2008 Anoxic oxidation of arsenite linked to denitrification in sludges and sediments. Water Research 4 2, 4569-4577.

Sun, X. and Doner, H. E. 1996. An investigation of arsenate and arsenite binding structures on goethite by FTIR. Soil Science 161, 865-872. 
Tamaki, S. and Frankenberger, W. T. 1992. Environmental biochemistry of arsenic. Review of Environmental Contamination and Toxicology 124, 79-110.

Tu, S.and Ma, L.Q., 2004. Comparison of arsenic and phosphate uptake and distribution in arsenic hyperaccumulating and non-hyperaccumulating fern. Journal of Plant Nutrition 27, 1227-1242.

Ullrich-Eberius, C. I. A. Novacky, A. Van Bel, A. J. E. 1984. Phosphate uptake in Lemna gibba G1: energetics and kinetics. Planta 161, 46-52.

Ullrich-Eberius, C. I., Sanz, A., Novacky. A. J. 1989. Evaluation of arsenate- and vanadate-associated changes of electrical membrane potential and phosphate transport in Lemna gibba G1. J Exp Bot. 40, 119-28.

Van Geen, A., Robertson, A. P., Leckie, J. O. 1994. Complexation of carbonate species at the goethite surface: Implications for adsorption of metal ions in natural waters. Environmental Science Technology 58, 2073-2086.

Vela, N. P., Heitkemper, D. T., Stewart, K. R. 2001. Arsenic extraction and speciation in carrots using accelerated solvent extraction, liquid chromatography and plasma mass spectrometry. Analyst 126, 1011-1017.

Violante, A., Barberis, E., Pigna, M., Boero, V. 2003. Factors affecting the formation, nature, and properties of iron precipitation products at the soil-root interface. J. of Plant Nutrition 26, 1889-1908.

Wang, J., Zhao, F.J., Meharg, A. A., Raab, A., Feldmann, J., McGrath, S. P. 2002. Mechanisms of arsenic hyperaccumulation in Pteris Vittata. Uptake kinetics, interactions with phosphate, and arsenic speciation. Plant Physiol 130, 1552-1561.

Warren, G. P., Alloway, B. J., Leepnusingh, P. B., Bochereau, F. J. and Peeny, C. 2003. Sci. Total Environ. 311, 19-33.

Wauchope, R. D. 1983. Uptake, translocation and phytotoxiciy of arsenic in plants, in Arsenic: Industrial, Biomedical, Environmental Perspectives. New York, 348-374. Waychunas, G. A., Rea, B. A., Fuller, C. C., Davis, J. A. 1993. Surface chemistry of ferrihydrite. Part 1. EXAFS. Studies of the geometry of coprecipitated and adsorbed arsenate. Geochimica Cosmochimica Acta 57, 2251-2269.

Weber, K. A., Picardal, F. W. and Roden, E. E. 2001. Microbially catalyzed Nitratedependent oxidation of biogenic solid-phase Fe (II) compounds. Environ. Sci. Technol., 35, 1644-1650. 
Welch, A. H., Westjohn, D. B., Helsel, D. R., Wanty, R. B. 2000. Arsenic in ground water of the United States: occurrence and geochemistry. Ground Water 38, 589604.

WHO, 1993. Guidelines for drinking-water, WHO, Geneve.

WHO, 1989. Evaluations of Certain Food Additive and Contaminants, $33^{\text {rd }}$ report of the Joint FAO/WHO expert Committee of Food Additives, WHO Technical Report Series 759, World Health Organization, Geneve.

Wilkie, J. A. and, Hering, J. G. 1996. Adsorption of arsenic onto hydrous ferric oxide. Effects of adsorbate/adsorbent ratios and co-occurring solutes. Colloids and Surfaces A: Physical Chemical Engineering Aspects 107, 97-110.

Williams, P., Raab, A., Price, A. H., Hossain, S. A., Feldmann, J. \& Meharg, A. A. 2005. Variation in Arsenic Speciation and Concentration in Paddy Rice Related to Dietary Exposure. Environmental Science \& Technology 39, 5531-5540.

Williams, P. N., Islam, S., Islam, R., Jahiruddin, M., Adomako, E., Soliaman, A. R. M., Rahman, K., Lu, Y., Deacon, C. M., Zhu, Y. Meharg, A. A. 2009. 'Arsenic limits Trace Mineral Nutrition (Selenium, Zinc, and Nickel) in Bangladesh Rice Grain'.' Environmental Science \& Technology, vol 43, 8430-8436.

Woolson, G. A., Axley, J. H., Kearney, P. C., 1971. The Chemistry and Phytotoxicity of Arsenic in Soil: I. Contamined fields soils. Soil Sci. Soc. Am. J. 35, 938-943.

$\mathrm{Xu}, \mathrm{J}$ and Thornton, I. Environ. Geochem. Health, 1985, 7, 131-133.

Yathavakilla, S. K V., Fricke, M., Creed, P. A., Heitkemper, D. T., Shockey,N. V., Schwegel, C., Caruso, J. A., Creed, J. T. 2008. Arsenic speciation and identification of monomethylarsonous acid and monomethylthioarsonic acid in a complex matrix. Anal. Chem. 80/3.

Zhang, W., Cai, Y., Downum, k. R., Ma, L. Q. 2004. Thiol synthesis and arsenic hyperaccumulation in Pteris vittata (Chinese brake fern), Environ. Pollut. 131, 337-345.

Zobrist, J., Dowdle, P. R., Davis, J. A., Oremland, R.S. 2000. Mobilization of arsenite by dissimilatory reduction of adsorbed arsenate. Environmental Science Technology 34,4747-4753. 


\section{A. García-Sánchez \\ A. Moyano \\ P. Mayorga}

\section{High arsenic contents in groundwater of central Spain}

presence of Pseudomonas genera bacteria, which secrete siderophores (Fe chelating agents) could mobilize As adsorbed on $\mathrm{Fe}$ oxides through their dissolution. These combined microbiological and chemical processes might have increased the natural mobility of As.

Keywords As-contamination · Groundwater $\cdot$ Spain $\cdot$ As-mobility

\author{
A. García-Sánchez $(\bowtie)$ \\ Department of Environmental \\ Geochemistry, IRNA-CSIC, Aptdo. 257, \\ Salamanca, Spain \\ E-mail: misfis@usal.es \\ Tel.: + 34-923-219606 \\ Fax: + 34-923-219609 \\ A. Moyano · P. Mayorga \\ EUIA Soria, University of Valladolid, \\ Valladolid, Spain
}

\begin{abstract}
The chemical and microthis area, the concentrations of concentrations, set internationally between $10 \mu \mathrm{g} / 1$ and $50 \mu \mathrm{g} / 1$, reaching levels over $100 \mu \mathrm{g} / 1$. A narrow correlation between the contents of arsenic and $\mathrm{HCO}_{3}{ }^{-}$was observed. These data suggest a possible mechanism of the As mobilization from aquifer sediments to groundwater: the bicarbonate ions could displace $\mathrm{HAsO}_{4}{ }^{2-}$ adsorbed on aquifer oxyhydroxides. Sediments containing relatively high contents of adsorbed arsenic are deposited in surface water environments with low carbonate concentrations. Subsequently, the sediments become exposed to groundwater with highly dissolved carbonate content, and arsenic can be mobilized by displacement from mineral surfaces. In addition, the
\end{abstract}

\section{Introduction}

Arsenic is an ubiquitous toxic element present in trace concentration in the environment; its mobilization or redistribution is influenced by both abiotic and biotic processes. The As contamination of soil and surface- or groundwater represents a threat to human health, and may be regarded as a global issue. Symptoms of chronic exposure to As in drinking water are numerous and include several cancer types, particularly of skin and bladder, as well as cardiovascular, renal, hematological and respiratory disorders. Drinking water, which is normally derived from surface or groundwater depending on local availability, has variable As contents, although the highest concentrations are often found in groundwater. In several parts of the world, such as Argentina, Bangladesh, Chile, China, Hungary, India, Mexico, Taiwan, USA, etc., there are numerous cases of As contents $>50 \mu \mathrm{g} / 1$ in water supplies, significantly above the WHO (1993) guideline value for As in 
drinking water. These water supplies are located at different types of aquifers with variable depth and redox conditions (reducing or oxidizing environment) (Smedley and Kinniburgh 2002). Recently, new cases of high As contents in drinking water were reported when As analysis was included in routine water analyses. This is the case of some areas of Spain where elevated As contents ( $>50 \mu \mathrm{g} / \mathrm{l})$ were found recently. Likewise, these As contents can be considered as a natural geochemical anomaly since the As contents in groundwater worldwide rarely exceed $10 \mu \mathrm{g} / 1$ (Baur and Onishi 1978; Welch and others 2000; Smedley and Kinniburgh 2002) and an anthropogenic origin (agricultural or industrial) is not probable in these areas.

Among the chemical forms or species of arsenic in water, soil and sediment, arsenate predominates under oxidizing conditions (Sadiq et al. 1983; Haswell et al. 1985). Adsorption of $\mathrm{As}(\mathrm{V})$ on mineral surfaces is a very important process that affects its mobility and fate in the environment (Tamaki and Frankenberger 1992). Hydroxyl groups on the surface of many minerals are the most abundant and reactive adsorption sites, and consequently, oxides and hydroxides (Fe, $\mathrm{Al}, \mathrm{Mn}$ ) have a strong affinity for As(V) (Pierce and Moore 1982; Gustafsson and Jacks 1995; Wilkie and Hering 1996; Smith et al. 1998). The strong retention of As(V) by oxides and oxyhydroxides is probably caused by the formation of inner-sphere mononuclear or binuclear monodentate-bidentate complexes (Sun and Doner 1996; Waychunas et al. 1993; Fendorf et al. 1997). Under moderately reducing conditions, arsenic solubility can be controlled by the dissolution of oxyhydroxides (Masscheleyn et al. 1991). The soluble arsenic species that exist in a natural-water system are controlled by a combination of redox conditions, $\mathrm{pH}$, adsorption reactions on mineral, and biological activity (Matisoff et al. 1983). Different arsenic mobilization mechanisms to groundwater were reported. Smedley and Kinniburgh (2002) reported that the reducing nature of the groundwater would reduce $\mathrm{As}(\mathrm{V})$ to $\mathrm{As}(\mathrm{III})$ and cause the possible desorption of As, because As(III) is less strongly sorbed by oxyhydroxides; under oxidizing conditions $\mathrm{As}(\mathrm{V})$ is predominant and is mobilized at high $\mathrm{pH}$ values. Nickson et al. (1998, 2000), McArthur et al. (2001), Kneebone et al. (2002) have reported that reductive dissolution of iron oxyhydroxide carrier phase and not just $\mathrm{As}(\mathrm{V})$ reduction can be considered the most probable mechanism responsible to mobilize high concentrations of arsenic in groundwater. Appelo et al. (2002) pointed out the displacing effect of anion carbonate on sorbed arsenate and arsenite on ferrihydrite. Microbial mobilization of arsenic from sediments was reported in anaerobic environments by dissimilatory $\mathrm{Fe}(\mathrm{III})$-reducing bacteria (Ahman et al. 1997; Cumming et al. 1999; Jones et al. 2000; Zobrist et al. 2000; Langner and Inskeep 2000; Haas and Dichristina 2002); these studies emphasize the potential role of microorganisms in solubilizing arsenic associated with $\mathrm{Fe}$ (III) solid phases, independent of whether $\mathrm{As}(\mathrm{V})$ is reduced to $\mathrm{As}(\mathrm{III})$. In aerobic environment, microbes can produce siderophores that strongly bind $\mathrm{Fe}(\mathrm{III})$ increasing $\mathrm{FeOOH}$ dissolution and other iron minerals (Newman and Banfield 2002).

In the past few years, As contents above $50 \mu \mathrm{g} / \mathrm{l}$ were detected in groundwater from some areas of central Spain, when As analysis was included in routine drinking water analyses. The objective of this work is to contribute to the knowledge of the causes of the As contamination in groundwater from these areas. These waters come from relatively deep wells (in the order of $100 \mathrm{~m}$ or more), and were meant for human consumption and agricultural use.

\section{Materials and methods}

The study area (Figs. 1 and 2) lies in the southeastern part of the Tertiary Duero Basin of the North Iberian Meseta. The Miocene successions of this area can be grouped into four informal lithostratigraphic units, named from bottom to top: Marly Unit (or Facies "Dueñas"); Lutitic Unit (or Facies "Tierra de Campos"); Marly-Gypsiferous Unit (or Facies "Las Cuestas"); and Carbonate Unit (or Facies "Los
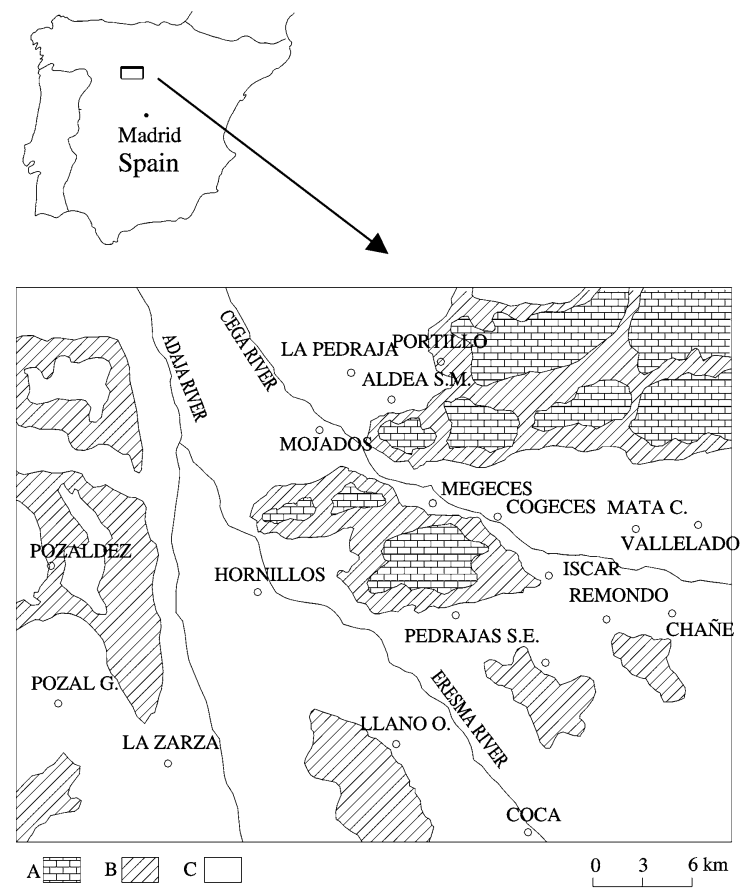

A: Limestones, Facies "Los Paramos". Upper Miocene

B: Clays, marls, gypsum, Facies "Las Cuestas". Middle-upper Miocene C: Aeolian sands, arkoses, Quaternary, "Arenales"

Fig. 1 Sketch of geological map of the study area 


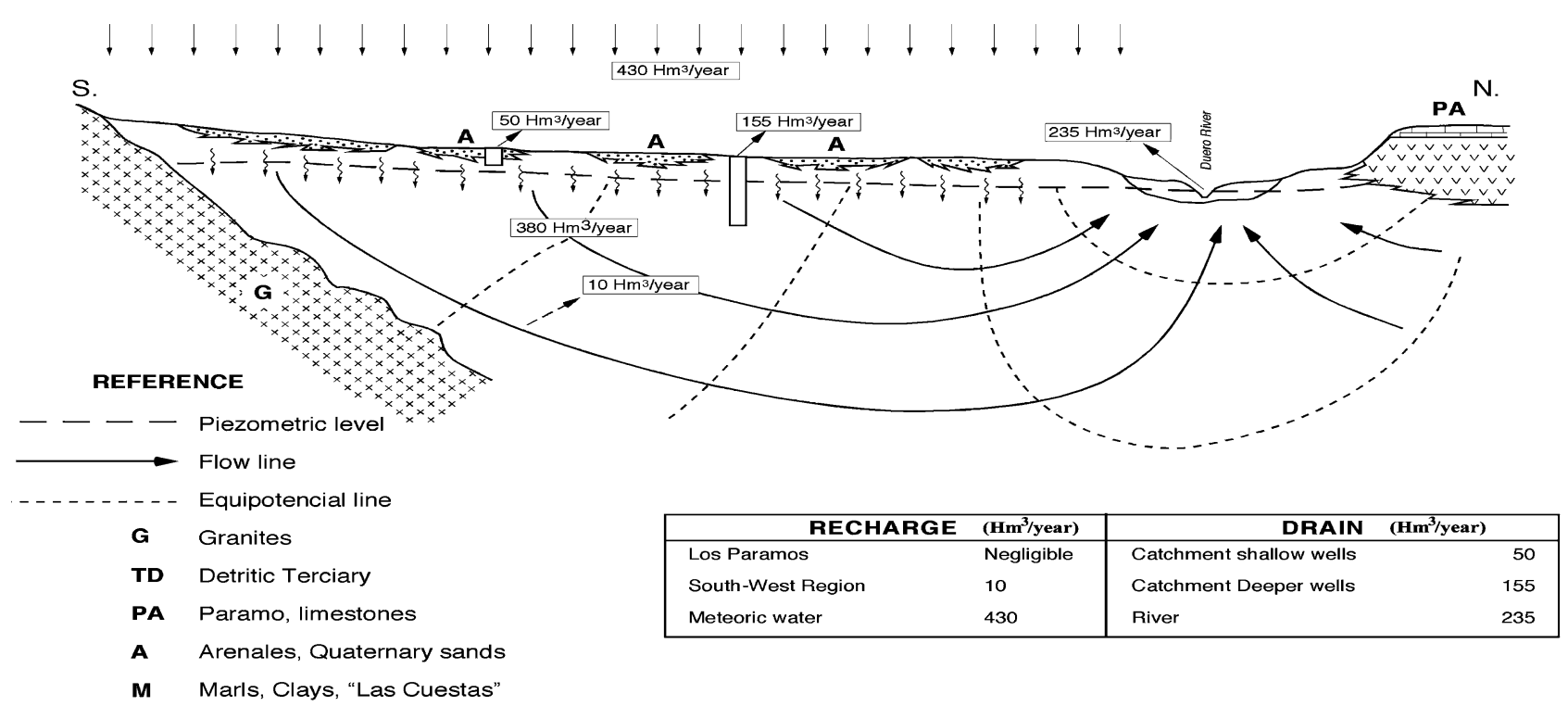

Fig. 2 Model of groundwater flow in the "Los Arenales" and deeper aquifers of the study area and hydric balance (modified of IGME 1980)

Paramos"), Armenteros (1991), IGME (1982). The Marly Unit has a thickness of around $40 \mathrm{~m}$ and is constituted of marls and mudstones. The Lutitic Unit has a thickness of around $80 \mathrm{~m}$ and is composed of arkoses intercalated with silt-clay mudstones; some palaeochannels of sand and gravel are also present. The Marly-Gypsiferous Unit presents a thickness of 80 $100 \mathrm{~m}$ and is constituted by mudstones, arkoses, sandstones, conglomerates and some layers of gypsiferous or calcareous sediments. The Carbonate Unit is mainly composed of limestone and has a thickness of 10-20 m. The Quaternary materials are mainly aeolian sands (5 to 15-m thickness) and other alluvial sediment terraces. The Precambrian-Palaeozoic basement consists of metamorphic rocks (sandy slates and phyllites, with lesser amounts of banded black slates, greywackes and intercalated quartzites and conglomerates), and different types of Hercynian granites with numerous occurrences of different mineralization types (Sn, W, S, As, etc.), moreover, some strata of black slates contain abundant pyrite.

The Duero River Basin constitutes the major aquifer system in the Iberian Peninsula. It can be subdivided into various regional aquifers (IGME 1980). In the quaternary terrains, there are several unconfined aquifers in the layers of aeolian sands of 5- to 15-m thickness ("Arenales"), which are highly permeable. In addition, in some zones of the study area, other unconfined aquifers occur in limestones (fractures and karsts) of upper Miocene age (Facies "Los Páramos"). Other deeper aquifers occur in arkoses, paleochannels of sands and gravels, Facies "Villalba de Adaja", which are the most important in terms of water yield in this area. The latter drains towards the central part of the basin of the Duero river. Their recharge originates in part through the leakage from the upper unconfined aquifer, "Arenales".

The climate in this region is Mediterranean-continental with low humidity; the annual precipitation is around $500 \mathrm{~mm}$, very irregular and usually absent in July and August. During the dry season, the hydric balance is clearly negative.

Twenty-eight wells were sampled (February-May 2001) in different towns affected by As pollution of the Valladolid and Segovia provinces (Fig. 1). Water samples were filtered $(0.45 \mu \mathrm{m})$ on site into acid-washed polyethylene bottles and sub-samples for $\mathrm{Fe}$ analysis were acidified $(1 \% \mathrm{HCl}$ analytical grade) to avoid $\mathrm{Fe}$ hydroxide precipitation. The $\mathrm{pH}$ and $\mathrm{Eh}$ in water samples were analysed in situ, As by AAS following the method of Jimenez et al. (1996) with a hydride generator; analytical accuracy was checked with BCR reference material CRM-320 and US Geological Survey reference G-1. The precision of the method was assessed by performing the analysis ten times for a single sample. The relative standard deviation was between $5 \%$ and $10 \%$. Sulphates, chlorides and nitrates were analysed by ion chromatography (Metrohm); $\mathrm{Ca}, \mathrm{Fe}, \mathrm{Mg}, \mathrm{Na}$ and $\mathrm{K}$ by AAS, and bicarbonates by titration.

In order to assess microbiological water features, microorganisms were isolated from several wells. Water samples were collected in sterile containers and stored at $4^{\circ} \mathrm{C}$ until bacteriological examinations were carried out (24 h later). Fifty milliliters of water was filtered (Millipore membrane filter $0.45 \mu \mathrm{m}$ ) and the filters were put over the surface of plates of LB agar (Miller 1972) and cetrimide agar (Brown and Lowbury 1965). The plates were incubated under aerobic conditions at room tem- 
perature $\left(26^{\circ} \mathrm{C}\right)$ during several days to obtain aerobic isolates. Routine biological tests were carried out to characterize colonies (Gram tinction and cytochrome oxidase).

\section{Results and discussion}

The analytical data of water samples are presented in Table 1. Simple elemental correlation analyses show some significant correlations, which are presented in Figs. 3 and 4.

Bicarbonate concentration significantly correlated with As concentration $(R=0.69, P<0.01)$, which suggests a possible mechanism of As dissolution from aquifer sediments, as was pointed out by Nickson et al. $(1998,2000)$ in groundwater of Bangladesh. In the detritic sediments of the Duero Basin aquifer, the As could be mainly included in the $\mathrm{Fe}$ oxyhydroxides coating mineral grains (Nriagu 1994; Smith et al. 1998), of some sediment levels such as red arkoses, as well as sandstone and palaeochannels of sands and gravels, where $\mathrm{Fe}$ oxides adhere to the surface of the quartz and feldspar grains to act as a cement. In spite of the As contents in the sediments of the Duero Basin being relatively low, range $<0.2-16 \mathrm{mg} / \mathrm{kg}$, with higher values in clay and

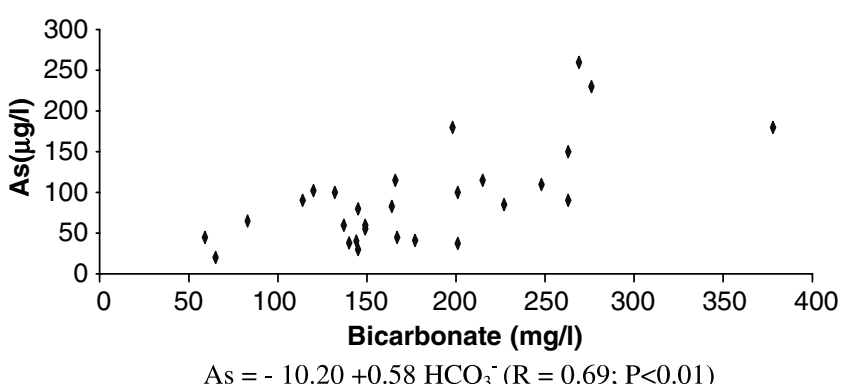

Fig. 3 Relationships between $\mathrm{As}$ and $\mathrm{HCO}_{3}{ }^{-}$

ferrous sediments ( $>10 \mathrm{mg} / \mathrm{kg}$ ) (Garcia-Sanchez and Alvarez-Ayuso 2003), some degree of arsenic dissolution might cause the groundwater contamination since the critical value is only $10 \mu \mathrm{g} / \mathrm{l}$. Reductive dissolution of $\mathrm{FeOOH}$ may cause the As sorbed onto iron oxyhydroxides to be liberated and an increase in the content of $\mathrm{HCO}_{3}{ }^{-}$would also take place. This process is assisted by the action of determining microorganisms that reduce the $\mathrm{Fe}^{3+}$, dissolving the $\mathrm{FeOOH}$. Likewise, they oxidize organic matter producing $\mathrm{HCO}_{3}{ }^{-}$. This mobilization of As has also been proposed by Langner and Inskeep (2000), by means of the $\mathrm{Fe}$ reduction with Clostridium sp., and by Cumming et al. (1999) with Schewanella BrY

Table 1 Chemical composition of water samples

\begin{tabular}{|c|c|c|c|c|c|c|c|c|c|c|c|c|c|}
\hline Well & Location, depth & $\mathrm{HCO}_{3}{ }^{-}$ & $\mathrm{NO}_{3}{ }^{-}$ & $\mathrm{SO}_{4}=$ & $\mathrm{Cl}^{-}$ & As & $\mathrm{pH}$ & $\mathrm{Ca}$ & $\mathrm{Mg}$ & $\mathrm{K}$ & $\mathrm{Na}$ & $\mathrm{Fe}$ & $\mathrm{Eh}(\mathrm{mV})$ \\
\hline 1 & Mojados $150 \mathrm{~m}$ & 263 & 9 & 82 & 41 & 150 & 8.2 & 6 & 4.9 & 3.2 & 203 & $<0.01$ & 231 \\
\hline 2 & Megeces $116 \mathrm{~m}$ & 269 & 6 & 40 & 19 & 260 & 9.1 & 2 & 0.9 & 6.8 & 230 & 0.02 & 218 \\
\hline 3 & Megeces $3 \mathrm{~m}$ & 263 & 218 & 766 & 74 & 90 & 8.1 & 251 & 11.7 & 13.3 & 55 & 0.01 & 247 \\
\hline 4 & Coca $130 \mathrm{~m}$ & 132 & 1 & 4 & 8 & 100 & 7.9 & 1 & 0.2 & 5.9 & 81 & $<0.01$ & 199 \\
\hline 5 & Cogeces $130 \mathrm{~m}$ & 198 & 3 & 9 & 11 & 180 & 8.1 & 1 & 0.1 & 3.5 & 134 & $<0.01$ & 179 \\
\hline 6 & Iscar $360 \mathrm{~m}$ & 276 & 2 & 50 & 18 & 230 & 8.3 & 1 & 0.1 & 2.1 & 166 & 0.03 & 150 \\
\hline 7 & Iscar $5 \mathrm{~m}$ & 227 & 103 & 186 & 80 & 85 & 7.7 & 63 & 43.3 & 8.5 & 90 & $<0.01$ & 163 \\
\hline 8 & La Pedraja $6 \mathrm{~m}$ & 83 & 112 & 499 & 80 & 65 & 8.1 & 123 & 80.6 & 14.4 & 61 & $<0.01$ & 180 \\
\hline 9 & La Pedraja $7 \mathrm{~m}$ & 59 & 96 & 433 & 83 & 45 & 8.2 & 113 & 65.6 & 4 & 53 & $<0.01$ & 184 \\
\hline 10 & La Pedraja $8 \mathrm{~m}$ & 137 & 206 & 319 & 143 & 60 & 7.6 & 134 & 64.2 & 22.5 & 57 & $<0.01$ & 209 \\
\hline 11 & La Pedraja $150 \mathrm{~m}$ & 166 & 1 & 31 & 18 & 115 & 8.2 & 1 & 0.2 & 4.5 & 70 & $<0.01$ & 191 \\
\hline 12 & Aldea S.M. 3 m & 114 & 60 & 104 & 17 & 90 & 7.6 & 61 & 16.7 & 13 & 11 & 0.03 & 184 \\
\hline 13 & Aldea S. M. $120 \mathrm{~m}$ & 248 & 2 & 58 & 14 & 110 & 8.6 & 1 & 0.6 & 1.6 & 166 & 0.02 & 151 \\
\hline 14 & Aldea S.M. 4 m & 149 & 85 & 180 & 25 & 55 & 7.7 & 70 & 19.8 & 45.2 & 39 & $<0.01$ & 301 \\
\hline 15 & Arrabal P. $140 \mathrm{~m}$ & 120 & 1 & 124 & 118 & 102 & 8.3 & 3 & 1.7 & 2.4 & 208 & 0.20 & 257 \\
\hline 16 & Arrabal P. $3 \mathrm{~m}$ & 149 & 11 & 801 & 42 & 60 & 7.9 & 215 & 86 & 7.7 & 58 & $<0.01$ & 168 \\
\hline 17 & Arrabal P. $5 \mathrm{~m}$ & 167 & 58 & 800 & 49 & 45 & 7.8 & 180 & 116.1 & 8.8 & 56 & $<0.01$ & 174 \\
\hline 18 & Hornillos $80 \mathrm{~m}$ & 378 & 1 & 118 & 169 & 180 & 8.6 & 7 & 2.5 & 2.1 & 289 & 0.31 & 198 \\
\hline 19 & Llano O. $210 \mathrm{~m}$ & 145 & 6 & 11 & 18 & 80 & 9.3 & 1 & 0.4 & 1.3 & 121 & $<0.01$ & 192 \\
\hline 20 & La Zarza $120 \mathrm{~m}$ & 201 & 17 & 14 & 35 & 100 & 8.3 & 3 & 0.5 & 0.4 & 137 & 0.02 & 202 \\
\hline 21 & Pozal G. 140 m & 177 & 56 & 16 & 30 & 41 & 8.3 & 23 & 13.7 & 2.4 & 58 & 0.01 & 151 \\
\hline 22 & Remondo $230 \mathrm{~m}$ & 144 & 23 & 24 & 18 & 40 & 8.9 & 3 & 3.2 & 1.2 & 125 & 0.01 & 150 \\
\hline 23 & Mata C. $300 \mathrm{~m}$ & 215 & 26 & 345 & 20 & 115 & 9.1 & 121 & 62.7 & 8.8 & 148 & 0.01 & 174 \\
\hline 24 & Mata C. $185 \mathrm{~m}$ & 65 & 1 & 4 & 3 & 20 & 9.4 & 1 & 0.1 & 0.4 & 59 & $<0.01$ & 245 \\
\hline 25 & Villaverde I. $30 \mathrm{~m}$ & 140 & 11 & 12 & 9 & 38 & 8.4 & 15 & 5.1 & 3.6 & 36 & 0.03 & 246 \\
\hline 26 & Chañe 300 m & 145 & 2 & 10 & 6 & 30 & 9.5 & 1 & 0.1 & 0.3 & 110 & 0.01 & 320 \\
\hline 27 & Chañe $185 \mathrm{~m}$ & 201 & 29 & 26 & 15 & 37 & 8.4 & 19 & 8.1 & 2.2 & 83 & 0.01 & 243 \\
\hline 28 & Vallelado $70 \mathrm{~m}$ & 164 & 2 & 92 & 7 & 83 & 9.5 & 1 & 0.3 & 1.3 & 149 & $<0.01$ & 400 \\
\hline
\end{tabular}

Mean values in $\mathrm{mg} / \mathrm{l} ; \mathrm{As}$ in $\mu \mathrm{g} / \mathrm{l}$ 


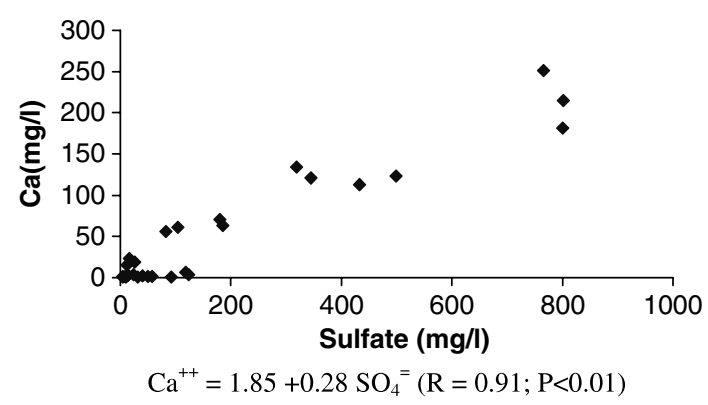

Fig. 4 Relationships between $\mathrm{Ca}^{2+}$ and $\mathrm{SO}_{4}{ }^{=}$

alga. However, this mechanism in the case of the Duero Basin groundwater has some inconsistency. The dissolved $\mathrm{Fe}$ contents in the water samples are very low with a range between $<0.01$ and $0.38 \mathrm{mg} / 1$ (Table 1); moreover, there is no correlation between $\mathrm{Fe}$ and $\mathrm{As}$ concentrations in water samples and the $\mathrm{Fe} / \mathrm{HCO}_{3}{ }^{-}$ratio is much too small. In addition, the Eh range between $150 \mathrm{mV}$ and $400 \mathrm{mV}$ (Table 1), and it can be seen in the Eh-pH diagram for the As- $\mathrm{H}_{2} \mathrm{O}$ system (Masscheleyn et al. 1991) that the thermodynamically dominant arsenic species present is $\mathrm{HAsO}_{4}{ }^{2-}$, and $\mathrm{Fe}^{2+}$ species are not possible. The "dissolved" iron is actually the total iron that passes through a filter of $0.45 \mu \mathrm{m}$, which can include inorganic and organic $\mathrm{Fe}^{3+}$ complexes as well as colloidal iron compounds. However, in these oxic conditions, the carbonate ions could be the cause of the As mobilization from sediments to groundwater. Van Geen and others (1994) suggested that adsorbed carbonate complexes onto goethite reduce the binding capability of metal oxide surface sites for trace metals. Pantsar-Kallio and Manninen (1997) reported the ability of bicarbonate to extract As from a polluted soil. The results of bath tests (Anawar et al. 2004) show that bicarbonate solutions effectively extract arsenic from arsenic sorbed to clay and silty sand sediments. Also, if the ligand exchange theory for oxyanion sorption on mineral surfaces is considered (McBride 1994), the anion $\mathrm{HAsO}_{4}{ }^{2-}$ adsorption at high $\mathrm{pH}$ is disfavored by competition with carbonate and $\mathrm{OH}^{-}$. So, the mobilization of arsenic from aquifer sediments by effect of bicarbonate ions is feasible, as it is pointed out by the significant correlation between As and bicarbonate in water samples (Fig. 3). The bicarbonate ions could displace $\mathrm{HAsO}_{4}{ }^{2-}$ sorbed on aquifer oxyhydroxides. Sediments containing relatively high contents of sorbed arsenic are deposited in surface water environments with low carbonate concentrations. Subsequently, the sediments become exposed to groundwater with a high dissolved carbonate content, and arsenic can be mobilized by displacement from mineral surfaces, which may be favored at high $\mathrm{pH}$ values (Dzombak and Morel 1990).
The specific source area of the arsenic contamination in this part of the Duero Basin is not clearly defined. A likely source for As may include the pyrite and arsenopyrite, which occur sporadically in mineralized pegmatites and Q-veins as well as in some metamorphic rocks (black slates) and hydrothermally altered granitic rocks and shales from the source-areas of the Duero Basin sediments located in the Central System Range at the southern border of the basin. The As amounts in breakup would be in very low concentrations, in the order of microgram per liter. However, in a extended period of time, this process could propitiate the As accumulation in the Fe oxyhydroxides of the Tertiary red sediments. It is also possible that the arsenic water contamination is produced in an arsenic source zone of the aquifer and subsequently carried by flowing to other non-arsenic source zones where the sampled wells are situated.

Another possibility is that the high As content is derived from the oxidation of pyrite and arsenopyrite contained in the sediments of the aquifers. The excessive water extraction would have produced a reduction of the water level in the wells; the entrance of atmospheric $\mathrm{O}_{2}$ into the aquifer would take place, originating the process of oxidation. The oxidation of the mineral sulphides would also dissolve the As contained in them.

Nevertheless, this explanation is not consistent with some observations. Oxidation of pyrite by molecular oxygen yields acidity, but the water $\mathrm{pH}$ is alkaline. The year 2001 was very rainy and originated ascents of the water level; however, the amounts of As in the water have not decreased. In addition, if the descriptions and interpretations of some stratigraphic columns of the study zone (IGME 1982; Armenteros 1991), are kept in mind, the presence of pyrite and arsenopyrite in the Tertiary sediments of the affected aquifers has not been reported. Pyrite does not occur naturally as a detritic mineral and might be diagenetic and must form during sulphate reduction stage of diagenesis, which might occur after sediment deposition. However, the presence of framboidal pyrite typical of that formed during diagenesis is not reported. Even if there was a minimum amount of diagenetic pyrite, it would have been formed by gypsum dissolution after deposition of the sediments. So, this diagenetic pyrite would probably not contain As. Moreover, the oxidation of the arsenopyrite leads to the formation of scorodite $\left(\mathrm{FeAsO}_{4} \cdot 2 \mathrm{H}_{2} \mathrm{O}\right)$ that is very insoluble. The hydrolysis of scorodite produces $\mathrm{Fe}$ oxyhydroxides (goethite, etc.) that have a great capacity of sorption of the liberated As (Mok and Wai 1994; Joshi and Chaudhuvi 1996; García-Sánchez et al. 2002). Hence, this As sorption process would prevent its mobilization.

The high correlation between $\mathrm{Ca}$ and $\mathrm{SO}_{4}{ }^{=}$(Fig. 4), and exploratory data analysis indicate two probable processes about the origin of these ions in groundwater. A process could occur mainly in the shallow wells 
Table 2

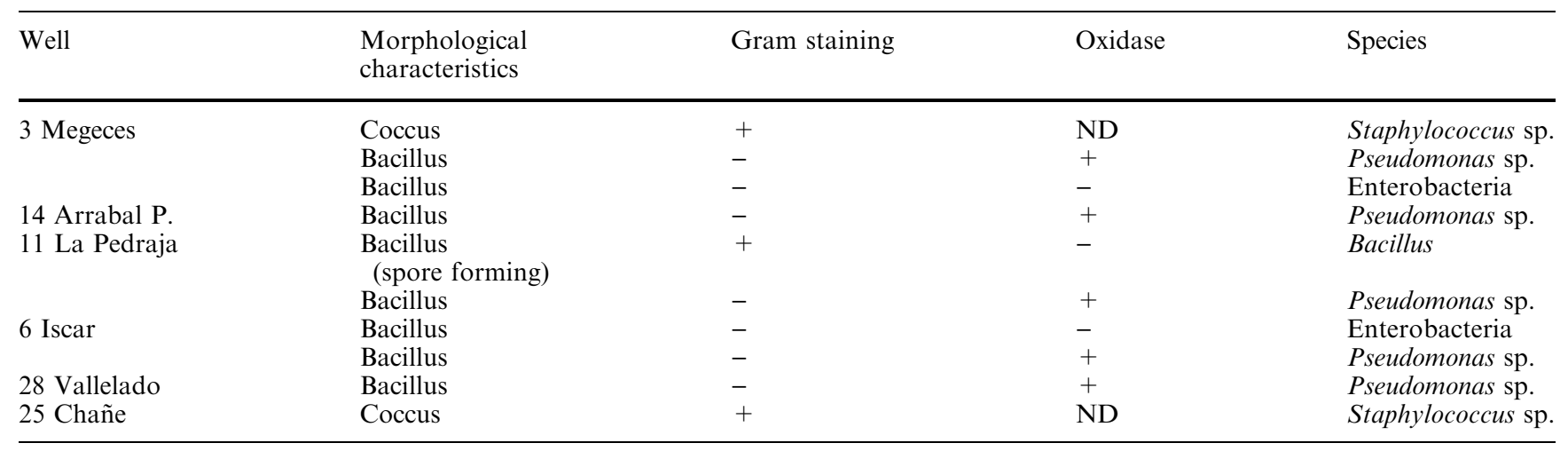

$N D$ not detected

(depth $<10 \mathrm{~m}$ ) situated in the strata of Facies "Las Cuestas" (Fig. 1) with abundant gypsum. Direct dissolution of this mineral may occur as groundwater moves slowly through the gypsum-bearing units. Other processes could occur in deeper wells with lower contents in both elements by mineral weathering and ion-exchange reactions in Marly or Lutitic Units. If arsenic is being released to the groundwater by oxidation of pyrite or arsenopyrite, a positive correlation of concentration of arsenic with sulphate is expected. However, no such correlation exists, which also agree with the findings of Jain and Loeppert (2000), who reported that sulfate had no influence on arsenate sorption or mobilization.

The results of the microbiological analysis in selected water samples (Table 2) show the presence of gramnegative and oxidase-positive colonies included in Pseudomonas genera. These microorganims are not capable of using $\mathrm{Fe}$ as a terminal electron acceptor for oxidative phosphorylation in contrast to dissimilatory iron-reducing bacteria, which were not found in the water samples analysed. Pseudomonas aeruginosa as well as other microorganisms, produces a class of biomolecules called siderophores that strongly bind iron, thereby increasing oxyhydroxide dissolution rates (Kalinowski et al. 2000; Maurice et al. 2000; Newman and Banfield 2002; Violante et al. 2003); this process could liberate arsenic sorbed to the Fe oxides. Therefore, in addition to the arsenic leaching by bicarbonate ions, another possible arsenic mobilization mechanism could be the $\mathrm{Fe}$ oxide dissolution induced by some chelating agents secreted by bacteria.

\section{Conclusions}

Although the As contents in the strata of the aquifers are relatively low with higher values in clay and ferrous sediments ( $>10 \mathrm{mg} / \mathrm{kg}$ ), some degree of arsenic dissolution might cause the groundwater contamination since the critical value is only $10 \mu \mathrm{g} / \mathrm{l}$. Bicarbonate concentration significantly correlated with As, which suggests a possible mechanism of As dissolution from aquifer sediments to groundwater. In the oxic conditions of the studied aquifers, the bicarbonate ions compete with arsenate on the sorption sites of mineral surfaces. Thereby bicarbonate could displace $\mathrm{HAsO}_{4}{ }^{2-}$ sorbed on aquifer oxyhydroxides. Sediments containing relatively high contents of sorbed arsenic are deposited in surface water environments with low carbonate concentrations. Subsequently, the sediments become exposed to groundwater with a highly dissolved carbonate content, and arsenic can be mobilized by displacement from mineral surfaces, which may be favored at high $\mathrm{pH}$ values.

The origin of $\mathrm{Ca}$ and $\mathrm{SO}_{4}{ }^{=}$in groundwater may be due to two different processes. A process may occur mainly in the shallow wells by dissolution of gypsum. Other processes could occur in deeper wells with lower contents in both elements by mineral weathering and ion-exchange reactions. If arsenic is being released to the groundwater by oxidation of pyrite or arsenopyrite, a positive correlation of concentration of arsenic with sulphate is expected. However, no such correlation exists; sulfate may not be a competing anion on arsenate sorption or mobilization.

The Pseudomonas genera bacteria produce a class of biomolecules called siderophores that strongly bind iron from mineral surface and mobilize it to the cell surface, thereby increasing $\mathrm{Fe}$ mineral dissolution rates. This process may mobilize As sorbed on $\mathrm{Fe}$ oxides. The combination of microbiological and geochemical processes might be the cause of the natural As mobility increase and subsequent contamination of groundwater in the study area. 


\section{References}

Ahmann D, Krumholz LR, Hemond HF, Lovley DR, Morel FMM (1997) Microbial mobilization of arsenic from sediments of the Aberjona watershed. Environ Sci Technol 31:2923-2930

Anawar HM, Akai J, Sakugawa H (2004) Mobilization of arsenic from subsurface sediments by effect of bicarbonate ions in groundwater. Chemosphere 54:753762

Appelo CAJ, Van der Weiden MJJ, Tournassat C, Charlet L (2002) Surface complexation of ferrous iron and carbonate on ferrhydrite and the mobilization of arsenic. Environ Sci Technol 36:3096-3103

Armenteros I (1991) Contribución al conocimiento del Mioceno lacustre de la Cuenca Terciaria del Duero. Sector centro-oriental, Valladolid-PeñafielSacramencia-Cuellar (Contribution to the knowledge of the lake Miocene of the Tertiary Duero Basin. East and central sector, Valladolid- PeñafielSacramencia-Cuellar). Acta Geol Hispánica 26:97-131

Baur WH, Onishi H (1978) Arsenic. In: Wedepoohl KH (ed) Handbook of geochemistry. Springer, Berlin Heidelberg New York

Brown VI, Lowbury EJL (1965) Use of improved cetrimide agar medium and other culture methods for Pseudomonas aeruginosa. J Clin Pathol 18:725-756

Cumming DE, Caccabo F, Fendorf S, Rosenzweig RF (1999) Arsenic mobilization by the dissimilatory Fe IIIreducing bacterium Scewanella alga BrY. Environ Sci Technol 33:723-729

Dzombak DA, Morel FMM (1990) Surface complexation modelling. Hydrous ferric oxide. Wiley, New York

Fendorf S, Eick MJ, Grossl P, Sparks DL (1997) Arsenate and chromate retention mechanism on goethite. 1. Surface structure. Environ Sci Technol 31:315320

García Sánchez A, Alvarez-Ayuso E (2003) Arsenic in soils and waters and its relation to geology and mining activities (Salamanca Province, Spain). J Geochem Explor 80:69-79

García Sánchez A, Alvarez-Ayuso E, Rodriguez F (2002) Sorption of As (V) by some oxyhydroxides and clay minerals. Application to its immobilization in two polluted mining soils. Clay Miner 37:187-194

Gustafsson JP, Jacks G (1995) Arsenic geochemistry in forest soil profiles as revealed by soil-phase studies. Appl Geochem 10:307-315
Haas JR, Dichristina TJ (2002) Effects of $\mathrm{Fe}(\mathrm{III})$ chemical speciation on dissimilatory Fe(III) reduction by Shewanella putrefaciens. Environ Sci Technol 36:373-380

Haswell SJ, O`Neill P, Bancroft KKH (1985) Arsenic speciation in soil-pore waters from mineralized and unmineralized areas of South-West England. Talanta 32:69-72

IGME (1980) Investigación Geologíca de la Cuenca del Duero. Sistema $N^{\circ} 8$ y 12 (Duero Basin Geological Investigation. System $\mathrm{N}^{\circ} 8$ and 12). Grafic, Ibergesa, Madrid

IGME (1982) Mapa Geológico de España, E. 1:50.000. Hoja 400 (Geological Map of Spain, E. 1:50.000. $\left.\mathrm{N}^{\circ} 400\right)$. Portillo

Jain A, Loeppert RH (2000) Effects of competing anions on the adsorption of arsenate and arsenite by ferrihydrite. J Environ Qual 29:1422-1430

Jimenez O, Rodriguez N, Garcia-Sanchez A (1996) Determination of total arsenic and selenium in soils and plants by AAS with $\mathrm{HG}$ and FIA coupled techniques. J AOAC Int 79:764-768

Jones CA, Langner HW, Anderson K, McDermott TR, Inskeep WP (2000) Rates of microbial mediated arsenate reduction and solubilization. Soil Sci Soc Am J 64:600-608

Joshi A, Chaudhuvi M (1996) Removal of As from ground water by iron oxidecoated sand. J Environ Eng 122:769771

Kalinowski BE, Lierman LJ, Givens S, Brantley SL (2000) Rates of bacteria promoted solubilization of $\mathrm{Fe}$ from minerals: review of problems and approaches. Chem Geol 169:357-370

Kneebone PE, O'Day PA, Jones N, Hering JG (2002) Deposition and fate of arsenic in arsenic-enriched reservoir sediment. Environ Sci Technol 36:381-386

Langner HW, Inskeep WP (2000) Microbial reduction of arsenate in the presence of ferrihydrite. Environ Sci Technol 34:3131-3136

Masscheleyn PH, Delaune RD, Patrick WH Jr (1991) Effect of redox potential and $\mathrm{pH}$ on arsenic speciation and solubility in a contaminated soil. Environ Sci Technol 25:1414-1419

Matisoff G, Khourey CJ, Hall JF, Varnes AW, Strai WH (1983) The nature and source of arsenic in northeastern Ohio ground water. Ground Water 20:446456

Maurice PA, Lee YJ, Hersman LE (2000) Dissolution of Al-substituted goethites by an aerobic Pseudomonas mendocina var. bacteria. Environ Sci Technol 34:1363-1374
McArthur JM, Ravenscroft P, Safiullah S, Thirlwall MF (2001) Arsenic in groundwater: testing pollution mechanisms for sedimentary aquifers in Bangladesh. Water Res 37:109-117

McBride MB (1994) Environmental chemistry of soils. Oxford University Press, Oxford

Miller JH (1972) Experiments in molecular genetic. Cold Spring Harbor, New York

Mok WM, Wai CM (1994) Mobilization of As in contaminated river water. In: Nriagu JD (ed) Arsenic in the environment. Wiley, New York

Newman DK, Banfield JF (2002) Geomicrobiology: how molecular-scale interactions underpin biogeochemical systems. Science 296:1071-1077

Nickson R, McArthur J, Burgess W, Ahmed KM, Ravencroft P, Rahman M (1998) Arsenic poisoning of Bangladesh groundwater. Nature 394:338

Nickson RT, McArthur JM, Ravenscroft P, Burgess WG, Ahmed KM (2000) Mechanism of arsenic release to groundwater, Bangladesh and west Bengal. Appl Geochem 15:403-413

Nriagu JD (1994) Arsenic in the environment. Wiley, NewYork

Pantsar-Kallio M, Manninen PKG (1997) Speciation of mobile arsenic in soil samples as a function of $\mathrm{pH}$. Sci Total Environ 204:193-200

Pierce ML, Moore CB (1982) Adsorption of arsenite and arsenate on amorphous iron oxyhydroxides. Water Res 16:1247-1253

Sadiq M, Zaida TH, Mian AA (1983) Environmental behaviour of arsenic in soils. Water Air Soil Pollut 20:369-377

Smedley PL, Kinniburgh DG (2002) A review of the source, behaviour and distribution of arsenic in natural waters. Appl Geochem 17:517-568

Smith E, Naidu R, Alston AM (1998) Arsenic in the soil environment. Adv Agron 64:149-195

Sun X, Doner HE (1996) An investigation of arsenate and arsenite binding structures on goethite by FTIR. Soil Sci 161:865-872

Tamaki S, Frankenberger WT (1992) Environmental biochemistry of arsenic. Rev Environ Contam Toxicol 124:79110

Van Geen A, Robertson AP, Leckie JO (1994) Complexation of carbonate species at the goethite surface: implication for adsorption of metal ions in natural waters. Environ Sci Technol 58:20732086 
Violante A, Barberis E, Pigna M, Boero V (2003) Factors affecting the formation, nature, and properties of iron precipitation products at the soil-root interface. J Plant Nutr 26:1889-1908

Waychunas GA, Rea BA, Fuller CC, Davis JA (1993) Surface chemistry of ferrihydrite. Part 1. EXAFS. Studies of the geometry of coprecipitated and adsorbed arsenate. Geochim Cosmochim Acta 57:2251-2269
Welch AH, Westjohn DB, Helsel DR, Wanty RB (2000) Arsenic in ground water of the United States: occurrence and geochemistry. Ground Water 38:589-604

WHO (1993) Guidelines for drinking-water. WHO, Geneva

Wilkie JA, Hering JG (1996) Adsorption of arsenic onto hydrous ferric oxide. Effects of adsorbate/adsorbent ratios and co-occurring solutes. Coll Surf A Phys Chem Eng Aspects 107:97-110
Zobrist J, Dowdle PR, Davis JA, Oremland RS (2000) Mobilization of arsenite by dissimilatory reduction of adsorbed arsenate. Environ Sci Technol 34:47474753 
1

Impact of irrigation with arsenic-rich groundwater on soils and crops

A. Moyano, A. Garcia-Sanchez, ${ }^{*}$ P. Mayorga, H. M. Anawar and E. Alvarez-Ayuso

Soils and waters can be contaminated when irrigated with waters

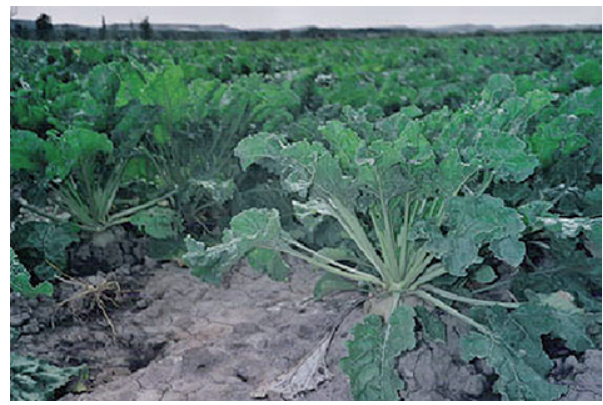

Please check this proof carefully. Our staff will not read it in detail after you have returned it.

Translation errors between word-processor files and typesetting systems can occur so the whole proof needs to be read. Please pay particular attention to: tabulated material; equations; numerical data; figures and graphics; and references. If you have not already indicated the corresponding author(s) please mark their name(s) with an asterisk. Please e-mail a list of corrections or the PDF with electronic notes attached - do not change the text within the PDF file or send a revised manuscript.

Please bear in mind that minor layout improvements, e.g. in line breaking, table widths and graphic placement, are routinely applied to the final version.

We will publish articles on the web as soon as possible after receiving your corrections; no late corrections will be made.

Please return your final corrections, where possible within $\mathbf{4 8}$ hours of receipt by e-mail to: proofs@rsc.org

Reprints-Electronic (PDF) reprints will be provided free of charge to the corresponding author. Enquiries about purchasing paper reprints should be addressed via: http://www.rsc.org/Publishing/ReSourCe/PaperReprints/. Costs for reprints are below:

\section{Reprint costs}

\section{No of pages}

2-4

5-8

9-20

21-40

$>40$

Cost for 50 copies

$£ 190$

$£ 315$

$£ 630$

$£ 1155$

$£ 1785$
Cost for each additional 50 copies

$£ 120$

$£ 230$

$£ 500$

$£ 915$

$£ 1525$

Cost for including cover of journal issue: $£ 55$ per 50 copies 


\title{
${ }^{1}$ I Impact of irrigation with arsenic-rich groundwater on soils and crops
}

\author{
A. Moyano, ${ }^{a}$ A. Garcia-Sanchez, ${ }^{* b}$ P. Mayorga,${ }^{a}$ H. M. Anawar ${ }^{b}$ and E. Alvarez-Ayuso ${ }^{b}$
}

5

Received 7th October 2008, Accepted 12th November 2008

First published as an Advance Article on the web ?????

DOI: 10.1039/b817634e

The study was carried out in an intensively cultivated agricultural area of central Spain where high arsenic (As) concentrations in groundwater were previously reported. The concentrations and distribution of As in soils and crops (wheat, potato, sugar beet and carrot) were determined to know the effect of irrigation with As-rich groundwater in the agricultural fields, and to estimate its impact on the food chain contamination. Irrigation water shows high As concentrations ranging between 10 and $136 \mu \mathrm{g} / \mathrm{l}$. Total As contents in the studied agricultural soils are higher than $10 \mathrm{mg} / \mathrm{kg}$ exceeding the As content in two control areas and the results of this study reflect that irrigation with As-rich groundwater led to the elevated As levels in the agricultural soils. Total As concentration in soils of a sugar beet plot $(36 \mathrm{mg} / \mathrm{kg}$ ) is higher than that found in soils of the less intensively watered field $(11 \mathrm{mg} / \mathrm{kg})$, and more than 3.5 times higher than that in the soils of the control area irrigated with uncontaminated water $(<10 \mathrm{mg} / \mathrm{kg})$. Water soluble As in soils ranges between 0.03 and $0.9 \mathrm{mg} / \mathrm{kg}$ exceeding the limit of $0.04 \mathrm{mg} /$ $\mathrm{kg}$ for agricultural use and shows a significant correlation with total As and organic matter (OM) content in soils. Arsenic contents in potato tuber samples are 35 times higher than that measured in potato tuber of uncontaminated control sites $(0.03 \mathrm{mg} / \mathrm{kg})$. Elevated As contents (3.9-5.4 mg/kg DW) were also found in root samples of sugar beet. The As contents in vegetable samples are higher than As content $(0.1 \mathrm{mg} / \mathrm{kg} \mathrm{DW})$ in plants of uncontaminated control areas, and the limits for foodstuffs $(0.5-1 \mathrm{mg} / \mathrm{kg} \mathrm{DW})$ set by legislation of many countries reflecting the risk of food chain contamination by As in this study area.

\section{Introduction}

Arsenic is one of the most important global environmental toxicants. Its elevated levels in water and soil threaten human health by contaminating the food chain. Drinking water is the main route of As intake in the human body, but the food chain can also be another significant route of As uptake where people are consuming contaminated crops, vegetables and animals. In spite of the low geochemical abundance of As (average earth crust: $1.8 \mathrm{mg} / \mathrm{kg}$, ${ }^{1}$ some degree of arsenic dissolution might cause groundwater contamination since the critical value is only $10 \mu \mathrm{g} / \mathrm{l}$. High concentrations of As in groundwater have been reported from several countries, including Argentina, Bangladesh, West Bengal (India), Chile, China, Hungary,

${ }^{a}$ E.U. Ingenierías Agrarias, Departamento Producción Vegetal, Universidad de Valladolid, Campus de Soria, España

${ }^{b}$ Instituto de Recursos Naturales y Agrobiología de Salamanca, IRNASACSIC, Apto.257, Salamanca, España.E-mail: misfis@usal.es; Fax: +34 923 219609; Tel: +34 923219606
Japan, Mexico, Mongolia, Nepal, Taiwan, Vietnam and USA. ${ }^{2-4}$ New cases of high concentrations of As in drinking water have been reported when As analysis was included in routine water analyses. These cases include some areas of Spain where elevated As concentration in groundwater $(>50 \mu \mathrm{g} / \mathrm{l})$ were recently found.$^{5-8}$

Typical uncontaminated agricultural soils contain $1-20 \mathrm{mg} / \mathrm{kg},{ }^{9}$ but contaminated soils in mining or industrial areas contain levels as high as 45-2600 mg/kg. ${ }^{5,10-12}$ In many cases, extensive use of As-rich groundwater has led to elevated As concentrations in agricultural soils, ${ }^{13,14}$ which may reduce soil productivity,${ }^{15}$ be toxic to plants, and enter into the crops. ${ }^{16,17}$ The bioavailable fraction of As in soils to crop plants depends on the different physical and chemical properties of soils. Different soil chemical extraction methods, including single chemical extractions and sequential extractions are available to extract various pools of soil As, ${ }^{18,19}$ but their ability to quantify the amount of plant-available As from soil is still uncertain. It has been reported that a good relationship exists between water-soluble As in soil and As in crop plants. ${ }^{20-22}$ Therefore, water soluble As in agricultural soil solution can be considered an indicator of the bioavailable As pool in soil solution. The concentrations of water soluble As in soils vary from $0.01 \mathrm{mg} / \mathrm{kg}$ in uncontaminated soils ${ }^{19}$ to $5 \mathrm{mg} / \mathrm{kg}$ in mining soils ${ }^{12}$ and $13 \mathrm{mg} / \mathrm{kg}$ in highly contaminated soils. ${ }^{23}$

Arsenic concentration in terrestrial plants rarely exceeds $1 \mathrm{mg} / \mathrm{kg}$ DW (dry weight basis). ${ }^{24}$ The "As reference plant value" ${ }^{25}$ is $0.1 \mathrm{mg} /$ $\mathrm{kg}$ DW. A few plant species are known to accumulate or hyperaccumulate high As contents in their biomass: some grass species ${ }^{26-28}$ and a few fern species ${ }^{29,30}$ grown in polluted industrial or mining soils. The As concentrations in plants is both species- and organ-specific. Generally, seeds and fruits are poor in As and grains of wheat, rye and barley in Europe contain $<1 \mathrm{mg}$ As $/ \mathrm{kg} ;{ }^{31}$ albeit it was reported that As content in rice range between $0.03 \mathrm{mg} / \mathrm{kg}$ and $1.83 \mathrm{mg} / \mathrm{kg}$ with the higher contents in samples from Bangladesh, India and USA. ${ }^{32,33}$ However, total As concentration cannot provide exact information about possible human health risks. The different As forms (As(III), $\mathrm{As}(\mathrm{v})$, and organic arsenic (MA, DA, AB, AC, etc.) are very different regarding their toxicities, with the highest toxicities observed for inorganic forms, which are the major forms in freshwater, soil and terrestrial plants. ${ }^{34-36}$ Besides these, arsenate predominates in soils under oxidizing conditions. ${ }^{37,38}$

The study area (Valladolid and Segovia provinces, Spain) lies in the south-western part of the Tertiary Duero Basin (North Iberian Meseta, Spain) (Fig. 1). Most of the groundwater in these areas are known to be contaminated with arsenic. This arsenic anomaly was considered geogenic with no influence of any anthropogenic activities in the area. The mechanisms of arsenic mobilization from the $\mathrm{Fe}$ oxyhydroxides in the aquifer minerals were reported as desorption processes of As due to the high water $\mathrm{pH}$ and $\mathrm{HCO}_{3}{ }^{-}$content, as well as, possible microbiological processes caused by the presence of Pseudomonas genera bacteria, which can secrete siderophores, Fe 


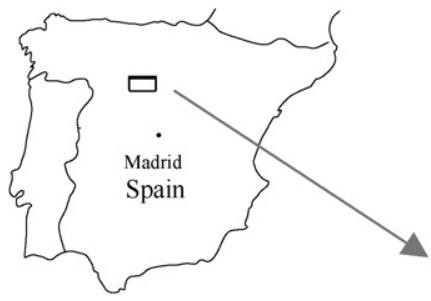

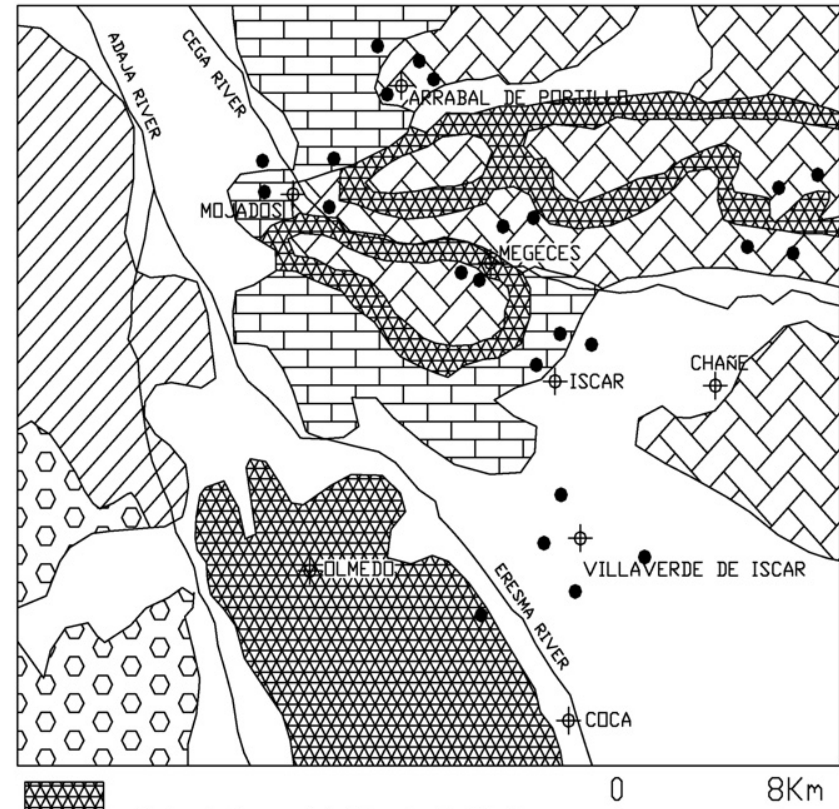

Calcaric Regosol + Calcaric Cambisol

Albic Arenosol + Cambic Arenosol

Eutric Cambisol + Luvic Arenosol

Calcaric Cambisol + Choromic Cambisol + Calcic Luvisol

Chromic Luvisol + Albic Arenosol

Haplic Luvisol + Chromic Luvisol + Gleyc Cambisol

- Plot or sampling: soil irrigation water and vegetable

Fig. 1 Sketch of main soil types of the study area (FAO, 1999) showing the sampling plots.

chelating agents. ${ }^{7}$ Our previous study determined As contents above $50 \mu \mathrm{g} / \mathrm{l}$ in groundwater ${ }^{7}$ that are intensively exploited for irrigation in the agricultural fields of this study area posing a possibility of As uptake by the crop plants. Therefore, the aim of the present study was to investigate the distribution of As in agricultural soils and crops of the above mentioned area to know the influence of irrigation with Asrich groundwater in the agricultural fields and to estimate its impact on food chain contamination.

\section{Materials and methods}

\subsection{Sampling and preparation}

Water, soils and crop plants were collected from the agricultural plots at Arrabal de Portillo, Chañe, Pozal, Mojados, Megeces, Remondo, Pedrajas, Hornillos and Iscar sites (Fig. 1). The sampling points in the study area were designed in such an array that may represent the whole area. A total of 23 top soil samples were collected to $0-10 \mathrm{~cm}$ depth from 23 different agricultural plots irrigated with As rich groundwater, and three soil samples were collected from two control areas irrigated with low As groundwater (Olmedo, Tudela de Duero). A total of 45 crop samples of carrot (Daucus carota L.), potato (Solanum tuberosum L.), wheat (Triticum aestivum L.) and sugar beet (Beta vulgaris L.) were collected from the studied contaminated area and 12 samples from the control area. Irrigation water samples were collected in sterilized polyethylene bottles and filtered (using 0.45 $\mu \mathrm{m}$ filter) in situ; sub-samples for $\mathrm{Fe}$ analysis were acidified $(1 \% \mathrm{HCl}$ analytical grade) to avoid $\mathrm{Fe}$ oxyhydroxide precipitation. In addition, as a contribution to the knowledge of the regional As background and of the As content of soil parent material, a total of 62 rock or sediment samples of several stratigraphic sections in the studied area or nearly areas of the Tertiary Duero Basin (Portillo, Cuellar, Villalba de Adaja, Zaratan, Villamayor, Los Villares, Salamanca) were collected for As analysis.

\subsection{Soil properties analysis}

The soil samples were dried to constant weight in an air circulated oven $\left(50^{\circ} \mathrm{C}\right)$, mixed, homogenized and sieved through a $2 \mathrm{~mm}$ screen. The $<2 \mathrm{~mm}$ fractions were used for determination of selected soil properties: $\mathrm{pH}$ was determined potentiometrically, organic carbon and $\mathrm{CaCO}_{3}$ with a Carmograph H.Wostoff GMBH and cation exchange capacity (CEC) according to the method of Chapman. ${ }^{39}$

\subsection{Analysis of As in soil, water and plant samples}

The finely powdered and homogenized soil and the sediment and rock samples $(0.1 \mathrm{~g})$ were digested with $5 \mathrm{ml}$ aqua regia $+1 \mathrm{ml} \mathrm{HF}$ 
using a CEM (MDS-2000) microwave oven; a pressure of 7 atm was applied for $30 \mathrm{~min}$. Arsenic determinations were performed using a VARIAN spectra AA-220 and hydride generator VGA-76 Atomic Absorption Spectrophotometer (AAS) following the method of Jimenez et $a l .^{40}$ Analytical accuracy was checked with BCR reference material CRM-320 (river sediment) and US Geological Survey reference G-2 (granite). The precision of the method was assessed by performing the analysis ten times for a single sample. The relative standard deviation (RSD) was between 5 and $10 \%$.

Collected plant samples were cleaned with fresh-water, rinsed with deionized water and air-dried at room temperature for several days. The air-dried plant samples were powdered homogenously for analysis. Plant samples $(0.5 \mathrm{~g})$ were digested with water $(2 \mathrm{ml})$, hydrogen peroxide $(2 \mathrm{ml})$ and conc. $\mathrm{HNO}_{3}(8 \mathrm{ml})$ using a CEM (MDS-2000) microwave oven at a pressure of 9 atm $(10 \mathrm{~min})$ and at $12 \mathrm{~atm}$ (15 min). After cooling, the digests were passed through a prewashed filter (Whatman no. 540), the digestion tubes were rinsed three times, passing washings through the filter and the digests were enriched with conc. $\mathrm{H}_{2} \mathrm{SO}_{4}(0.5 \mathrm{ml})$. The digests were then heated at $230{ }^{\circ} \mathrm{C}$ for $2-3 \mathrm{~h}$ and concentrated by evaporation to approximately $0.5 \mathrm{ml}$. Finally $5 \mathrm{ml}$ ascorbic acid (25\%), $5 \mathrm{ml}$ potassium iodide $(25 \%)$ and hydrochloric acid (2M) were added to the digests up to the volume of $25 \mathrm{ml} .{ }^{41}$ Arsenic concentrations were measured in duplicate by using VARIAN spectra AA-220 and hydride generator VGA-76

25 AAS with a commercial stock standard (Panreac Quimica SA). The calibration curve fit (at least five standard concentrations) displayed $\mathrm{R}^{2}$ values $>0.98$ in all cases. The method's recovery of As $(0.79 \pm 0.08$ $\mathrm{mg} / \mathrm{kg}$ ) from a certified reference material (Maize leaves material FD8, Commission of the European Communities, Joint Research Centre ISPRA) was not significantly different from the certified value $(0.77 \pm 0.1 \mathrm{mg} / \mathrm{kg})$. The mean As concentration in blank digests was
$0.09 \mu \mathrm{g} / \mathrm{l}$ and the method detection limit for As in plant tissue was $0.07 \mu \mathrm{g} / \mathrm{l}$.

\subsection{Water-soluble As analysis}

Water-soluble As in soil samples was measured as follows: soil and Milli-Q water were mixed in $1: 10$ proportion and the mixed solution was shaken for $24 \mathrm{~h}$ using a rotary shaker. The solution was centrifuged at $3000 \mathrm{rpm}$ and then the supernatant was collected and filtered using $0.45 \mu \mathrm{m}$ filter. The As concentration in the supernatant solutions were determined using the above AAS method.

\subsection{Data analysis}

The soil-plant transfer coefficient for As (AsTC) was calculated as the ratio of As concentration in plant to that in soil. It was estimated as follows: $\mathrm{AsTC}=\left[\mathrm{As}_{\text {plant }}\right] /\left[\mathrm{As}_{\text {soil }}\right]$, where $\left[\mathrm{As}_{\text {plant }}\right]$ is the As concentration $(\mathrm{mg} / \mathrm{kg})$ accumulated in the plant, and $\left[\mathrm{As}_{\text {soil }}\right]$ is the As concentration $(\mathrm{mg} / \mathrm{kg})$ in the soil. The bioconcentration factor, AsBFw, based on water-soluble As was estimated as follows: AsBFw $=\left[\mathrm{As}_{\text {plant }}\right] /\left[\mathrm{As}_{\mathrm{H} 2 \mathrm{O}}\right]$, where $\left[\mathrm{As}_{\text {plant }}\right]$ is the As concentration $(\mathrm{mg} / \mathrm{kg})$ accumulated in the plant and $\left[\mathrm{As}_{\mathrm{H} 2 \mathrm{O}}\right]$ is the water-soluble As concentration $(\mathrm{mg} / \mathrm{kg})$ in the soil.

Box and whisker plots were conducted using the SPSS statistical software.

\section{Results and discussion}

The soil $\mathrm{pH}$ values (Table 1 ) vary from 6.22 to 8.86 with a mean value of 7.82, indicating the alkaline nature of soil caused by the weathering of some parent materials such as marls and limestone, which are very common in the Miocene Las Cuestas and Los Paramos facies. The

Table 1 Selected soil properties and As concentration in irrigation water

SOIL

SOIL

\section{soment}

Sample

\section{Arrabal de Portillo-2}

Arrabal de Portillo-3

Arrabal de Portillo-4

Arrabal de Portillo-5

Mojados-1

Mojados-2

Mojados-3

Hornillos-1

Hornillos-2

Pozal-1

Pozal-2

Iscar-1

Iscar-2

50 Chane-1

Chane-2

Chane-3

Megeces-1

Megeces-2

Remondo-1

Remondo-2

Pedrajas-1

Pedrajas-2

Olmedo-control

Tudela-control-1

Tudela-control-2

Total As (mg/kg)

Soluble As (mg/kg)

$\mathrm{pH}$

7.70

7.70
7.76

7.76
7.90

0.961

0.098

0.172

$$
0.321
$$

0.444

$$
0.196
$$

0.318

\subsection{1}

0.090

\subsection{0}

0.080

0.240

0.107

0.078

0.065

0.090

0.110$$
\begin{aligned}
& 0.220 \\
& 0.165
\end{aligned}
$$

0.080

0.065

$<0.001$

$<0.001$

$<0.001$
7.83

7.98

7.82

8.01

7.98

6.22

6.75

7.84

7.91

7.80

8.18

8.24

8.41

8.14

7.60

7.53

7.80

7.65

7.48

7.71
8.86

8.86

8.41

8.28

$\mathrm{CaCO}$
5.60
8.40
6.61
3.90
35.60
9.90
8.33
7.65
0.30
0.45
0.70
0.95
6.31
5.46
3.15
1.24
2.18
3.16
4.20
0.80
0.92
5.80
4.32
8.25
8.10
5.90

5.60
8.40

6.61

3.90

35.60

9.90

8.33

7.65

0.30

0.45

0.70

0.95

6.31

5.46

3.15

1.24

2.18

.16

4.20

.80

0.92

4.32

8.25

8.10

5.90
WATER As $(\mu \mathrm{g} / 1)$

\begin{tabular}{lrc} 
OM $(\%)$ & CEC $(\mathrm{meq} / 100 \mathrm{~g})$ & As $(\mu \mathrm{g} / 1)$ \\
\hline 1.28 & 10.78 & 125 \\
2.06 & 6.09 & 79 \\
0.56 & 3.01 & 79 \\
2.02 & 3.10 & 125 \\
1.86 & 6.80 & 125 \\
1.51 & 16.25 & 136 \\
1.80 & 14.05 & 105 \\
1.95 & 12.35 & 120 \\
0.26 & 2.84 & 91 \\
0.52 & 4.20 & 85 \\
0.23 & 4.25 & 65 \\
0.40 & 6.23 & 70 \\
2.30 & 10.09 & 48 \\
2.05 & 9.95 & 53 \\
0.70 & 8.25 & 38 \\
0.90 & 8.15 & 38 \\
0.79 & 9.24 & 42 \\
1.20 & 7.95 & 83 \\
1.16 & 6.82 & 83 \\
2.05 & 12.45 & 66 \\
1.63 & 10.93 & 68 \\
1.05 & 8.60 & 58 \\
1.32 & 7.41 & 55 \\
0.90 & 12.40 & 5 \\
0.88 & 10.85 & 4 \\
0.92 & 10.40 & 4
\end{tabular}


content of organic matter is low ranging between $0.23 \%$ and $2.30 \%$, with mean value of $1.16 \%$ and the CEC values vary from 2.84 to $16.25 \mathrm{meq} / 100 \mathrm{~g}$, with a mean value of $8.94 \mathrm{meq} / 100 \mathrm{~g}$. Carbonate content is high in some soil samples with an average content of $6.30 \%$ and the presence of gypsum is common. The most significant feature of the soil clay mineralogy is the presence of inherited gypsum and calcite minerals from parent materials.

The As contents in rock and sediment samples of the studied stratigraphic columns (Fig. 2) are not very high, ranging between 1.8 and $47.6 \mathrm{mg} / \mathrm{kg}$. The highest values $(30.0-47.6 \mathrm{mg} / \mathrm{kg})$ were found in samples of ferrous opaline rocks ( $>3 \% \mathrm{Fe}_{2} \mathrm{O}_{3}$ content) belonging to the Paleocene period, and some reddish arkoses of Middle Miocene Villalba de Adaja facies and black-organic marly Zaratan facies (13$17 \mathrm{mg} / \mathrm{kg}$ ), whereas the lowest values were found in limestone (1.8$4.0 \mathrm{mg} / \mathrm{kg}$ ) of Late Miocene Los Paramos facies. The results of As topsoil analysis are shown in Fig. 2. Total As contents in agricultural soils of this study that are generally higher than $10 \mathrm{mg} / \mathrm{kg}$, ranges between 8.0 and $36.0 \mathrm{mg} / \mathrm{kg}$, exceeding the As content in control areas (Olmedo, Tudela de Duero) and the regional background $^{5}$ and suggest that irrigation with As-rich groundwater (38$136 \mu \mathrm{g} / \mathrm{l}$; Fig. 3) has led to the enrichment of As concentrations in the agricultural soils.

Water soluble As in soils ranges between 0.030 and $0.961 \mathrm{mg} / \mathrm{kg}$ (Fig. 3) which is greater than the limit $(0.04 \mathrm{mg} / \mathrm{kg})$ recommended for agricultural soils ${ }^{42}$ and accounted for $0.41-2.50 \%$ of total As with a mean value of $1.12 \%$, which is relatively higher than other polluted mining soils, ${ }^{43,12}$ and lower than that reported in industrially polluted soils. ${ }^{44}$ Water soluble As shows a significant correlation with total As $\left(\mathrm{R}^{2}=0.61, \mathrm{p}<0.005\right)$ and also with $\mathrm{OM}$ content $\left(\mathrm{R}^{2}=0.68, \mathrm{p}<\right.$ $0.001)$. High soil $\mathrm{pH}$ in this study may favour As desorption from soil colloids $^{45,3}$ increasing the available fraction of As in soil solutions.

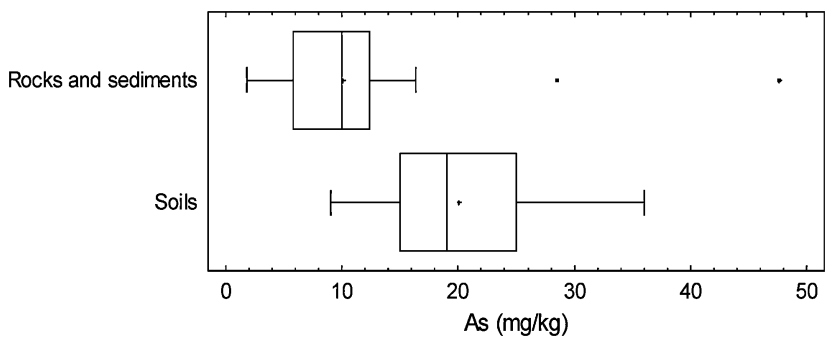

Fig. 2 Box and whisker plot of As concentration in rocks and sediments of some stratigraphic columns of the Duero river basin, and As concentration in agricultural soils.

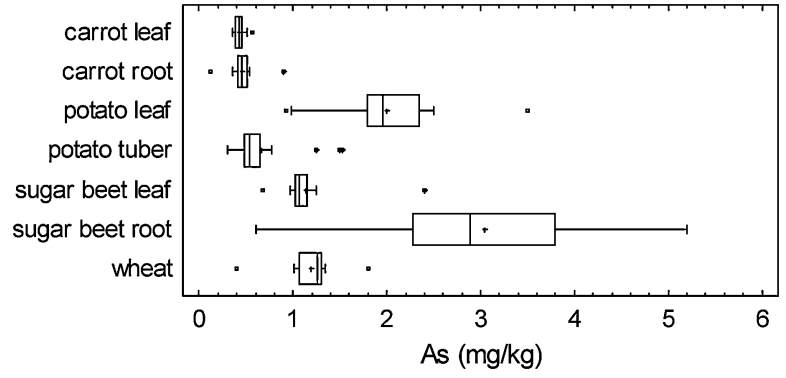

Fig. 4 Box and whisker plot of As concentration in vegetable samples.

Besides this, dissolved OM fraction (humic and fulvic acids) in soil solutions can block the adsorption sites of soil surface and reduce the As sorption by soils, as well as can form aqueous As complexes increasing As mobility and availability. ${ }^{46-48}$

Arsenic content in vegetable samples of this study (Fig. 4) are higher than those $(0.01-1 \mathrm{mg} / \mathrm{kg} \mathrm{DW})^{49}$ in a world-wide level. Some plant samples exceed the limits for foodstuffs $(0.5-1 \mathrm{mg} / \mathrm{kg} \mathrm{DW})$ set by legislation of many countries, e.g. Germany, UK, India and The Netherlands. ${ }^{50-53}$ In addition, the above values clearly exceed the As content of vegetables from control areas with identical soil and climate characteristics, which is evidence of the impact caused by high As content in irrigation waters. A comparison with some reported data shows that As content in vegetables of this study area are higher than those in vegetables of shopping baskets from Spain, ${ }^{54}$ in vegetables grown in Salamanca province, Spain, ${ }^{55}$ in vegetables from a mining region, Cornwall, $\mathrm{UK},{ }^{56}$ and similar to those in vegetables from geogenic polluted areas of Chile ${ }^{57}$ and Bangladesh, ${ }^{35,58}$ and in carrots grown in experimental plots of As polluted soils. ${ }^{16,59}$ On the other hand, As content in vegetables found in the present study are lower than those in vegetables grown in the soils with an available fraction of As $>1 \mathrm{mg} / \mathrm{kg}$. ${ }^{44}$

The elevated As content in wheat might stand for a relatively higher health risk than those in analysed vegetables since its concentrations (Fig. 4) are higher than the critical value $(1 \mathrm{mg} / \mathrm{kg}$ DW) set by legislation of many countries. ${ }^{53}$ Besides this, they are even higher than the As content reported in West Bengal where the crops were irrigated with As-richer groundwater. ${ }^{53}$

The transfer coefficient (AsTC) ranges from 0.02 to 0.12 and the bioaccumulation factor (AsBFw) from 1.1 to 15.4 which are greater than the transfer coefficient of $0.01-0.05$ and the bioaccumulation factors of 1-10 reported in the literature. ${ }^{16,43}$ These higher values, especially the bioaccumulation factors, show a high level of available As in the soils of the studied area, and therefore, indicate a high risk of As transfer to the food chain.

As regards to health implications, the limit of provisional tolerable weekly intake (PTWI) for inorganic As proposed by the World Health Organization $^{51}$ is $15 \mu \mathrm{g} \mathrm{As} / \mathrm{kg}$ body. Assuming an adult body weight of $65 \mathrm{~kg}$, the PTWI of As for an adult would be $975 \mu \mathrm{g}$. It is recommended that each person consumes $200 \mathrm{~g}$ vegetables/day from the nutritional point of view ${ }^{60}$ and if the vegetable consumption comes from vegetables (carrot, potato) of only this studied area, then the PTWI of As for an adult person will be less than $975 \mu \mathrm{g}$. Therefore, the people who consume vegetables grown in these areas may not have the risk of suffering from arsenicosis. By contrast, when the people consume $400 \mathrm{~g}$ wheat per day, the PTWI will be $3550 \mu \mathrm{g}$ As (based on average As content in wheat) indicating an elevated 
health risk. Therefore, the consumption of wheat, or combined with vegetables from these areas might represent a risk to human health.

\section{Conclusions}

The regional As background as well as the As contents in soil parent materials are low in relation to reported worldwide data. Therefore, the elevated As concentration in the agricultural soils of this study area is presumed to be due to the irrigation with As-contaminated groundwater. Water soluble As in soil accounted for $0.41-2.50 \%$ of total As with a mean value of $1.12 \%$, which is higher than other polluted mining soils, and shows a significant correlation with total As and OM content in agricultural soils. High soil $\mathrm{pH}$, and dissolved OM may favour As desorption from soil colloids resulting in the As available fraction to plants. Arsenic contents in vegetable and wheat grain samples are higher than those in the plants of control areas and other international studies, as well as the established limits for foodstuffs and could represent a risk to human health.

\section{Acknowledgements}

This work was supported by Junta de Castilla y Leon (Project VA094A06, Project CSI01A07 and Project VA014A07) and Ministerio de Educacion y Ciencia (Project CTM2006-02249/TECNO).

\section{Notes and references}

1 W. H. Baur and H. Onishi, Arsenic, in Handbook of Geochemistry, Berlin, 1978.

2 H. M. Anawar, J. Akai, K. M. G. Mostofa, S. Safiullah and S. M. Tareq, Environ. Int., 2002, 27, 597-604.

3 P. L. Smedly and D. G. Kinniburg, Appl.Geochem., 2002, 17, 517-568.

4 O. Muñoz, P. B. Díaz, I. Leyton, N. Nuñez, T. Devesa, M. A. Suñer, D. Velez and R. Montoro, J. Agric. Food Chem., 2002, 50, 642-647.

5 A. García-Sánchez and E. Alvarez-Ayuso, J. Geochem. Expl., 2003, 80, 69-79.

6 E. Hernández-García and E. Custodio, Environ. Geol., 2004, 46, $173-$ 188.

7 A. García-Sánchez, A. Moyano and P. Mayorga, Environ. Geol., 2005, 47, 847-854.

8 J. J. Gómez, J. Lillo and B. Sahun, Environ. Geol., 2006, 50, 11511170 .

9 R. D. Wauchope, Uptake, translocation and phytotoxiciy of arsenic in plants, in Arsenic: Industrial, Biomedical, Environmental Perspectives. New York, 1983, pp. 348-374.

10 M. J. Dudas, Soil Sci. Soc. Am. J., 984, 48, 1451-1452.

11 A. Brandsetter, E. Lombi, W. W. Wenzel and D. C. Adriano, Arseniccontaminated soils: I. Risk assessment, in Remediation Engineering of Contaminated Soil, 2002, New York, pp 715-737.

12 H. M. Anawar, A. García-Sánchez, A. Murciego and T. Buyolo, Environ. Geol., 2006, 50, 170-179.

13 M. G. M. Alam, E. T. Snow and A. Tanaka, Sci. Total Environ., 2003, 308, 883-96.

14 P. K. Pandey, S. Yadav, S. Nair and A. Bhui, Environ. Int., 2002, 28, 235-245.

15 G. F. Liebig, Arsenic in Diagnostic Criteria for Plant and Soil, Riverside, CA, 1966, pp. 13-23.

16 H. Helgensen and E. H. Larsen, Analyst, 1998, 123, 791-796.

17 A. R. Marin, Effect of soil redox potential and pH on nutrient uptake by rice with special reference of arsenic forms and uptake. $\mathrm{Ph} . \mathrm{D}$. Dissertation, Louisiana State University, Baton Rouge, LA, Louisiana, 1995.

18 A. Kabata-Pendias, Geoderma, 2004, 123, 143-149.

19 H. M. Anawar, A. García-Sánchez and I. Santa Regina, Chemosphere, 2008, 70, 1459-1467.

20 E. A. Woolson, I. J. Axleyand and P. C. Kearny, Soil Sci. Soc. Am. Proc., 1971, 35, 101-105.
21 L. E. Deuel and A. R. Swoboda, Soil Sci. Soc. Am. Proc., 1972, 36, 276-278.

22 M. Sadiq, Plant Soil, 1986, 91, 241-247.

23 A. A. Meharg, J. Taylor and M. R. Macnair, J. Environ. Qual., 1994, 23, 234-238.

24 D. C. Adriano, Trace Elements in Terrestrial Environment. Biogeochemistry, bioavailability, and risks of metals, New York, 2001.

25 B. Markert, Instrumental element and multi-element analysis of plant samples, New York, 1997.

26 E. K. Porter and P. J. Peterson, Sci. Total Environ., 1975, 4, 365-371.

27 T. De Koe, Sci. Total Environ., 1994, 145, 103-109.

28 A. Garcia-Sanchez, I. Santa Regina and O. Jimenez, Toxicol. Environ. Chem., 1996, 53, 137-141.

29 L. Q. Ma, K. M. Komar, C. Tu, W. Zhang and Y. Cai, Nature, 2001, 409, 579.

30 K. Francesconi, P. Visoottiviseth, W. Sridokchan and W. Goessler, Sci. Total Environ., 2002, 284, 27-35.

31 M. Anke, Arsenic in plants, soils and some foodstuffs, in Trace and ultratrace elements in plants and soil, Boston, 2001, pp. 148-169.

32 A. A. Meharg, Trends Plant Sci., 2004, 9, 415-417.

33 P. N. Williams, A. H. Price, A. Raab, S. A. Hossain, J. Feldmann and A. A. Meharg, Environ. Sci. Technol., 2005, 39, 5531-5540.

34 K. Francesconi and D. Kuehnelt, (2002). Arsenic compounds in the environment, in Environmental chemistry of arsenic, New York, 2002.

$35 \mathrm{~W}$. Goessler and D. Kuehnelt. Analytical methods for the determination of arsenic and arsenic compounds in the environment, in Environmental chemistry of arsenic, New York, 2002.

36 M. Smith, R. Lee, D. Heitkemper, K. Cafferky, A. Haque and A. Henderson, Sci. Total Environ., 2006, 370, 294-301.

37 M. Sadiq, T. Zaida and A. Mian, Water, Air Soil Pollut., 1993, 20, 369-377.

38 S. J. Haswell, P. O’Neill and K. K. Bancroft, Talanta, 1985, 32, 69-72.

39 H. D. Chapman, Cation exchange capacity, in Methods of soil analysis. Soil Sci. Soc. Am, Madison, USA, 1965.

40 O. Jimenez, N. Rodríguez and A. García-Sánchez, J. AOAC Int., 1996, 79, 764-768.

41 W. Hammel, R. Debus and L. Steubing, Chemosphere, 2000, 41, 1791-1798.

42 H. L. Bohn, B. L. McNeal and G. A. O'Connor, Soil chemistry, New York, 1985.

43 G. P. Warren, B. J. Alloway, P. B. Leepnusingh, F. J. Bochereau and C. Peeny, Sci. Total Environ., 2003, 311, 19-33.

44 X. Cao and L. Ma, Environ. Pollut., 2004, 132, 435-442.

45 D. Dzombak and F. Morel, Surface complexation modelling-hydrous ferric oxide, New York, 1990.

46 P. Carey, R. McLaren and J. Adams, Air Soil Pollut., 1996, 87, 189203.

47 M. Casado, M. H. Anawar, A. García-Sánchez and I. Santa Regina, Bull. Environ. Contam. Toxicol., 2007, 79, 29-35.

48 H. Lin, M. Wang and K. Seshaiah, Chemosphere, 2008, 71, 742-749.

49 A. Kabata-Pendias and H. Pendias, Trace elements in soils and plants, Boca Raton. FL, USA 1992.

50 FAC, Feed Additive Compendium, Vol. 13. Minneapolis, USA, 1975.

51 WHO, Evaluations of Certain Food Additive and Contaminants, $33^{\text {rd }}$ report of the Joint FAO/WHO expert Committee of Food Additives; WHO Technical Report Series 759; World Health Organization, Geneva, 1989.

52 ANFA: Australian National Food Authority 1993. Australian Food Standart Code. Canberra, 1993.

53 S. Norra, Z. Berner, P. Agarwala, F. Wagner, D. Chandrasekhara and D. Stuben, Appl. Geochem., 2005, 20, 1890-1906.

54 J. Llobet, G. Falcoa, C. Casas, P. Teixido and J. Domingo, J. Agric. Food Chem., 2003, 51, 838-842.

55 M. Gomez, M. A. Gomez and A. Marine, Las Ciencias (in spanish), 1980, 45, 171-176.

56 J. Xu and I. Thornton, Environ. Geochem. Health, 1985, 7, 131-133.

57 F. Lara, L. Cornejo, J. Yañez, J. Freer and H. Mansilla, J. Chem. Technol. Biotechnol., 2006, 81, 1282-1287.

58 H. Das, A. Mitra, P. Sengupta, A. Hossain, F. Islam and G. Rabbani, Environ. Int., 2004, 30, 383-387.

59 X. C. Grant and A. J. Dobbs, Environ. Pollut., 1977, 14, 213-226.

60 R. A. Schoof, L. J. Yost, J. Eickhoff, E. A. Crecelius, D. W. Cragin, D. M. Meacher and D. B. Menzel, Food Chem. Toxicol., 1999, 37, 839-846. 


\section{Authors Queries}

Journal: EM

Paper: b817634e

Title: Impact of irrigation with arsenic-rich groundwater on soils and crops

Editor's queries are marked like this... 1, and for your convenience line numbers are inserted like this... 5

\begin{tabular}{|l|l|l|}
\hline $\begin{array}{l}\text { Query } \\
\text { Reference }\end{array}$ & Query & Remarks \\
\hline 1 & $\begin{array}{l}\text { For your information: You can cite this article } \\
\text { before you receive notification of the page numbers } \\
\text { by using the following format: (authors), (journal), } \\
\text { (year), DOI: } 10.1039 / \text { (paper number). }\end{array}$ & \\
\hline
\end{tabular}




\title{
Temporal variation of arsenic and nitrate content in groundwater of the Duero River Basin (Spain)
}

\author{
P. Mayorga ${ }^{\mathrm{a}}$, A. Moyano ${ }^{\mathrm{a}}$, A. García-Sánchez ${ }^{\mathrm{b}}$, Hossain M. Anawar ${ }^{\mathrm{c}, *}$, Andrew W. Rate \\ ${ }^{a}$ Departamento de Producción Vegetal. Universidad de Valladolid, Soria, Spain \\ ${ }^{b}$ Department of Environmental geochemistry, IRNASA-CSIC, Salamanca, Spain \\ ${ }^{c}$ School of Earth and Environment, The University of Western Australia, Crawley WA 6009, \\ Australia
}

*Corresponding author

School of Earth and Environment

The University of Western Australia

35 Stirling Highway Crawley WA 6009, Australia

Phone +61-8-6488 1714

Fax +61-08-6488 1050

E-mail: anawar4@hotmail.com

\begin{abstract}
High concentrations of arsenic (As) in groundwater of the Duero River Basin have created a public health concern in some provinces of Spain. However, the mechanism of As mobilization and influence of different geochemical reactions on As removal have not yet been clearly reported. Therefore, this study investigated the possible mechanisms of As release and temporal variations of As with respect to nitrate content in groundwater. Hydrogeochemical characteristics of groundwater sampled along three years in a region of central Spain showed high As contents exceeding EU guideline value of $10 \mu \mathrm{g} / \mathrm{l}$. Significant positive correlations were found between arsenic and bicarbonate concentrations in water samples of the first year. These results suggest a possible mechanism of As mobilization from sediments to groundwater as follows: bicarbonate ions can displace $\mathrm{HAsO}_{4}{ }^{2-}$ adsorbed on surface of aquifer Fe oxyhydroxide, other minerals and sediments. In addition, the high $\mathrm{pH}$ values of this groundwater might favour the As desorption processes. It is also observed that As concentrations in water samples decreased, whereas nitrate concentrations increased along the period of study (2001, 2003 and 2007). The negative and significant correlation between arsenic and nitrate contents in water might reflect the temporal evolution of arsenic concentration during the years considered in this study. The increased use of nitrogen fertilizers and pig manure in agriculture practices increased the nitrate content in groundwater during the period of this study, which could have favoured the precipitation of $\mathrm{Fe}$ oxyhydroxides and the adsorption of As on them.
\end{abstract}

Key words: Arsenic; Nitrate; Bicarbonate; Groundwater; Temporal variation

\section{Introduction}

High concentration of arsenic (As) in groundwater threatens human health and constitutes a high-priority public health problem worldwide, especially in several countries such as: Argentina, Bangladesh, Chile, China, Hungary, India, Mexico, Taiwan, Vietnam and USA 
(Nriagu, 1994; Welch et al., 2000; BGS-DPHE, 2001; Smedley and Kinninburgh, 2002; Welch and Stollenwerk, 2002). Mechanisms of arsenic mobilization to groundwater have been proposed by different researchers in different types of aquifers. Arsenic release from iron oxides appears to be the most common cause of the elevated As concentration in groundwater (Welch et al., 2000). Smedley and Kinninburgh (2002) reported that the reducing nature of groundwater in Bangladesh would reduce As(V) to As(III) and causes the possible desorption of arsenic, since As(III) is less strongly adsorbed by HFO than As(V). Nickson et al. (1998, 2000), McArthur et al. (2001, 2004), Kneebone et al. (2002) and Anawar et al. (2003) have reported that reductive dissolution of As-bearing iron oxyhydroxide and not just $\mathrm{As}(\mathrm{V})$ reduction can be considered the most probable mechanism responsible to mobilize high concentrations of arsenic in groundwater. Using model calculation, Appelo et al. (2002) showed that dissolved carbonate might displace arsenate from the sorption sites of the aquifer minerals causing mobilization of As to groundwater. Bicarbonate ions can extract As from aquifer sediment samples in both oxic and anoxic conditions (Anawar et al., 2004). The results of Harvey et al. (2002) showed that organic carbon may quickly mobilize As in groundwater of Bangladesh, whereas the addition of oxidant compounds, e.g. nitrate, may lower As concentration. Most recently, Seddique et al. (2008) suggested that biotite is a primary source of As in aquifer sediments, where chemical weathering of biotite might be the primary formation mechanism and prevailing reducing conditions contribute to the expansion of As-enriched groundwater in Bangladesh.

Arsenic adsorption on and desorption from the surfaces of aquifer minerals, especially by hydrous ferric oxides (HFO), can have an influence on the mobility, reactivity and toxicity of As in groundwater (Smedley and Kinninburgh, 2002). The strong retention of arsenic by HFO is probably caused by the formation of inner-sphere mononuclear or binuclear monodentatebidentate complexes (Fendorf et al., 1997). Both the surface complexation by HFO and redox processes involving iron ions have a strong effect on As mobility in groundwater (Cummins et al., 1999). The microbial degradation of organic matter requires oxidant consumption like dissolved oxygen $\left(\mathrm{O}_{2}\right)$, nitrate $\left(\mathrm{NO}_{3}{ }^{-}\right)$, etc. Therefore, oxidant or reductant pollutants in groundwater e.g. nitrate released from the agricultural practices, such as fertilization and widespread use of pig manures could affect As mobility in groundwater aquifers. Nitrate is consumed after $\mathrm{O}_{2}$, but before $\mathrm{Fe}$ (III), because nitrate is situated after $\mathrm{O}_{2}$, and before $\mathrm{Fe}(\mathrm{III})$ HFO in the redox scale (McBride, 1994). Benz et al. (1998) suggested that the oxidation of $\mathrm{Fe}$ (II) at circumneutral $\mathrm{pH}$ can be achieved by chemoheterotrophic nitrate reducing bacteria. More recently, some studies (Weber et al., 2001; Rhine et al., 2007; Sun et al., 2008) have identified the bacteria as the factor of oxidation of both $\mathrm{Fe}(\mathrm{II})$ and $\mathrm{As}$ (III) by $\mathrm{NO}_{3}{ }^{-}$, together with the $\mathrm{CO}_{2}$ fixation. Therefore, in aquatic ecosystems, nitrate contamination has a strong influence on the cycle of arsenic, given the oxidation of $\mathrm{Fe}(\mathrm{II})$ to produce As-sorbing particulate like HFO, and to generate also more oxidized form of As, that is As(V), which is more reactive than As(III) (Senn and Hemond, 2002). On the other hand, the inhibition of $\mathrm{Fe}(\mathrm{III})$ reduction by denitrification through biotic and abiotic processes, leads to arsenic coprecipitation with or adsorption on HFO in the aquifer sediments. Thus, the increase of nitrate content in groundwater can inhibit the As release from sediments and propitiate the precipitation of $\mathrm{Fe}$ (III) oxyhydroxides, which promote a mechanism for the immobilization of As through precipitation and adsorption decreasing the groundwater arsenic content. This explanation can be substantiated taking into account a test result done at Bangladesh, where dissolved arsenic levels declined when nitrate was injected into the aquifer, being probably a result of As adsorption mechanism (Harvey et al., 2002). 
In Spain, arsenic was detected in groundwater of the Tertiary Tajo River Basin in the South Iberian Meseta (Aragonés Sanz et al., 2001; Hernández García and Fernández Ruiz, 2002) and in the Tertiary Duero River Basin of the North Iberian Meseta (García-Sanchez and Álvarez-Ayuso, 2003; Sahun et al., 2004; García-Sanchez et al., 2005) in the last decade. Garcia-Sanchez et al. (2005) reported that the arsenic mobilisation from aquifer mineral surfaces into groundwater could be attributed to combined microbiological and chemical processes. However, the mobilization mechanism and dynamics of As in groundwater of Spain is poorly understood and remains obscure. In order to clearly understand the sources of As and the process of As mobilization from the sediments into groundwater, more detailed study is needed. Therefore, the main objective of this study was to contribute to the knowledge of the causes of the temporal variation of As concentration in groundwater of the South Duero River Basin, along three successive years and its relation with the agricultural use of some nitrate pollutants.

\section{Material and methods}

\subsection{Study area}

Study area is located in the South of the Duero River Basin, which constitutes the biggest system of aquifers of Iberian Peninsula (Fig.1), and it can be divided into various regional aquifers (IGME, 1980). The upper Oligocene-Miocene successions of this area can be grouped into five informal lithostratigraphic units, named from bottom to top: i) arkoses and paleochannels of sands and gravels unit, ii) Marly Unit, iii) Lutitic Unit, iv) MarlyGypsiferous Unit and v) Carbonate Unit (Armenteros, 1991; IGME, 1982). The Quaternary materials are mainly aeolian sands, with a thickness between 5 and 15 meters thick, and other alluvial sediment terraces. The Precambrian-Paleozoic basement consist of metamorphic rocks (sandy slates and phyllites, with lesser amounts of banded black slates, greywackes and intercalated quartzites and conglomerates), and different types of Hercynian granites with numerous occurrences of different mineralization types ( $\mathrm{Sn}, \mathrm{W}, \mathrm{S}, \mathrm{As}$ etc.), and moreover, some strata of black slates containing abundant pyrite. The climate is Mediterraneancontinental with an annual precipitation around $500 \mathrm{~mm}$, which is very irregular and usually absent in July and August indicating that during the dry season, the hydric balance is clearly negative.

\subsection{Sample collection and analysis}

Groundwater samples were collected from different wells of several towns, e.g. Valladolid and Segovia provinces (Fig.1), from 2001 to 2007 in three different periods. Thirty samples were collected during 2001, 35 samples during 2003 and 30 samples during 2007. Water samples were filtered using a pore of $0.45 \mu \mathrm{m}$, on site into acid-washed polyethylene bottles. The sub-samples for $\mathrm{Fe}$ analysis were acidified using $1 \% \mathrm{HCl}$ analytical grade to avoid $\mathrm{Fe}$ hydroxide precipitation. The analyses of $\mathrm{pH}$, redox potential, dissolved $\mathrm{O}_{2}$ and electric conductivity (EC) in groundwater samples were done "in situ". $\mathrm{pH}$ was determined by potentiometric method, redox potential (Eh) was measured with a potentiometer electrode of $\mathrm{Pt}$, the dissolved oxygen (DO) evaluated with an DO meter, and EC was shown by a conductivity metre. Arsenic content was measured by Atomic Absorption Spectrometer (AAS) with hydride generator following the method of Jimenez et al. (1996), $\mathrm{Ca}, \mathrm{Fe}, \mathrm{Mg}, \mathrm{Na}$ 
and $\mathrm{K}$ by AAS, where the precision of the method was assessed by performing the analysis 10 times for a single sample, and the relative standard deviation was between $5 \%$ and $10 \%$. Nitrate, sulphate and chloride were analyzed by Ion Chromatography (Metrohm) and bicarbonate by titration.

A total of 95 samples were taken into account for the statistical analyses. ANOVA were performed using the program SPSS 12.0 in order to test the influence of the different variables. Analytical precision, expressed as the relative standard deviation (RSD) ranges from 5 to $10 \%$.

\section{Results and discussion}

\subsection{Groundwater chemistry}

The summary of analytical data of groundwater samples are presented in Table 1. The Piper diagram (Fig. 2) shows that the fundamental geochemical processes occurring in the aquifer (hydrolysis of silicate and carbonate minerals, ion exchange, and precipitation) conduce to an evolutionary trend of groundwater towards $\mathrm{Na}-\mathrm{HCO}_{3}{ }^{-}$water type with high $\mathrm{pH}$ (8.0-9.0) in an oxic environment. The uptake of protons by mineral weathering and ion exchange during the evolution of groundwater can be the reason of high $\mathrm{OH}^{-}$concentrations.

\subsection{Arsenic release due to effect of high $\mathrm{pH}$ and bicarbonate}

Arsenic mobility in groundwater is a function of $\mathrm{pH}$, Eh, the type and abundance of sorption sites on mineral surface of the aquifer sediment, and microbial population. Desorption at high $\mathrm{pH}$ is a likely mechanism for the As release in groundwater since high $\mathrm{OH}^{-}$ and bicarbonate concentrations can promote the desorption of arsenate by competition for sorption sites (Mc Bride, 1994). Similar to the previously reported analytical results of García-Sánchez et al. (2005), this study found a significant correlation between arsenic and bicarbonate contents in water samples (Fig. 3) collected along first year (2001), which is coherent with the results obtained in other countries (Pantsar-Kallio and Manninen, 1997). Anawar et al. (2004) showed that bicarbonate solutions can effectively extract arsenic from clay, silt and sand sediments. Bicarbonate competes with arsenate on the sorption sites of mineral surface, primarily HFO, reducing the quantity of arsenic adsorbed. The role of bicarbonate in arsenic desorption is very important at high $\mathrm{pH}$ (Wilkie and Hering, 1996), that is substantiated by the results of this study. The water $\mathrm{pH}$ in this area (Table 1) is alkaline, and there is a significant correlation between $\mathrm{pH}$ and arsenic concentration in water (Fig. 4) reflecting that $\mathrm{pH}$ increase promoted arsenate desorption, especially above $\mathrm{pH} 8.5$ as demonstrated by Dzombak and Morel (1990) using the diffuse double layer model calculation. Based on model calculation and batch experiment results, Gustafsson and Bhattacharya (2007) demonstrated that adsorption capacity of As on HFO in the absence of bicarbonate ion was around 500 times higher than in the presence of bicarbonate concentrations of about $200 \mathrm{mg} / \mathrm{L}$. The average bicarbonate concentration of groundwater in this study is $177.5-200 \mathrm{mg} / \mathrm{L}$, equivalent to the concentration of Gustafsson and Bhattacharya (2007). Therefore, under this condition of alkalinity, bicarbonate and $\mathrm{OH}^{-}$ions could displace the arsenic from the surface of HFO and mobilize into the groundwater.

\subsection{Influence of nitrate on arsenic removal and temporal evolution of arsenic}


Dissolved iron contents in groundwater represent actually the total Fe including Fe(III) and/or $\mathrm{Fe}(\mathrm{II})$ complexes, particulate and colloidal forms with ability of passing through a filter of $0.45 \mu \mathrm{m}$ (Bauer and Blodau, 2009). Iron content varied between 0.01 and $0.31 \mathrm{mg} / \mathrm{l}$ representing the enough amount of iron to adsorb the high concentrations of arsenic in groundwater (Table 1).

The results demonstrated the negative correlation between arsenic and nitrate content in groundwater of this study area (Fig. 5). This may occur due to increased As adsorption on colloids, iron oxide and other mineral surface in sediments in the presence of nitrate, which may be propitiated by the oxidation (chemically or microbiologically) of Fe(II) favouring the As adsorption on HFO (Alvarez-Benedi et al., 2003; Weber et al., 2001; Smedley and Kinninburg, 2002; Senn and Hemond, 2002; Hoeft et al., 2002; Rhine et al., 2007; Sun et al., 2008). The increasing values of correlation coefficient are observed along the three successive years (2001, 2003 and 2007) of study reaching maximum at $\mathrm{R}=0.51$ in 2007 (Fig. 5), which reflect the temporal evolution of arsenic content along the different years. For the temporal evolution of arsenic content in groundwater, significant differences are observed along the three successive years (2001, 2003 and 2007) studied (Fig. 6).

The data show a simultaneous decrease of arsenic content, but increase of nitrate content in the last year, 2007 (Fig. 6 and 7). This is presumed due to about 20\% increase of irrigated agricultural surface in the studied area (AEDCYL, 2004, 2008) leading to the increased nitrate application via the widespread use of nitrogen fertilizer and pig manure, especially during the period of this study. Under both oxic and anoxic conditions, the nitrate increase, as a terminal electron acceptor, promoted the formation of $\mathrm{As}(\mathrm{V})$ and Fe(III) (Branson et al., 1975; Senn and Hemond, 2002) that subsequently adsorbed arsenic in groundwater of this study area. Moreover, the nitrate can inhibit the $\mathrm{Fe}$ (III) reduction in aquifer sediments, preventing HFO dissolution and hosted arsenic. A model test in Bangladesh, where nitrate was injected into the aquifer, showed that dissolved arsenic levels declined probably as a result of adsorption on newly formed HFO (Harvey et al., 2002). Some previous studies identified bacteria that could mediate $\mathrm{Fe}$ (II) oxidation through reduction of $\mathrm{NO}_{3}{ }^{-}$(Senn and Hemond, 2002), and field evidence suggested that $\mathrm{NO}_{3}{ }^{-}$may influence $\mathrm{Fe}$ cycle through the precipitation of $\mathrm{HFO}$ (Postma et al., 1991).

\section{Conclusions}

High concentrations of dissolved bicarbonate might have mobilized As from mineral surface by displacement reaction, which may be favoured at high $\mathrm{pH}$ values of this study area, since under oxic conditions of the aquifer, the bicarbonate ion compete with arsenate for sorption sites on hydrous ferric oxides of aquifer sediment. On the other hand, high nitrate contents in groundwater may lead to the oxidation of $\mathrm{Fe}(\mathrm{II})$ resulting in the formation of $\mathrm{HFO}$, that may adsorb dissolved arsenic and cause a decreasing content of As in groundwater. The temporal variations of arsenic content in groundwater can be the result of the changes in the proportion of the bicarbonate and nitrate concentrations along the time. Between the two variables under consideration, the nitrate concentration has undergone the most important changes during these years due to the increment in the use of nitrogen fertilizer and pig manure for agriculture in the study area.

\section{Acknowledgements}


This work was supported by Junta de Castilla y Leon (Project VA094A06, Project CSI01A07 and Project VA014A07) and Ministerio de Educación y Ciencia (Project CTM200602249/TECNO).

\section{References}

AEDCYL.-Consejería de Agricultura y Ganadería, Junta de Castilla y León (2004). Anuario de Estadística Agraria de Castilla y León. Consejería de Agricultura y Ganadería-Junta de Castilla y León. Valladolid.

AEDCYL.-Consejería de Agricultura y Ganadería, Junta de Castilla y León (2008). Anuario de Estadística Agraria de Castilla y León. Consejería de Agricultura y Ganadería-Junta de Castilla y León. Valladolid.

Alvarez-Benedí, J.; Bolado Rodríguez, S.; Cancillo Carro, I. and Calvo Revuelta, C. (2003). Dinámica de adsorción - desorción de arsénico (V) en suelos de cultivo en Castilla y León. Estudios de la Zona no Saturada del Suelo Vol. VI. 331-338.

Anawar, H.M; Akai, J; Komaki, K; Terao, H; Yoshioka, T; Ishizuka, T; Safiullah, S; Kato, K. (2003) Geochemical occurrence of arsenic in groundwater of Bangladesh: sources and mobilization processes. J. Geochem. Explor. 77, 109-131.

Anawar, H. M.; Akai, J. and Sakugawa, H. (2004). Mobilization of arsenic from subsurface sediments by effect of bicarbonate ions in groundwater. Chemosphere 54, 53-762.

Appelo, C. A. J.; Van der Weiden M. J. J.; Tournassat, C.; Charlet, L. (2002). Surface complexation of ferrous iron and carbonate on ferrhydrite and the mobilization of arsenic. Environ Sci. Technol., 36, 3096-3103.

Aragonés Sanz, N.; Palacios Diez, M.; Avello de Miguel, A.; Gómez Rodríguez, P.; Martínez Cortés, M. and Rodríguez Bernabeu, M. J. (2001). Nivel de arsénico en abastecimientos de agua de consumo de origen subterráneo en la Comunidad de Madrid. Revista Española de Salud Pública, 75, 421-432.

Armenteros, I. (1991). Contribución al conocimiento del Mioceno lacustre de la Cuenca Terciaria del Duero (sector centro-oriental, Valladolid-Peñafiel-Sacramenia-Cuéllar). Acta Geológica Hispánica, 26, 97-131.

Bauer, M. and Blodau, C. (2009). Arsenic distribution in the dissolved colloidal and particulate size fraction of experimental solutions rich in dissolved organic matter and ferric iron. Geochem. Cosmochim. Acta, 73, 529-542.

Benz, M.; Brune, A. and Schink, B. (1998). Anaerobic and aerobic oxidation of ferrous iron at neutral $\mathrm{pH}$ by chemoherotrophic nitrate reducing bacteria. Archives Microbial., 169, 159165.

BGS-DPHE, British Geological Survey and Department of Public Health Engineering (2001). Arsenic contamination of groundwater in Bangladesh. Kinniburgh, D.G. and Smedley, P.L. Eds. Volume 2: Final Report. BGS Technical Report WC/00/19, British Geological Survey. 267 pp.

Branson, R. L.; Pratt, P. F.; Rhoades, J. D. and Oster, J. D. (1975) Water quality in irrigated watersheds. J. Environ. Qual. 4, 33-40.

Cummings, D. E.; Caccavo, F.; Fendorf, R. F. and Rosenzweig, R. F. (1999). Arsenic mobilization by dissimilatory Fe(III) reducing bacterium Shewanella algae Bry. Environ. Sci. Technol., 33, 723-729.

Dzombak, D. A. and Morel, F. M. M. (1990). Surface complexation modelling. Hydrous ferric oxide. John Wiley, New York. 
Fendorf, S.; Eick, M. J.; Grossl, P. and Sparks, D. L. (1997) Arsenate and chromate retention mechanism on goethite. 1. Surface structure. Environmental Science Technology, 31, 315-320.

García-Sanchez, A. and Alvarez-Ayuso, E. (2003). Arsenic in soils and waters and its relation to geology and mining activities (Salamanca Province, Spain). Journal of Geochemical Exploration, 80, 69-79.

García-Sánchez, A.; Moyano, A. and Mayorga, P. (2005). High arsenic contents in groundwater of central Spain. Environmental Geology, 47, 847-854.

Gustafsson, J. P. and Bhattacharya, P. (2007). Geochemical modelling of arsenic adsorption to oxide surfaces. In Bhattacharya, P.; Mukherjee, A. B.; Bunsdchuh, J.; Zevenhoven, R. and Loeppert, R. H. Eds.: Arsenic in soil and groundwater environment, 159-206. Elsevier, New York.

Harvey, C. F.; Swartz, C. H.; Badruzzaman, A. B. M.; Keon-Blute, N.,Yu, W.; Ali, M. A.; Jay, J.; Beckie, R.; Niedan, V.; Brabander, D.; Oates, P. M., Ashfaque, K. N., Islam, S., Hemond, H. F. and Ahmed, M. F. (2002). Arsenic mobility and groundwater extraction in Bangladesh. Science 298 (5598), 1602-1606.

Hernández García, M. E. and Fernández Ruiz, L. (2002). Presencia de arsénico de origen natural en las aguas subterráneas del acuífero detrítico del Terciario de Madrid. Boletín Geológico y Minero, 113 (2), 119-130.

Hoeft. S. E.; Lucas. F.; Hollibaugh. J. T. and Oremland. R. S. (2002). Characterization of microbial arsenate reduction in anoxic bottom waters of Mono Lake. California. Geomicrobiology Journal, 19, 23-40.

Höhn, R.; Isenbeck-SchröterR.; Kent, D. B.; Davis, J. A.; Jakobsen, R.; Jann, S. Niedan, V.; Scholz, C.; Staler, S. A. and Tracer, A. (2006). Test with As(V) under variable redox conditions controlling arsenic transport in the presence of elevated ferrous iron concentrations. Journal of Contaminant Hydrology, 88 (1-2), 36-54.

IGME (1980) Investigación Geología de la Cuenca del Duero. System No 8 y 12. Graphic. Bergsma, Madrid.

IGME (1982). Hoja del Mapa Hidrogeológico de España, a escala 1:200.000, $\mathrm{n}^{\text {o }} 37$ de Salamanca, 4 pp.

Jimenez, O.; Rodriguez, N. and Garcia-Sanchez, A. (1996). Determination of total arsenic and selenium in soils and plants by AAS with HG and FIA coupled techniques. J. Of AOAC International, 79, 764-768.

Kneebone, P. E.; O`Day, P. A.; Jones, N.; Hering, J. G. (2002). Deposition and fate of arsenic in arsenic-enriched reservoir sediment. Environ. Sci. Technol. 36, 381-386.

McArthur, J.M.; Ravenscroft, P.; Safiullah, S.; Thirlwall, M.F. (2001). Arsenic in groundwater: testing pollution mechanisms for sedimentary aquifers in Bangladesh. Water Res. 37, 109-117.

McArthur, J. M.; Banerjee, D. M.; Hudson-Edwards, K.A.; Mishra, R.; Purohit, R.; Ravenscroft, P.; Cronin, A.; Howarth, R. J.; Chatterjee, A.; Talukder, T.; Lowry, D.; Houghton, S.; Chadha, D. K. (2004). Natural organic matter in sedimentary basins and its relation to arsenic in anoxic ground water: the example of West Bengal and its worldwide implications. Appl. Geochem. 19, 1255-1293

Mc Bride, B. M. (1994). Environmental Chemistry of Soils. Oxford Univ. Press, New York.

Nickson, R.; McArthur J. M.; Burgess, W.; Ahmed, K. M.; Ravencroft, P.; Rahman, M. (1998). Arsenic poisoning of Bangladesh groundwater. Nature 394, 338. 
Nickson, R.; McArthur, J. M.; Ravenscroft, P.; Burgess, W. G.; Ahmed, K.M. (2000). Mechanism of arsenic release to groundwater, Bangladesh and west Bengal. Appl Geochem 15, 403-413.

Nriagu, J. O. (1994). Arsenic in the environment. Part II: Human Health and Ecosystem Effects. Advances in Environmental Science and Technology. Wiley Series. 27. 320 pp.

Pantsar-Kallio, M. and Manninen, P. K. G. (1997). Speciation of mobile arsenic in soil samples as a function of pH. Science of Total Environment, 204, 193-200.

Postma, D.; Boesen, C.; Kristiansen, H. and Larsen, F. (1991). Nitrate reductionin an unconfined sandy aquifer: water chemistry, reduction processes, and geochemical modeling. Water Resour. Res. 27, 2027-2045.

Rhine, E. D.; Chadhain, S. M. Ní; Zylstra, G. J. and Young, L. Y (2007). The arsenite oxidase genes (aroAB) in novel chemoautotrophic arsenite oxidizers. Biochemical and Biophysical Research Communications 354, 662-667.

Sahun, B.; Gómez, J. J.; Lillo, J. and del Olmo, P. (2004). Arsénico en aguas subterráneas e interacción agua-roca: un ejemplo en la Cuenca Terciaria del Duero (Castilla y León, España). Rev. Soc. Geol. De España, 17 (1-2), 137-155.

Senn, D. B. and Hemond, H. F. (2002). Nitrate controls on Iron and Arsenic in urban lake. Science, 296, 2373-2376.

Smedley P. L. and Kinninburgh, D. G. (2002). A review of the source, behaviour and distribution of arsenic in natural waters. Applied Geochemistry, 17, 517-568.

Sun, W.; Sierra, R and Field, J. A. (2008) Anoxic oxidation of arsenite linked to denitrification in sludges and sediments. Water Research, 4 2, 4569-4577.

Weber, K. A.; Picardal, F. W. and Roden, E. E. (2001). Microbially catalyzed Nitratedependent oxidation of biogenic solid-phase Fe (II) compounds. Environ. Sci. Technol., $35,1644-1650$.

Welch, A. H.; Westjohn, D. B.; Helsel, D. R. and Wanty, R. B. (2000). Arsenic in ground water of the United States: Occurrence and Geochemistry. Ground Water, 38, 589-604.

Welch, A. H. and Stollenwerk, K. G. (Eds.) (2002). Arsenic in ground water geochemistry and occurrence. Academic Publishers. Kluwer, 488 pp.

Wilkie, J. A. and Hering, J. G. (1996). Adsorption of arsenic onto hydrous ferric oxide: Effects of adsorbate/adsorbent ratios and co-occurring solutes. Colloids Surfaces APhysicochem. Engineer. Aspects, 107, 97-110. 


\section{Legend of figures}

Figure 1. Sketch of study area and sampling points

Figure 2. Piper diagram of the studied groundwater

Figure 3. Relationship between $\left[\mathrm{HCO3}^{-}\right]$(in $\mathrm{mg} / \mathrm{l}$ ) and arsenic content during first year, (expressed as Ln As) $(\mathrm{R}=0.67 ; \mathrm{p}<0.01)$

Figure 4. Relationship between $\mathrm{pH}$ and $\mathrm{Ln} \mathrm{As}(\mathrm{R}=0.54 ; \mathrm{p}<0.01)$

Figure 5. Relationship between Ln As with Ln nitrate during third, year $(R=-0.51 ; p<0.01)$

Figure 6. As concentration (expressed by Ln As) in the three years sampled, being: $1=2001$, $2=2003$ and $3=2007(\mathrm{p}<0.05)$

Figure 7. The nitrate concentration (expressed by $\mathrm{Ln} \mathrm{NO}^{-}$) in the three years sampled, being: $1=2001,2=2003$ and $3=2007(\mathrm{p}<0.05)$ 
Table 1. Statistical summary of selected properties of the groundwater

\begin{tabular}{|c|c|c|c|c|}
\hline Property & Year & Range & Average & Standard Deviation $( \pm)$ \\
\hline As $(\mu \mathrm{g} / \mathrm{l})$ & $\begin{array}{l}1 \\
2 \\
3\end{array}$ & $\begin{array}{l}20-260 \\
3-187 \\
5-51\end{array}$ & $\begin{array}{l}93 \\
48 \\
15\end{array}$ & $\begin{array}{l}60 \\
45 \\
10\end{array}$ \\
\hline $\mathrm{Fe}(\mathrm{mg} / \mathrm{l})$ & $\begin{array}{l}1 \\
2 \\
3\end{array}$ & $\begin{array}{l}0.005-0.310 \\
0.005-0.300 \\
0.005-0.099\end{array}$ & $\begin{array}{l}0.03 \\
0.03 \\
0.02\end{array}$ & $\begin{array}{l}0.066 \\
0.050 \\
0.023\end{array}$ \\
\hline $\mathrm{DO}(\mathrm{mg} / \mathrm{l})$ & $\begin{array}{l}1 \\
2 \\
3\end{array}$ & $\begin{array}{l}2.29-8.18 \\
2.29-8.80 \\
2.29-8.18\end{array}$ & $\begin{array}{l}5.71 \\
7.47 \\
5.66\end{array}$ & $\begin{array}{l}1.90 \\
1.68 \\
1.82\end{array}$ \\
\hline $\mathrm{pH}$ & $\begin{array}{l}1 \\
2 \\
3\end{array}$ & $\begin{array}{l}7.7-9.3 \\
7.2-9.5 \\
7.1-9.0\end{array}$ & $\begin{array}{l}8.6 \\
8.3 \\
8.1\end{array}$ & $\begin{array}{l}0.5 \\
0.7 \\
0.5\end{array}$ \\
\hline $\mathrm{EC}\left(\mu \mathrm{Scm}^{-1}\right)$ & $\begin{array}{l}1 \\
2 \\
3\end{array}$ & $\begin{array}{l}202-2980 \\
215-3760 \\
228-1934\end{array}$ & $\begin{array}{c}917 \\
1182 \\
885\end{array}$ & $\begin{array}{l}732 \\
837 \\
412\end{array}$ \\
\hline Eh $(\mathrm{mV})$ & $\begin{array}{l}1 \\
2 \\
3\end{array}$ & $\begin{array}{l}135-281 \\
217-668 \\
144-241\end{array}$ & $\begin{array}{l}198.7 \\
332.9 \\
201.8\end{array}$ & $\begin{array}{l}38.3 \\
96.3 \\
22.8\end{array}$ \\
\hline $\mathrm{HCO}_{3}^{-}(\mathrm{mg} / \mathrm{l})$ & $\begin{array}{l}1 \\
2 \\
3\end{array}$ & $\begin{array}{l}59.0-378.0 \\
92.0-413.0 \\
6.5-386.0\end{array}$ & $\begin{array}{l}178.4 \\
202.2 \\
177.5\end{array}$ & $\begin{array}{l}71.1 \\
59.8 \\
94.7\end{array}$ \\
\hline $\mathrm{NO}_{3}^{-}(\mathrm{mg} / \mathrm{l})$ & $\begin{array}{l}1 \\
2 \\
3\end{array}$ & $\begin{array}{l}1.0-218.0 \\
0.3-187.0 \\
7.0-423.0\end{array}$ & $\begin{array}{l}41.0 \\
37.0 \\
81.9\end{array}$ & $\begin{array}{l}59.4 \\
44.8 \\
93.8\end{array}$ \\
\hline $\mathrm{Cl}^{-}(\mathrm{mg} / \mathrm{l})$ & $\begin{array}{l}1 \\
2 \\
3\end{array}$ & $\begin{array}{l}2.0-69.0 \\
3.0-71.0 \\
3.0-80.0\end{array}$ & $\begin{array}{l}23.2 \\
32.4 \\
26.4\end{array}$ & $\begin{array}{l}16.1 \\
9.0 \\
24.7\end{array}$ \\
\hline $\mathrm{CO}_{3}^{-2}(\mathrm{mg} / \mathrm{l})$ & $\begin{array}{l}1 \\
2 \\
3\end{array}$ & $\begin{array}{l}0.2-32.2 \\
0.11-26.5 \\
0.03-9.7\end{array}$ & $\begin{array}{l}5.9 \\
4.8 \\
1.5\end{array}$ & $\begin{array}{l}5.1 \\
7.2 \\
2.0\end{array}$ \\
\hline $\mathrm{SO}_{4}{ }^{2-}(\mathrm{mg} / \mathrm{l})$ & $\begin{array}{l}1 \\
2\end{array}$ & $\begin{array}{l}4.0-92.0 \\
5.0-81.0\end{array}$ & $\begin{array}{l}41.6 \\
34.4\end{array}$ & $\begin{array}{l}27.8 \\
23.1\end{array}$ \\
\hline
\end{tabular}




\begin{tabular}{lllll} 
& 3 & $4.0-80.2$ & 38.2 & 23.5 \\
& & & & \\
$\mathrm{Ca}^{++}(\mathrm{mg} / \mathrm{l})$ & 1 & $0.4-251.1$ & 51.2 & 72.9 \\
& 2 & $1.0-369.9$ & 97.0 & 109.5 \\
& 3 & $0.4-292.0$ & 103.6 & 92.2 \\
$\mathrm{~K}^{+}(\mathrm{mg} / \mathrm{l})$ & 1 & $0.3-45.2$ & 6.8 & 9.2 \\
& 2 & $0.4-14.0$ & 3.6 & 3.3 \\
& 3 & $0.5-21.0$ & 5.6 & 4.6 \\
$\mathrm{Mg}^{++}(\mathrm{mg} / \mathrm{l})$ & 1 & & & \\
& 2 & $0.1-117.0$ & 25.5 & 37.5 \\
& 3 & $0.1-158.0$ & 43.9 & 52.8 \\
& & $0.2-163.0$ & 57.9 & 53.7 \\
$\mathrm{Na}^{+}(\mathrm{mg} / \mathrm{l})$ & 1 & & & \\
& 2 & $10.8-289.2$ & 109.0 & 67.2 \\
& 3 & $3.1-200.0$ & 72.9 & 51.7 \\
& & $6.0-201.0$ & 70.8 & 42.3 \\
$\mathrm{Depth}(\mathrm{m})$ & 1 & & & \\
& 2 & $120-300$ & 185.0 & 78.5 \\
& 3 & $116-300$ & 216.5 & 97.4 \\
& & $116-380$ & 181.2 & 77.8 \\
\hline
\end{tabular}


3
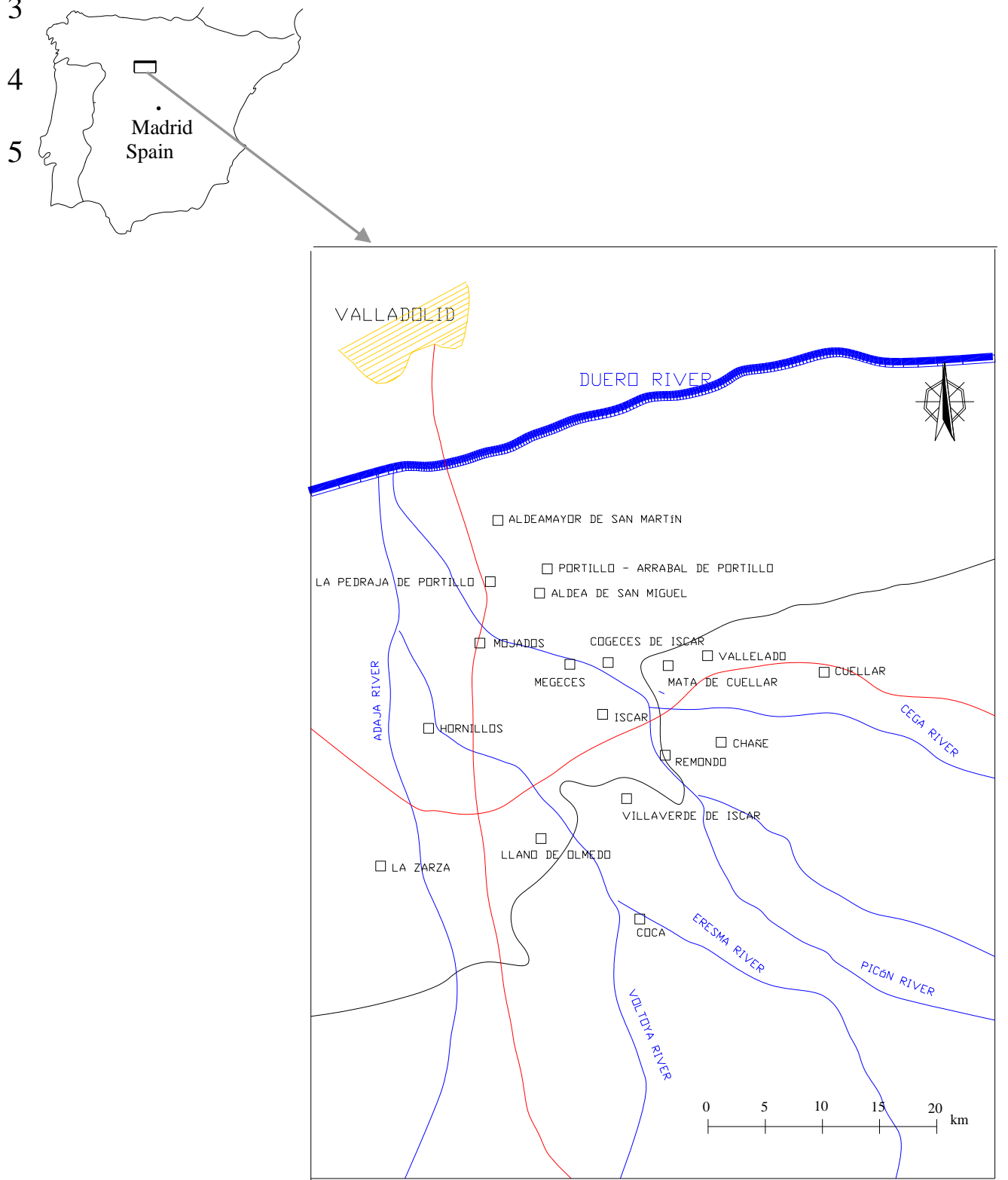

6

Fig. 1. Sketch of study area and sampling points.

8 


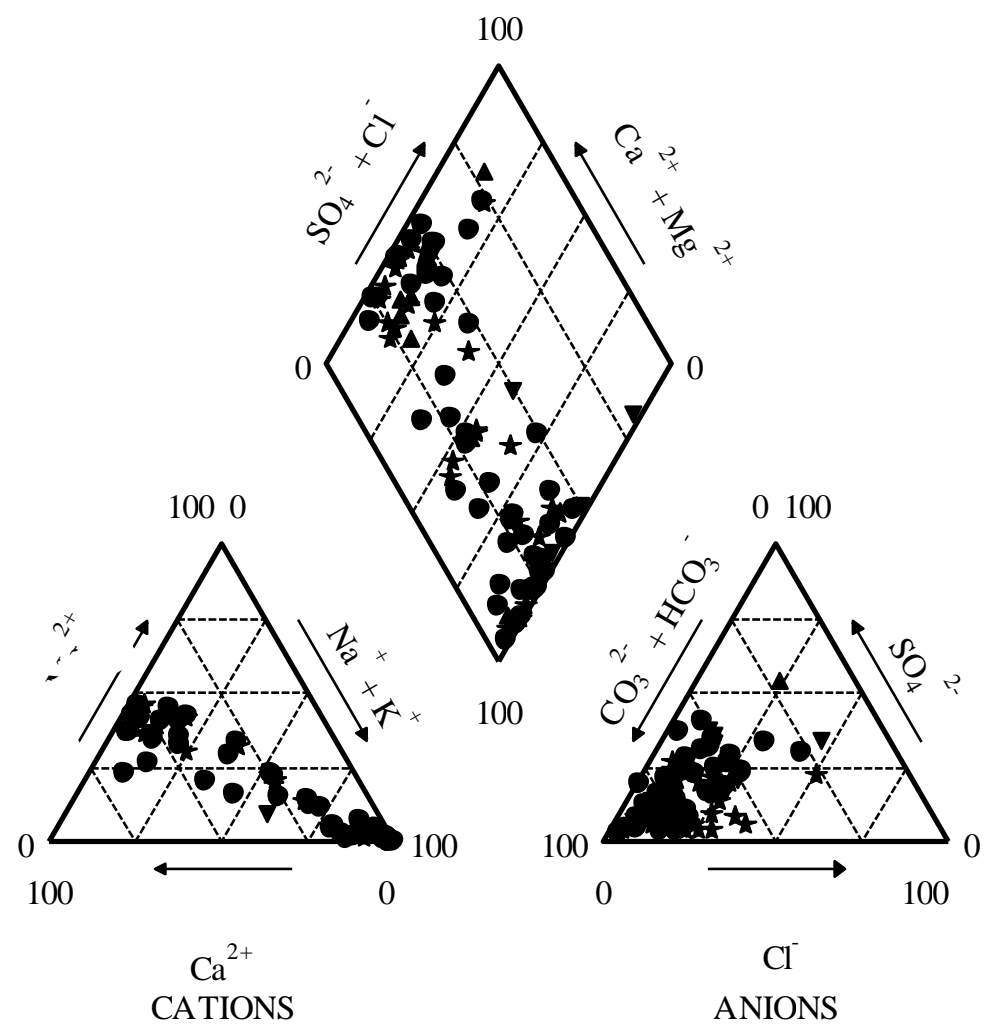

14 Fig. 2. Piper diagram of the studied groundwater 


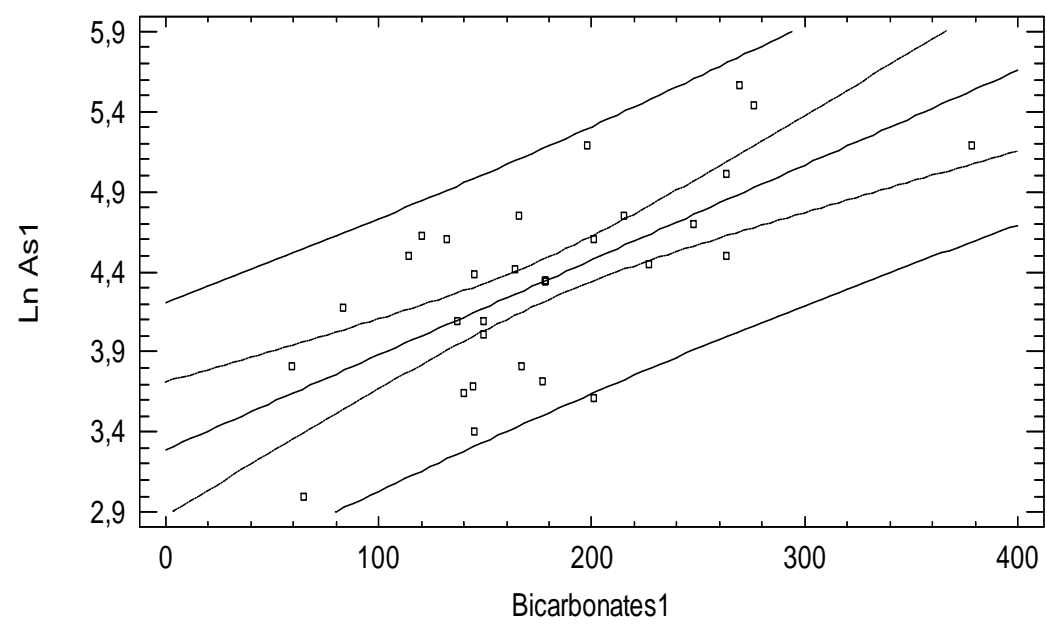

15

16 Fig 3. Relationship between $\left[\mathrm{HCO}^{-}\right]$(in $\mathrm{mg} / \mathrm{l}$ ) and arsenic content (expressed as $\mathrm{Ln} \mathrm{As}$ )

17 during first year $(\mathrm{R}=0.67 ; \mathrm{p}<0.01)$.

18

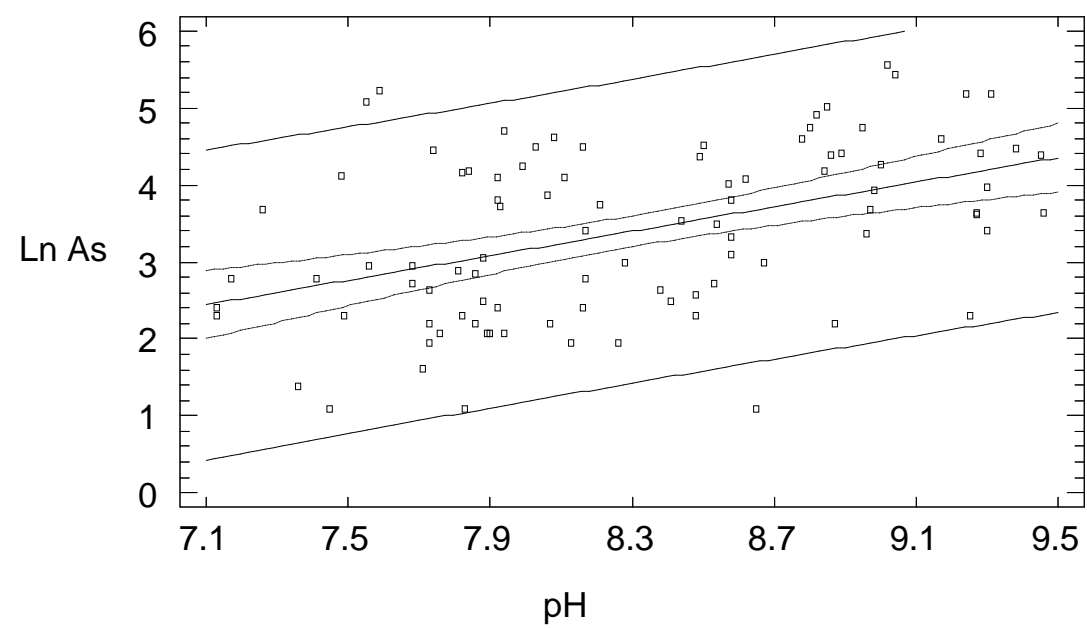

19

20 Fig. 4. Relationship between $\mathrm{pH}$ and $\mathrm{Ln}$ As $(\mathrm{R}=0.54 ; \mathrm{p}<0.01)$.

21 


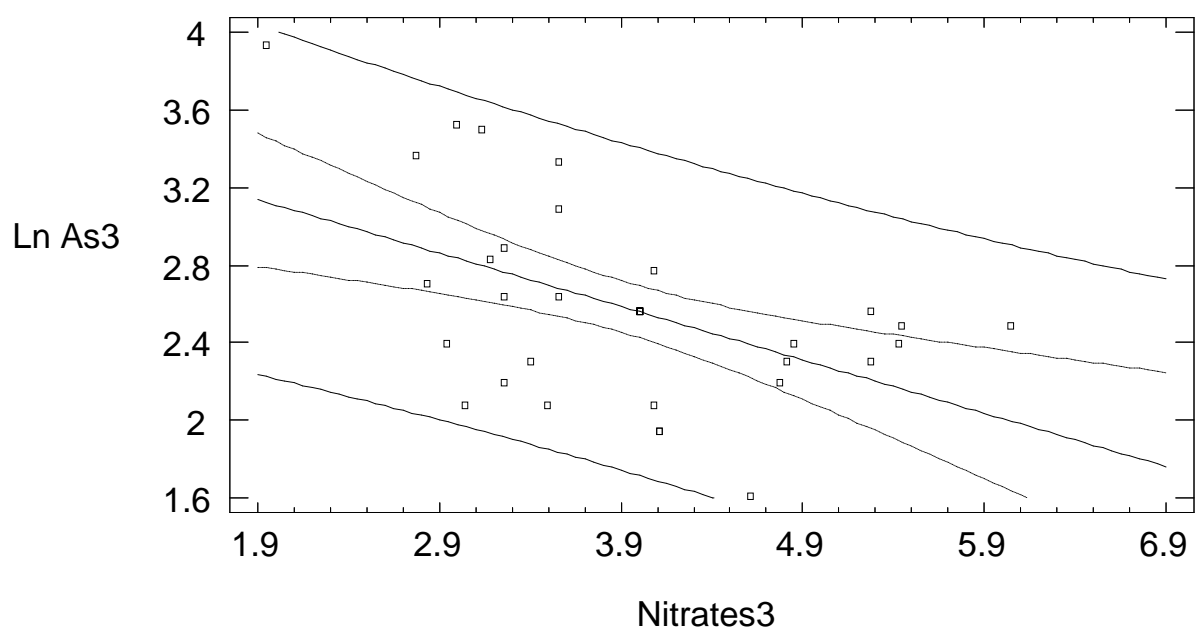

23

24 Fig. 5. Relationship between Ln As with Ln nitrate during third year $(\mathrm{R}=-0.51 ; \mathrm{p}<0.01)$.

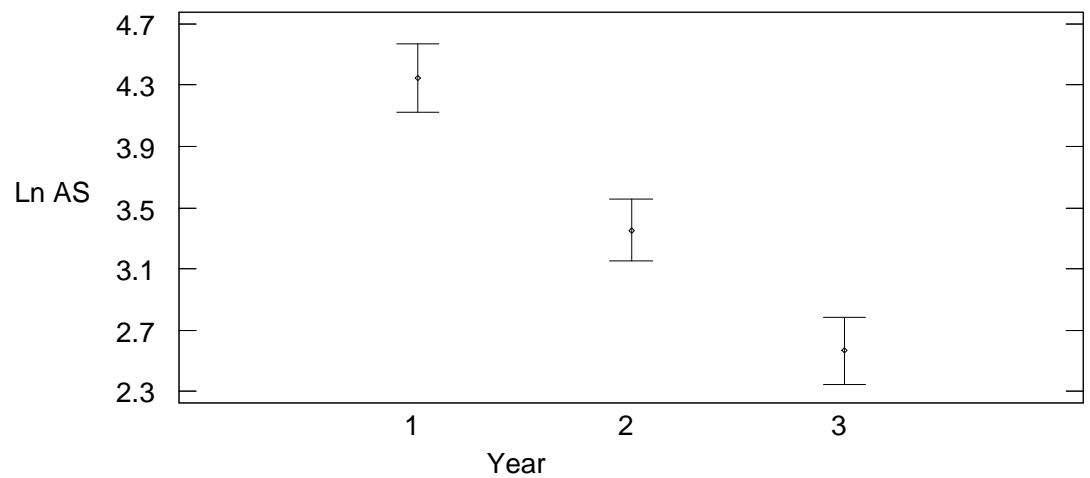

26 Fig. 6. Mean and Percent LSD Interval, As concentration (expressed by Ln As) in the three

27 years sampled, being: $1=2001,2=2003$ and $3=2007(p<0.05)$ 


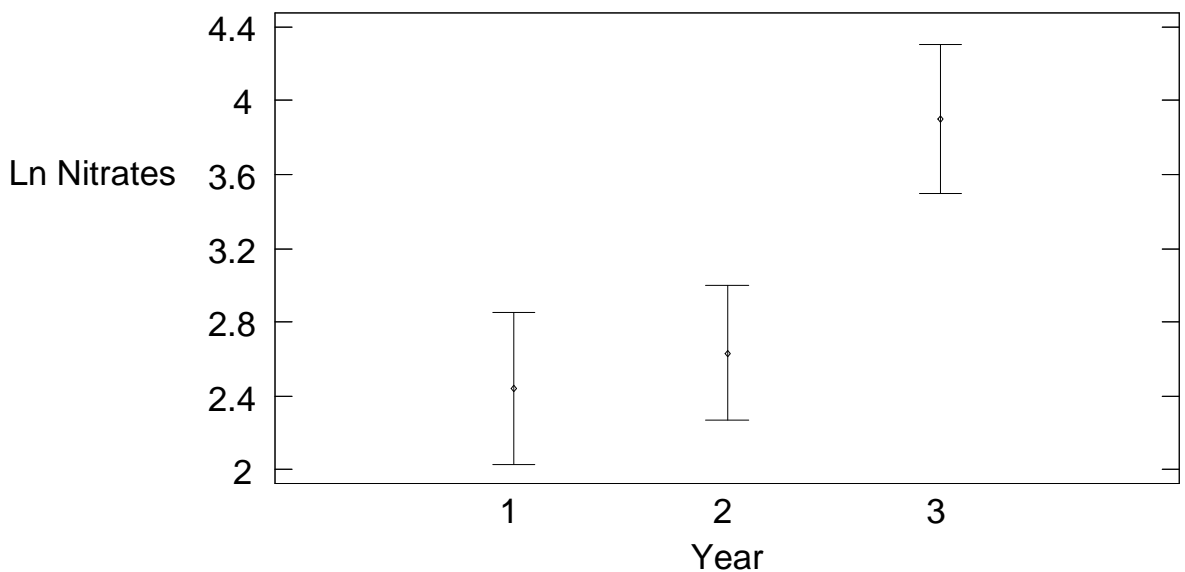

29

30 Fig. 7. Means and Percent LSD Intervals, nitrate concentration (expressed by $\mathrm{Ln} \mathrm{NO}_{3}^{-}$) in

31 the three years sampled, being: $1=2001,2=2003$ and $3=2007(p<0.05)$

32

33 


\section{Uptake and accumulation of arsenic in different organs of}

\section{2 carrot irrigated with As-rich water}

3

4 P. Mayorga ${ }^{1}$, A. Moyano ${ }^{1}$, H.M. Anawar ${ }^{2 *}$, A. Garcia-Sanchez ${ }^{3}$

5

$6 \quad{ }^{1}$ Departamento de Producción Vegetal, Universidad de Valladolid, Soria, Spain

$7 \quad{ }^{2}$ Okavango Research Institute, University of Botswana, Private Bag 285, Maun,

8 Botswana

$9{ }^{3}$ Departamento de Procesos de Degradación Ambiental, IRNASA-CSIC, Salamanca,

10 Spain

11

$12 *$ Corresponding author address

13 Okavango Research Institute,

14 University of Botswana,

15 Private Bag 285, Maun, Botswana

16 Tel.: +267-686-1833;

17 Fax: +267-686- 1835 .

18 E-mail: anawar4@hotmail.com

19

20

21

22 


\section{Abstract}

27 Irrigation with arsenic (As)-rich water in agricultural soil may increase high levels of As in crops and cause food chain contamination. In this study, a greenhouse experiment was established using Spanish agricultural soil (Valladolid and Segovia provinces), that are extensively cultivated for carrot plant, to investigate the process of As uptake, bioaccumulation, and translocation of As from root to shoot and leaves in carrot plant. Arsenic concentrations in different organs of carrot plant, rhizosphere soil, and soil solutions were determined by hydride generation atomic absorption spectrometry. High concentrations of As in irrigation water, and the alkaline and sandy character of this soil enhanced As uptake in carrot plants indicating the potential health risk from consumption of carrots cultivated in these areas. No differences were found in the growth or toxicity symptoms, such as leaves discolorations or necrosis, with irrigation treatments of $0,20,50,100$ and $150 \mu \mathrm{gL}^{-1}$ of As in irrigation water. Bioaccumulation of As into the leaves and roots increased with increase of As concentration in irrigation water. Both roots and leaves demonstrated a higher accumulation rate of As at an As concentration of $41 \mu \mathrm{gL}^{-1}$ than $131 \mu \mathrm{gL}^{-1}$ in the soil solution. The ratios of $\mathrm{As}_{\mathrm{root}}$ / $\mathrm{As}_{\text {leaves }}$ showed no statistically significant differences for the different irrigation treatments, and had an average value of 0.36 indicating the high magnitude of As translocation from roots to leaves in carrot plants. The leaves of carrots had a higher affinity for As than roots did. The correlation between As uptake by leaves or roots of carrots and the soluble As in rhizosphere soil did not demonstrate a linear or a plateau curve, indicating a slow but continuous constant As absorption which could be prolonged over time with high potential environmental risks. 
50 Keywords: Arsenic; Carrot; Irrigation water; Agricultural Soil; Plant uptake;

51 Bioaccumulation; Translocation of As

\section{Introduction}

54 Arsenic is a major global environmental contaminant across the globe. Its presence at 55 high levels in drinking water, soil, crops and vegetables in many regions of the world 56 endangers human health $[1,2]$. Although drinking water is the main route of As intake in the human body, the food chain can also be another significant route of As uptake where people eat contaminated crops, vegetables and animals. Clinical manifestations of As poisoning are associated with various forms of skin disease and progress via damage

60 to internal organs, and ultimately to cancer and death [3]. Along with malnutrition and

61 micronutrient deficiencies, the onset of arsenicosis or other As-related illnesses may be aggravated further. Williams et al. [4] reported that As could perturb rice grain trace element micronutrient balances, resulting in severe yield reductions and alteration of the normal levels of $\mathrm{Se}, \mathrm{Zn}$ and $\mathrm{Ni}$ in the rice grain.

Typical uncontaminated agricultural soil contain $1-20 \mathrm{mgkg}^{-1}$ of As [5], but contaminated soil in mining or industrial areas may contain levels as high as 45-2600

$67 \mathrm{mgkg}^{-1}$ [6]. The extensive use of As-rich groundwater has led to elevated As concentrations in agricultural soil of Bangladesh, West Bengal (India), Vietnam,

69 Thailand, Taiwan, Argentina, Chile and Spain, with respect to normal levels of 0.1-40 $70 \mathrm{mgkg}^{-1}$ [7]. That may reduce soil productivity, can be toxic to plants, and enter into the 71 crops and vegetables [8-12]. The contents of iron oxides and organic matter, $\mathrm{pH}$ and Eh values, and microbial activity have relevant effects on As adsorption and mobility in soil [13-14]. 
Arsenic concentration in terrestrial plants, especially crop plants, rarely exceeds 1 $\mathrm{mgkg}^{-1} \mathrm{DW}$ (dry weight basis) [15] and the "As reference plant value" is $0.1 \mathrm{mgkg}^{-1}$ DW [16]. Since inorganic As is the most toxic fraction of this metalloid, it is used by the World Health Organization (WHO) to establish the guideline limit (15 $\mu$ g inorganic As / kg body weight per week) for As intake by humans. The percentage of inorganic As in the edible tissues of vegetables (carrot, garlic, potato, and beetroot) depends on the species, growth stage, organ, etc. and varies from 28 to $100 \%$ of the total As contents [17].

Arsenate is the dominant form of phytoavailable As in aerobic soil, and is an analogue of phosphate [18]. It has been reported that arsenate is taken up via the phosphate transporters in all plant species tested and reduced to arsenite [19]. Even low levels of phosphate can displace arsenic from soil particles to increase uptake and phytotoxicity, while larger amounts of phosphate compete with arsenic at root surfaces to decrease uptake and phytotoxicity [20]. Arsenic is present as oxyanions (arsenate and arsenite), As(III)-tris thiolate complex and As(III)-tris glutathione in the shoot and roots of Brassica juncea plant species. Arsenic resistance has been identified in a range of plant species [6]. Arsenate may be detoxified through reduction to arsenite, which is subsequently complexed with sulphur rich thiols, particularly thiol-containing compounds, metallothioneins (MTs), phytochelatins (PCs) and sulphur rich-glutathione (GSH); and sequestered in vacuoles [21-22]. Another way of plants to defend

94 themselves from external stress factors such as toxic elements is through the plant oxidative defence, low molecular weight antioxidants, and enzymatic antioxidants.

Carrot (Daucus carota var. Sativa) belongs to the Umbelliferae family, and is widely

97 cultivated and consumed in the Valladolid and Segovia provinces (Spain) and all over 
soluble As [25]. The root growth of this plant occurs in two stages: initially a stage of

100 active cell division with subsequent growth in length and production and use of

101 carbohydrates, and later a second stage of cell elongation and extension in diameter

102 (thickening), accumulation of carbohydrates and water and potentially other toxic

103 substances such as As-rich compounds [23]. Radishes, like carrots, have tap roots and

104 the presence of sulphur compounds with As(III) in root, stem and leaf indicating that

105 these compounds may play an important role in the transport and storage of this element $106[24]$.

107 The aim of the present work conducted in greenhouse was to determine: (1) the As 108 uptake in carrot plants cultivated in control soil, and irrigated and contaminated 109 agricultural soil; (2) total and water extractable As in both control and irrigated soil

110 under rhizosphere; (3) bioaccumulation and distribution of As in different organs of 111 carrot; and (4) the relationship between the total and water extractable As in irrigated 112 soil and the corresponding total As in the edible parts of carrot.

1142 Materials and methods

\section{$115 \quad 2.1$ Soil sampling and preparation}

116 Soil was collected from an agricultural site at Remondo (Segovia province, Spain) (41 ${ }^{\circ}$

$1172036.33 \mathrm{~N} 4^{\circ} 2844.89 \mathrm{~W}$ ). This is an intensive agricultural area located in the

118 southwest of the Tertiary Duero Basin (northern Iberian plateau), and affected by the

119 irrigation of As-rich groundwater (shallow and deep wells). Top soil samples (Cambic

120 Arenosol) were collected to 0-10 cm depth, in the Ap horizon.

\subsection{Experimental greenhouse culture}

123 Twenty-one experimental pots were prepared with $4 \mathrm{~kg}$ of soil in each pot during June 
124 2008. Six seeds of carrot (Daucus carota commercial variety Nantesa) were sown in

125 each experimental pot. Experimental pots were sufficiently irrigated (depending on the

126 values of $\mathrm{pF}$; at $\mathrm{pF} 4.2$, humidity was $2.68 \%$, and at $\mathrm{pF} 2.7$, humidity was $14.79 \%$ ) with

$127200 \mathrm{ml}$ of water per day. Five pots were used as "control" and the others were irrigated

128 with water containing increasing amounts of As: 4 pots with $20 \mu \mathrm{gL}^{-1}, 4$ with $50 \mu \mathrm{gL}^{-1}$,

1294 with $100 \mu \mathrm{gL}^{-1}$ and 4 with $150 \mu \mathrm{gL}^{-1}$ of As. Fertilizers were applied in two portions

130 during 01/06/2008 and 19/08/2008 period with the following compounds and amounts,

131 respectively: $\mathrm{NH}_{4} \mathrm{NO}_{3}: 1.143 \mathrm{~g} ; 0.171 \mathrm{~g} ; \mathrm{K}_{2} \mathrm{HPO}_{4}: 0.503 \mathrm{~g} ; 0.075 \mathrm{~g} ; \mathrm{K}_{2} \mathrm{SO}_{4}: 0.245 \mathrm{~g}$;

$1320.037 \mathrm{~g} ; \mathrm{CaCl}_{2} .2 \mathrm{H}_{2} \mathrm{O}: 0.522 \mathrm{~g} ; 0.078 \mathrm{~g} ; \mathrm{MgSO}_{4} .7 \mathrm{H}_{2} \mathrm{O}: 0.304 \mathrm{~g} ; 0.045 \mathrm{~g}$.

133 After 5 weeks of growth, 4 carrots in each pot were collected. After 19 weeks the carrot

134 plants were harvested, separated into root and leaves and then a total of 61 root and 61

135 leaf samples were collected.

136

$137 \quad 2.3$ Soil properties analysis

138 The soil was dried to constant weight in an air circulated oven $\left(40^{\circ} \mathrm{C}\right)$, mixed, 139 homogenized and sieved through a $2 \mathrm{~mm}$ sieve. The $<2 \mathrm{~mm}$ fraction was used for

140 determination of selected soil properties: $\mathrm{pH}$ was determined potentiometrically, organic

141 carbon content and $\mathrm{CaCO}_{3}$ content were determined with a Carmograph $\mathrm{H}$. Wostoff

142 GMBH, cation exchange capacity (CEC) was measured according to the method of

143 Chapman [26] and phosphorus content by the Olsen method [27].

\section{$145 \quad 2.4$ Arsenic analysis in soil samples}

146 The finely powdered and homogenized soil $(0.1 \mathrm{~g})$ was digested with $5 \mathrm{ml}$ aqua regia +

$1471 \mathrm{ml} \mathrm{HF}$ using a CEM (MDS-2000) microwave oven at a pressure of 7 atm for $30 \mathrm{~min}$.

148 The solution was centrifuged at $3000 \mathrm{rpm}$ and then the supernatant was collected and 
149 filtered using $0.45 \mu \mathrm{m}$ filter. The As concentration in the supernatant solution was

150 determined using a VARIAN spectra AA-220 and hydride generator VGA-76 atomic

151 absorption spectrometry (AAS) following the method of Jimenez et al. [28]. Analytical

152 accuracy was checked with BCR reference material CRM-320 (river sediment) and US

153 Geological Survey reference G-2 (granite). The precision of the method was assessed by

154 performing the analysis ten times for a single sample. The relative standard deviation

155 (RSD) was between 5 and $10 \%$.

\subsection{Water-soluble As analysis}

158 Water-soluble As in soil samples was measured as follows: soil and Milli-Q water were

159 mixed in 1:10 proportion and the mixed suspension was shaken for $24 \mathrm{~h}$ using a rotary

160 shaker. The suspension was centrifuged and filtered, and As concentration in the 161 supernatant solution was determined using hydride generator atomic absorption 162 spectrometry (HG-AAS).

\subsection{Arsenic analysis in carrots}

165 Collected carrot (roots and leaves) samples were cleaned with tap water, rinsed with 166 deionized water and air-dried at room temperature for several days. The air-dried plant 167 samples were powdered homogeneously (by lyophilization) for analysis. Plant samples

$168(0.5 \mathrm{~g})$ were digested with water $(2 \mathrm{ml})$, hydrogen peroxide $(2 \mathrm{ml})$ and conc. $\mathrm{HNO}_{3}(8$ $169 \mathrm{ml}$ ) using a CEM (MDS-2000) microwave oven at a pressure of 9 atm (10 $\mathrm{min})$ and at 17012 atm (15 $\mathrm{min})$. After cooling, the digests were passed through a pre-washed filter 171 (Whatman $n^{\circ}$. 540). The digestion tubes were rinsed three times, passing washings 172 through the filter and the digests were enriched with conc. $\mathrm{H}_{2} \mathrm{SO}_{4}(0.5 \mathrm{ml})$. The digests 173 were then heated at $230^{\circ} \mathrm{C}$ for $2-3 \mathrm{~h}$ and concentrated by evaporation to approximately 
$1740.5 \mathrm{ml}$. Finally $5 \mathrm{ml}$ ascorbic acid (25\%), $5 \mathrm{ml}$ potassium iodide (25\%) and hydrochloric

175 acid $(2 \mathrm{M})$ were added to the digests and brought to the final volume of $25 \mathrm{ml}$. Arsenic

176 concentrations were measured in duplicate by using VARIAN spectra AA-220 and

177 hydride generator VGA-76 AAS with a commercial stock standard (Panreac Quimica

178 SA). The calibration curve fit (at least five standard concentrations) displayed $\mathrm{R}^{2}$ values

$179>0.98$ in all cases. The method's recovery of As $\left(0.79+/-0.08 \mathrm{mgkg}^{-1}\right)$ from a certified

180 reference material (Maize leaves material FD8, Commission of the European

181 Communities, Joint Research Centre ISPRA) was not significantly different from the

182 certified value $\left(0.77+/-0.1 \mathrm{mgkg}^{-1}\right)$. The mean As concentration in blank digests was

$1830.09 \mu \mathrm{gL}^{-1}$, and the method detection limit for As in plant tissue was $0.07 \mu \mathrm{gL}^{-1}$.

184

\section{$185 \quad 2.7$ Data analysis}

186 The bioaccumulation factor, AsBFw, based on water-soluble As was estimated as

187 follows: $\mathrm{AsBFw}=\left[\mathrm{As}_{\text {plant }}\right] /\left[\mathrm{As}_{\mathrm{H} 2 \mathrm{O}}\right]$, where $\left[\mathrm{As}_{\text {plant }}\right]$ is the As concentration $(\mathrm{mg} / \mathrm{kg})$

188 accumulated in the plant and $\left[\mathrm{As}_{\mathrm{H} 2 \mathrm{O}}\right]$ is the water-soluble As concentration $(\mathrm{mg} / \mathrm{kg})$ in

189 the soil. Box and whisker plots were conducted using the SPSS 12.0 statistical software.

190

1913 Results and discussion

\section{$192 \quad 3.1$ Soil physico-chemical analysis}

193 The physical and chemical characteristics of soil used in the greenhouse experiments are

194 provided in Table 1. The grain size analysis exhibited the soil as sandy type, and the

195 characteristics of whose parent materials are: Quaternary aeolian sands deposited on

196 Tertiary Duero basin, and consequently, the cation exchange capacity (CEC) was very

197 low, $1.76 \mathrm{cmolkg}^{-1}$. The water soluble As concentrations in the rhizosphere soil were

198 different for the different greenhouse experiments (at the end of experiment), that were 
199 mostly related to the As concentrations in the irrigation water $\left(\mu \mathrm{gL}^{-1}\right)$ added to the soil.

200 The soil soluble As concentrations were 28, 44, 130, 170 and $196 \mu \mathrm{gkg}^{-1}$ after

201 treatments of irrigation water containing As concentrations of $0,44,50,100$ and 150

$202 \mu \mathrm{gL}^{-1}$, respectively.

\section{$204 \quad 3.2$ Arsenic uptake by carrot}

205 Carrot root samples (Fig. 1) grown in pot experiment irrigated with water containing As concentration of 100 or $150 \mu \mathrm{gL}^{-1}$ showed As contents higher than previously reported

207 value of $0.01-1 \mathrm{mgkg}^{-1} \mathrm{DW}$ [29] at world-wide level, exceeding the limits for 208 foodstuffs $\left(0.5-1 \mathrm{mgkg}^{-1} \mathrm{DW}\right)$ set by legislation of many countries, e.g. Germany, UK, 209 India and The Netherlands. In spite of the higher As levels, As content in the carrot root 210 found in the present study is lower than those reported in other As polluted soil [25, 30-

211 31]. Carrot is a crop plant and a target food for arsenic exposure and human health risk.

212 The results found in this study indicated the potential health risk from consumption of 213 carrots grown in As contaminated soil. Therefore, analysis of the As content in 214 vegetables, especially carrots is essential everywhere to provide a reliable assessment of 215 the health risk from their consumption.

216 Statistical treatment of As content in carrot samples showed significant differences 217 (ANOVA 95\% confidence level) between different irrigation treatments and 218 concentration of arsenic in root (Fig. 1) and leaves (Fig. 2). No differences were found 219 in the growth or toxicity symptoms such as leaves discolorations or necrosis. 220 Relationship between bioaccumulation factors (As in plant tissue / soluble As in soil) and As contents in irrigation water showed, in general, that As storage in leaves and roots is higher when As concentration in irrigation water is higher [32]. 
In this study, the same agricultural soil was used for control and all the irrigation treatment experiments. However, if different types of agricultural soil were used in the greenhouse experiments and in the irrigation fields, they may contribute different amounts of As in carrots, although the irrigation water treatments have the same As concentrations. Because the variation in As concentrations of baseline soil is a major factor in As accumulation in crops; and higher concentrations of As uptake occur at low soil/shoot As levels [33]. Where irrigation fields have high baseline soil As, further additional As from irrigation water only leads to a gradual increase in As concentration 231 of crops.

\subsection{Bioaccumulation index and uptake of As in carrot plant}

234 The relationships between bioaccumulation index $\left(\mathrm{As}_{\mathrm{root}} / \mathrm{As}_{\text {soil }}\right)$ and $\mathrm{As}$ concentrations in irrigation water are presented in Fig. 3 (roots) and Fig. 4 (leaves). Both organs of the carrot plant showed a considerable accumulation of As in the irrigation treatment of 20 $\mu \mathrm{gL}^{-1}$ of As, the lowest concentration of As treatment, and a particularly low accumulation in the treatment of $50 \mu \mathrm{gL}^{-1}$ of $\mathrm{As}$ in irrigation water. The results suggested that As uptake in the carrot plant followed the similar behaviour of the Pi

240 (inorganic phosphorus)-plant uptake system that indicated a high-affinity transport activity operating at low concentrations and a low-affinity activity operating at higher concentrations [18, 34-36]. The available phosphate concentration in the soil used in

243 this study is $8.3 \mathrm{mgkg}^{-1}$ (Olsen method); and probably, the concentration in soil solution 244 might be $<10 \mu \mathrm{gL}^{-1}$ of $\mathrm{P}$ [37]. Therefore, plant uptake could be carried out by the high245 affinity transporters. The different soil solution As contents in the different As treatments influenced the competition between As and phosphate; and subsequent As

247 uptake in plants. The soil solutions under the rhizosphere of the carrot plants in the 
248 treatment of irrigation water containing $20 \mu \mathrm{gL}^{-1}$ of As had a mean As content of 41 $249 \mu \mathrm{gL}^{-1}$ that is expected closest to the range of high-affinity transporters at low

250 concentrations. Arsenic content in soil solutions of the treatment $3\left(50 \mu \mathrm{gL}^{-1}\right)$ had a

251 mean value of $131 \mu \mathrm{gL}^{-1}$ of As; and this concentration is nearest to the range of low-

252 affinity transporters and could explain the less efficient absorption of As by roots.

253 Although phosphate inhibits efficiently As uptake by plants due to the competition

254 between them [38], its influence could be negligible in this study because of the 255 extremely low concentration of phosphate with respect to As contents.

\subsection{Bioaccumulation of As in different organs of carrot}

258 Arsenic accumulation in carrots follows the characteristics that most of the arsenate

259 absorbed by root is reduced to arsenite and transported to leaves, especially in 260 glutathione, phytochelatins and other chelating agents [24]; and thus the toxicity of As

261 is reduced [39]. The magnitude of this translocation generally can explain the amount of 262 As in different plant organs. However, the location of As-complexes within plant tissue 263 is still debateable, and not clearly known, but they are stable in the vacuoles under 264 acidic conditions [40-41].

265 In this study, the relationship of $\mathrm{As}_{\text {root }} / \mathrm{As}_{\text {leaves }}$ showed no statistically significant 266 differences for all of the different irrigation treatments, and presented the average value 267 of 0.36 (Fig. 5). Smith et al. [24] also showed a very similar ratio of 0.35 between $268 \mathrm{As}_{\text {root }} / \mathrm{As}_{\text {leaves }+ \text { stems }}$ in Radishes (Raphanus sativus) plants.

269 The statistical correlation between As uptake by leaves or roots of carrots and the 270 soluble As in rhizosphere soil did not follow a linear relationship (constant partitioning 271 model), nor a plateau curve (saturation model). The bioaccumulation factor $\left(\mathrm{As}_{\text {tissue }} /\right.$ 
$\left.272 \mathrm{As}_{\text {soil solub }}\right)$ is represented in y-axis in Fig. 6 and 7. Roots and leaves showed the

273 following regression equations:

274

275

$\mathrm{As}_{\text {roots }} / \mathrm{As}_{\text {soil solub }}=2.9731+0.00388066^{*} \mathrm{As}$ roots

276

277

$\mathrm{As}_{\text {leaves }} / \mathrm{As}_{\text {soil solub }}=9.72497+0.00352939 *$ As leaves

278

279

The results of the above regression analyses clearly demonstrated that the leaves of

280 carrots had a higher affinity for As than roots did.

\section{Conclusions}

283 High concentrations of As in carrot roots grown in agricultural soil irrigated with water containing As concentration equivalent to groundwater of Valladolid and Segovia provinces of Spain indicated the potential health risk from consumption of carrots grown in these areas. No differences were found in the growth or toxicity symptoms

287 such as leaves discolorations or necrosis in different irrigation treatments. Relationship 288 between bioaccumulation factors (As in plant tissue / soluble As in soil) and arsenic contents in irrigation water showed, in general, that As storage into leaves and roots was higher when As concentration in irrigation water was higher. Both root and leaves

291 of the carrot plant showed a particularly efficient and high accumulation of As at the

292 lowest As treatment of $20 \mu \mathrm{gL}^{-1}$ of As in irrigation water and a mean As content of 41

$293 \mu \mathrm{gL}^{-1}$ in the soil solutions, whereas a particularly lower As accumulation was found

294 with $50 \mu \mathrm{gL}^{-1}$ of As in irrigation water and a mean As content of $131 \mu \mathrm{gL}^{-1}$ in soil

295 solutions. The ratios of $\mathrm{As}_{\text {root }} / \mathrm{As}_{\text {leaves }}$ showed no statistically significant differences for

296 the different irrigation treatments, had the average value of 0.36 , and indicated the high 
magnitude of As translocation from roots to leaves in plants. The leaves of carrots had a

higher affinity for As than roots did. The correlation between As uptake by leaves or roots of carrots and the soluble As in rhizosphere soil did not show a linear relationship, nor a plateau curve.

301

302 Acknowledgments

303 The authors thank the anonymous reviewers for their critical comments that improved

304 the quality of the manuscript.

305

The authors have declared no conflict of interest.

307

308

\section{References}

[1] A. A. Carbonell-Barrachina, A. J. Signes-Pastor, L. Vazquez-Araffljo, F. Burlo, B. Sen Gupta, Presence of Arsenic in Agricultural Products from Arsenic-endemic Areas and Strategies to Reduce Arsenic Intake in Rural Villages, Molecular Nutrition and Food Res. 2009, 53, $531-541$.

[2] A. Farooqi, H. Masuda, N. Firdous, Toxic Fluoride and Arsenic Contaminated Water in Lahore and Kasur Districts, Punjab, Pakistan and Possible Contaminant

[3] M.F. Hossain, Arsenic Contamination in Bangladesh-An overview, Agric. Ecosyst. Environ. 2006, 113, 1-16.

[4] P. N. Williams, S. Islam, R. Islam, M. Jahiruddin, E. Adomako, A. R. M. Soliaman, G. K. M. M. Rahman, Y. Lu, C. Deacon, Y.G. Zhu, A.A. Meharg, Arsenic Limits Trace Mineral Nutrition (selenium, zinc, and nickel) in Bangladesh Rice Grain. Environ. Sci. Technol. 2009, 43 (21), 8430-8436. 
322 [5] R. D. Wauchope, Uptake, Translocation and Phytotoxiciy of Arsenic in Plants, in Arsenic: Industrial, Biomedical, Environmental Perspectives, New York 1983, $348-374$.

[6] H.M. Anawar, A. Garcia-Sanchez, A. Murciego, T. Buyolo, Exposure and Bioavailability of Arsenic in Contaminated Soil from the La Parrilla Mine, Spain, Environ. Geol. 2006, 50, 170-179.

[7] S. Tu, L.Q. Ma, Comparison of Arsenic and Phosphate Uptake and Distribution in Arsenic Hyperaccumulating and Non-hyperaccumulating Fern, J. Plant Nutrition 2004, 27, 1227-1242.

[8] D. K. Nordstrum, World-wide Occurrences of Arsenic in Groundwater, Science

[9] M. G. M. Alam, E. T. Snow, A. Tanaka, Arsenic and Heavy Metal Contamination of Vegetables Grown in Samta Village, Bangladesh, Sci. Total Envorn. 2003, 308, 883-896.

[10] L. C. Roberts, S. J. Hug, J. Dittmar, A. Voegelin, G. C. Saha, M. A. Ali, A. B. M. Badruzzaman, R. Kretzschmar, Spatial Distribution and Temporal Variability of Arsenic in Irrigated Rice Fields in Bangladesh. 1. Irrigation Water, Environ. Sci. Technol. 2007, 41 (17), 5960-5966.

[11] A. Moyano, A. Garcia-Sánchez, P. Mayorga, H.M. Anawar, E. Alvarez-Ayuso, Impact of Irrigation With Arsenic-rich Groundwater on Soil and Crops, J. Environ. Monit. 2009, 11, 498-502.

[12] C. De la Fuente, R. Clemente, J. A. Alburquerque, D. Velez, M. P. Bernal, 346 
347 [13] P. O’Neil, Arsenic, In Heavy Metals in Soil (Ed.: B. J. Alloway), Blackie Academic

348 \& Professional, London 1995, 105-121.

349 [14] J. Kumpiene, I. Montesinos, A. Lagerkvist, C. Maurice, Evaluation of the Critical

350 Factors Controlling Stability of Chromium, Copper, Arsenic and Zinc in Iron-

$351 \quad$ treated Soil, Chemosphere 2007, 67, 410-417.

352 [15] D.C. Adriano, Trace Elements in Terrestrial Environment, Biogeochemistry,

$353 \quad$ Bioavailability and Risks of Metals, New York 2001.

354 [16] B. Markert, Instrumental Element and Multi-element Analysis of Plant Samples,

$355 \quad$ New York 1997.

356 [17] O. Muñoz, P. B. Díaz, I. Leyton, N. Nuñez, M. A. Devesa Suäñer, D. Veälez, R.

357 Montoro, Vegetables Collected in the Cultivated Andean Area of Northern Chile:

358 Total and Inorganic Arsenic Contents in Raw Vegetables, J. Agric. Food Chem.

$359 \quad 2002,50,642-647$.

360 [18] A. A. Meharg, M. R. Macnair, Suppression of the High-affinity Phosphate Uptake

361 System: A Mechanism of Arsenate Tolerance in Holcus lanatus L, J. Exp. Bot.

$362 \quad \mathbf{1 9 9 2 ,}, 43,519-524$.

363 [19] J. Wang, F. J. Zhao, A. A. Meharg, A. Raab, J. Feldmann, S. P. McGrath,

364 Mechanisms of arsenic hyperaccumulation in Pteris Vittata. Uptake kinetics,

365 interactions with phosphate, and arsenic speciation, Plant Physiol. 2002, 130,

$366 \quad 1552-1561$.

367 [20] P. J. Peterson, C. A. Girling, L. M. Benson, R. Zieve, Metalloids, In Effect of

368 Heavy Metal Pollution on Plants (Ed.: N.W. Lepp), Vol. 1, Applied Science,

$369 \quad$ London 1981, 299-322.

370 [21] A. A. Meharg, J. Hartley-Whitaker, Arsenic uptake and metabolism in arsenic

371 resistant and non-resistant plant species, New Phytol. 2002, 154, 29-43. 
372 [22] W. Zhang, Y. Cai, K.R. Downum, L.Q. Ma, Thiol synthesis and arsenic

373

374

375

376

377

378

379

380

381

382

383

384

385

386

387

388

389

390

391

392

393

394

395 hyperaccumulation in Pteris vittata (Chinese brake fern), Environ. Pollut. 2004, 131, 337-345.

[23] S. K V. Yathavakilla, M. Fricke, P. A. Creed, D. T. Heitkemper, N. V. Shockey, C. Schwegel, J. A. Caruso, J. T. Creed, Arsenic Speciation and Identification of Monomethylarsonous Acid and Monomethylthioarsonic Acid in a Complex Matrix, Anal. Chem. 2008, 80/3.

[24] P. G. Smith, Koch, I., Kenneth, J. Reimer, K. J. Uptake, Transport and Transformation of Arsenate in Radishes (Raphanus sativus), Sci. Total Environ. 2008, 390, $188-197$.

[25] C. Grant, A. J. Dobbs, The Growth and Metal Content of Plants Grown in Soil Contaminated by a Copper/Chrome/Arsenic Wood Preservative, Environ. Pollut. 1977, 14, 213-226.

[26] H. D. Chapman, Cation-exchange capacity, In Methods of Soil Analysis, (Ed.: C.A. Black, D.D. Evans, J.L. White, L.E. Ensminger, F.E. Clark), Madison, W.I., Soil Sci. Soc. Amer. 1965.

[27] R. S. Olsen, V. C. Cole, F. S. Watanabe, L. A. Dean, Estimation of Available Phosphorus in Soil by Extraction with Sodium Bicarbonate, USDA, Washington, D.C. Circular 939, 1954.

[28] O. Jimenez, N. Rodríguez, A. García-Sánchez, J. AOAC Int. 1996, 79, 764-768. [29] A. Kabata-Pendias, H. Pendias, Trace Elements in Soil and Plants, 2nd edn, CRC Press, Boca Raton, FL, USA 1992.

[30] H. Helgesen, E. H. Larsen, Bioavailability and Speciation of Arsenic in Carrots Grown in Contaminated Soil, Analyst 1998, 123/5, 791-796. 
[31] N. P. Vela, D. T. Heitkemper, K. R. Stewart, Arsenic Extraction and Speciation in Carrots using Accelerated Solvent Extraction, Liquid Chromatography and Plasma Mass Spectrometry, Analyst 2001, 126, 1011-1017.

[32] X. Y. Xu, S. P. McGrath, A. A. Meharg, F. J. Zhao, Growing Rice Aerobically Markedly Decreases Arsenic Accumulation, Environ. Sci. Technol. 2008, 42 (15), $5574-5579$.

[33] Y. Lu, E. E. Adomako, A. R. M. Solaiman, M. R. Islam, C. Deacon, P. N. Williams, G. K. M. M. Rahman, A. A. Meharg, Baseline Soil Variation is A Major Factor in Arsenic Accumulation in Bengal Delta Paddy Rice, Environ. Sci. Technol. 2009, 43(6), 1724-1729.

[34] I. R. McPharlin, R.L. Bieleski, Phosphate Uptake by Spirodela and Lemna During Early Phosphorus Deficiency, Aust. J. Plant Physiol. 1987, 14, 561-572.

[35] C. I. Ullrich-Eberius, A. Sanz, A. J. Novacky, Evaluation of Arsenate- and Vanadate-associated Changes of Electrical Membrane Potential and Phosphate Transport in Lemna gibba, J. Exp. Bot. 1989, 40, 119-28.

[36] T. Furihata, M. Suzuki, H. Sakurai, Kinetic Characterization of Two Phosphate Uptake Systems with Different Affinities in Suspension-cultured Catharanthus roseus Protoplasts, Plant Cell Physiol. 1992, 33, 1151-1157.

[37] K. Mengel, E. A. Kirkby, H. Kosegarten, T. Appel, Principles of Plant Nutrition, 5th edition, Kluwer Academic Publishers, July 1, 2001.

[38] A. A. Meharg, J. Naylor, M. R. Macnair, Phosphorus Nutrition of Arsenate-tolerant and Nontolerant Phenotypes of Velvetgrass, J. Environ. Qual. 1994, 23, 234-238.

[39] D. K. Gupta, R. D. Tripathi, S. Mishra, S. Srivastava, S. Dwived, U. N. Rai, X. E. Yang, H. Huanj, M. Inouhe, Arsenic Accumulation in Root and Shoot Vis-à-vis: Its 
Effects on Growth and Level of Phytochelatins in Seedlings of Cicer arietinum L., J. Environ. Biol. 2008, 29(3), 281-286.

422

423

424

425

426

427

428

429

430

431

432

433

\section{$434 \quad$ Figure captions}

435

436

437

438

439

440

441

442

443

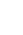
$95 \%$. level $95 \%$.

[40] D. K. Gupta, H. Tohoyama, M. Joho, M. Inouhe, Changes in the Levels of Phytochelatins and Related Metal-binding Peptides in Chickpea Seedlings Exposed to Arsenic and Different Heavy Metal Ions, J. Plant Res. 2004, 117, 253-256.

[41] A. Raab, A. A. Meharg, M. Jaspars, R. Genney, J. Feldmann, Arsenic Glutathione Complexes: Their Solubility in Solution and During Separation by Different HPLC modes, J. Anal. At. Spectrom. 2004, 19, 183-90.

Figure 1. Box-plots of As in roots, each box represents 12 root samples (4 pots, 3 samples per pot). As concentrations in water in $\mu \mathrm{gL}^{-1} ; 1: 0 \mu \mathrm{gL}^{-1} ; 2: 20 \mu \mathrm{gL}^{-1} ; 3: 50$ $\mu \mathrm{gL}^{-1} ; 4: 100 \mu \mathrm{gL}^{-1} ; 5: 150 \mu \mathrm{gL}^{-1}$. As concentration in root in $\mu \mathrm{gkg}^{-1}$. Confidence level

440 Figure 2. Box-plots of As in leaves, each box represents 12 leaf samples (4 pots, 3 samples per pot). As concentrations in water in $\mu \mathrm{gL}^{-1} ; 1: 0 \mu \mathrm{gL}^{-1} ; 2: 20 \mu \mathrm{gL}^{-1} ; 3: 50$ $\mu \mathrm{gL}^{-1} ; 4: 100 \mu \mathrm{gL}^{-1} ; 5: 150 \mu \mathrm{gL}^{-1}$. As concentration in leaves in $\mu \mathrm{gkg}^{-1}$. Confidence 
445 Figure 3. Relationship between the ratio of $A s_{\text {root }} / \mathrm{As}_{\text {soil }}$ and $A s_{\text {water }}$. As concentration in 446 water in $\mu \mathrm{gL}^{-1} ; 1: 0 ; 2: 20 ; 3: 50 ; 4: 100 ; 5: 150$. Confidence level 95\%.

447

448

449 Figure 4. Relationship between the ratio of $\mathrm{As}_{\text {leaves }} / \mathrm{As}_{\text {soil }}$ and $\mathrm{As}_{\text {water }}$. As concentration 450 in water in $\mu \mathrm{gL}^{-1} ; 1: 0 ; 2: 20 ; 3: 50 ; 4: 100 ; 5: 150$. Confidence level $95 \%$.

451

452 Figure 5. Relationship between the ratio of $\mathrm{As}_{\mathrm{root}} / \mathrm{As}_{\text {leaves }}$ and $\mathrm{As} \mathrm{s}_{\text {water }}$. As concentration 453 in water in $\mu \mathrm{gL}^{-1} ; 1: 0 ; 2: 20 ; 3: 50 ; 4: 100 ; 5: 150$. Confidence level 95\%.

454

455 Figure 6. Linear form of the Langmuir equation. As concentration in water in $\mu \mathrm{gL}^{-1} ; 1$ : $4560 ; 2: 20 ; 3: 50 ; 4: 100 ; 5: 150 . \mathrm{R}=0.92$. As concentration in root in $\mu \mathrm{gkg}^{-1}$. Confidence 457 level 99\%.

458

459 Figure 7. Relationship between the ratio of $\mathrm{As}_{\text {leaves }} / \mathrm{As}_{\text {soil }}$ and $\mathrm{As} \mathrm{s}_{\text {leaves. }}$. As concentration 460 in water in $\mu \mathrm{gL}^{-1} ; 1: 0 ; 2: 20 ; 3: 50 ; 4: 100 ; 5: 150$. As concentration in leaves in $\mu \mathrm{gkg}^{-1}$. $461 \mathrm{R}=0.89$. Confidence level $99 \%$.

462

463 Table 1. Soil physico-chemical characteristics

\begin{tabular}{|l|l|l|l|l|l|l|}
\hline $\mathrm{pH}$ & Organic & $\mathrm{N}(\%)$ & $\mathrm{P}$ & Clay & Silt & Sand \\
matter & $(\%)$ & & (Olsen) & $(\%)$ & $(\%)$ & $(\%)$ \\
\hline 7.2 & 0.45 & 0.038 & 8.3 & 3.3 & 3.1 & 93.6 \\
\hline
\end{tabular}

464 


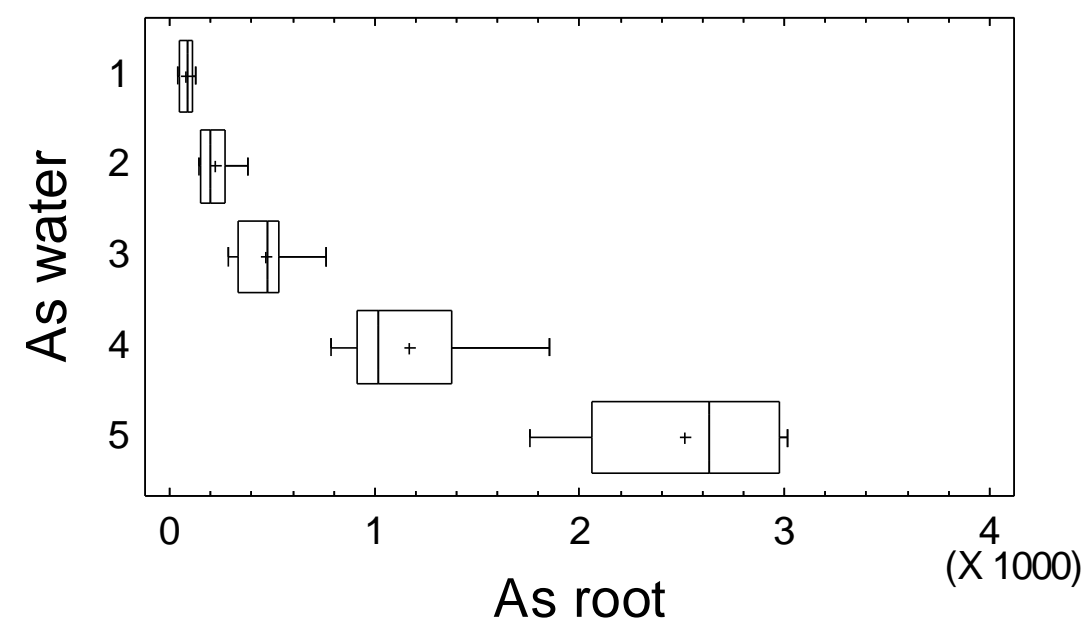

466

467 Figure 1. Box-plots of As in roots, each box represents 12 root samples (4 pots, 3 468 samples per pot). As concentrations in water in $\mu \mathrm{gL}^{-1} ; 1: 0 \mu \mathrm{gL}^{-1} ; 2: 20 \mu \mathrm{gL}^{-1} ; 3: 50$ $469 \mu \mathrm{gL}^{-1} ; 4: 100 \mu \mathrm{gL}^{-1} ; 5: 150 \mu \mathrm{gL}^{-1}$. As concentration in root in $\mu \mathrm{gkg}^{-1}$. Confidence level $470 \quad 95 \%$

471

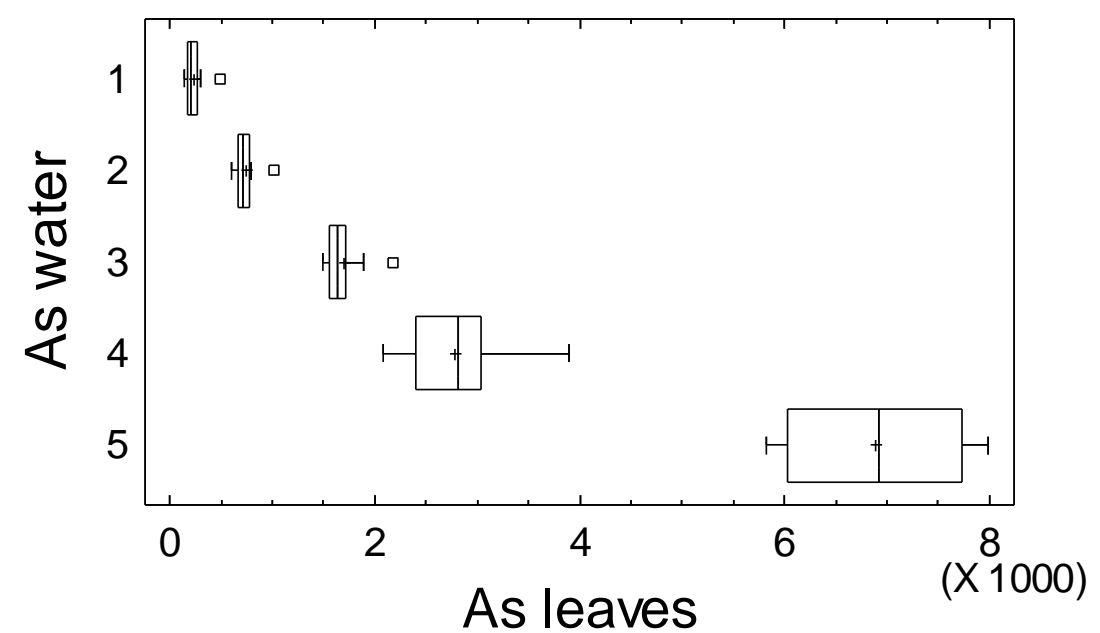

472

Figure 2. Box-plots of As in leaves, each box represents 12 leaf samples (4 pots, 3 475 samples per pot). As concentrations in water in $\mu \mathrm{gL}^{-1} ; 1: 0 \mu \mathrm{gL}^{-1} ; 2: 20 \mu \mathrm{gL}^{-1} ; 3: 50$ $476 \mu \mathrm{gL}^{-1} ; 4: 100 \mu \mathrm{gL}^{-1} ; 5: 150 \mu \mathrm{gL}^{-1}$. As concentration in leaves in $\mu \mathrm{gkg}^{-1}$. Confidence 477 level $95 \%$ 


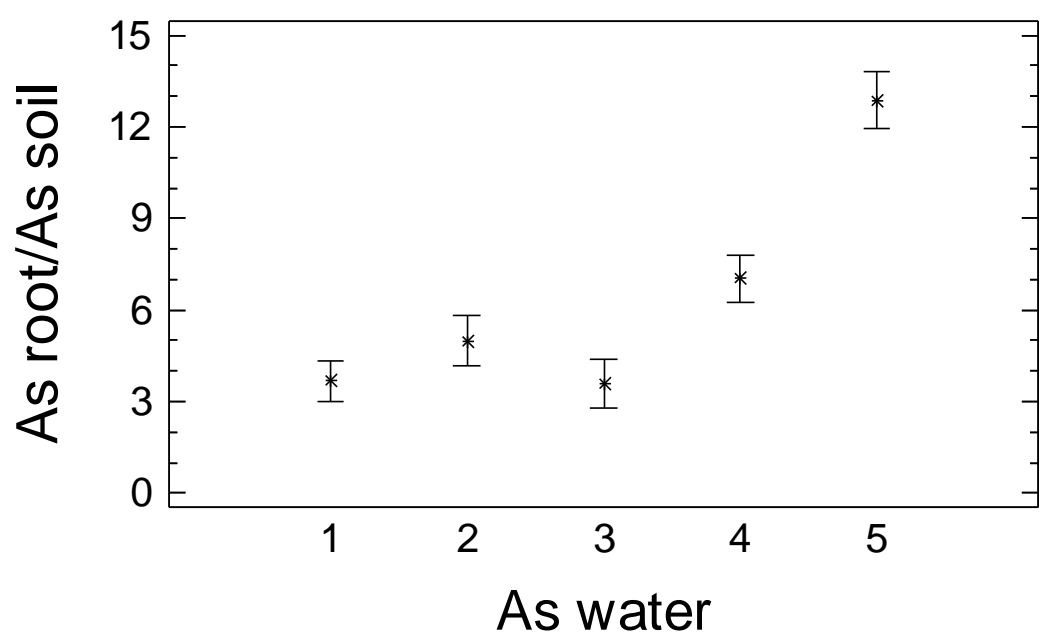

484

485

486

487

488

489

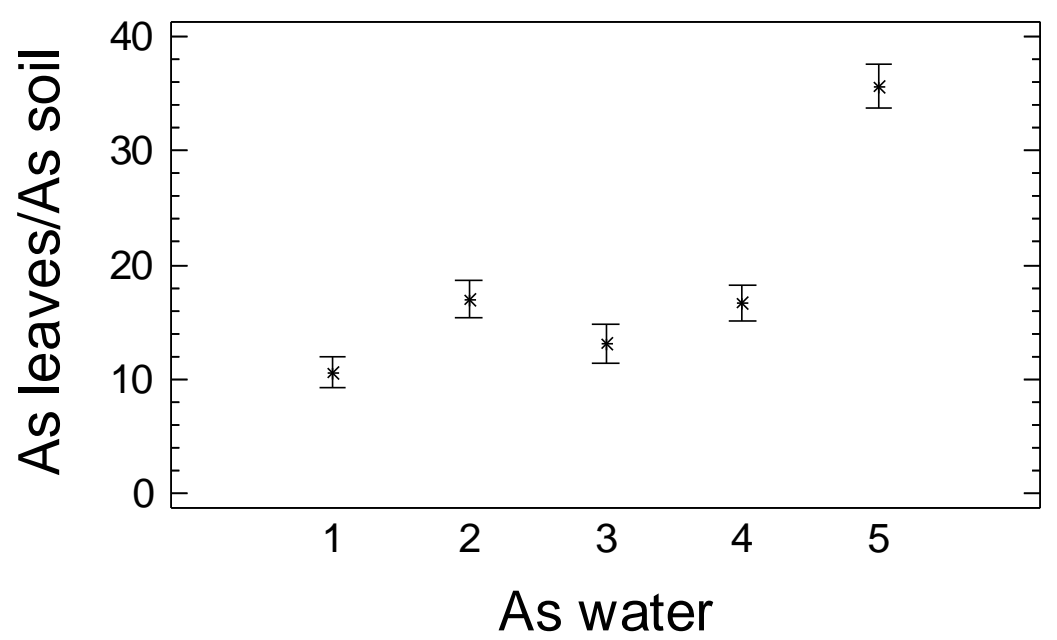

Figure 3. Relationship between the ratio of $\mathrm{As}_{\text {root }} / \mathrm{As}_{\text {soil }}$ and $\mathrm{As} s_{\text {water }}$. As concentration in water in $\mu \mathrm{gL}^{-1} ; 1: 0 ; 2: 20 ; 3: 50 ; 4: 100 ; 5: 150$. Confidence level 95\%.

As water

492

Figure 4. Relationship between the ratio of $\mathrm{As}_{\text {leaves }} / \mathrm{As}_{\text {soil }}$ and $\mathrm{As}_{\text {water }}$. As concentration 493 in water in $\mu \mathrm{gL}^{-1} ; 1: 0 ; 2: 20 ; 3: 50 ; 4: 100 ; 5: 150$. Confidence level 95\%. 
50

50

50

$5 C$

50

51

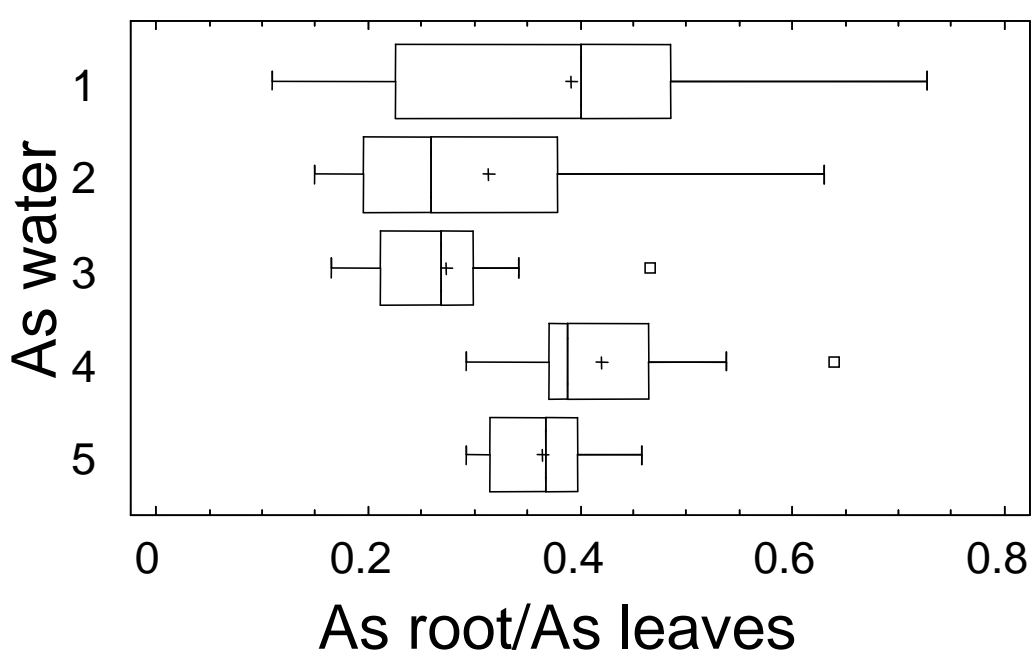

Figure 5. Relationship between the ratio of $\mathrm{As}_{\mathrm{root}} / \mathrm{As}_{\text {leaves }}$ and $\mathrm{As}_{\mathrm{water}}$. As concentration in water in $\mu \mathrm{gL}^{-1} ; 1: 0 ; 2: 20 ; 3: 50 ; 4: 100 ; 5: 150$. Confidence level 95\%.

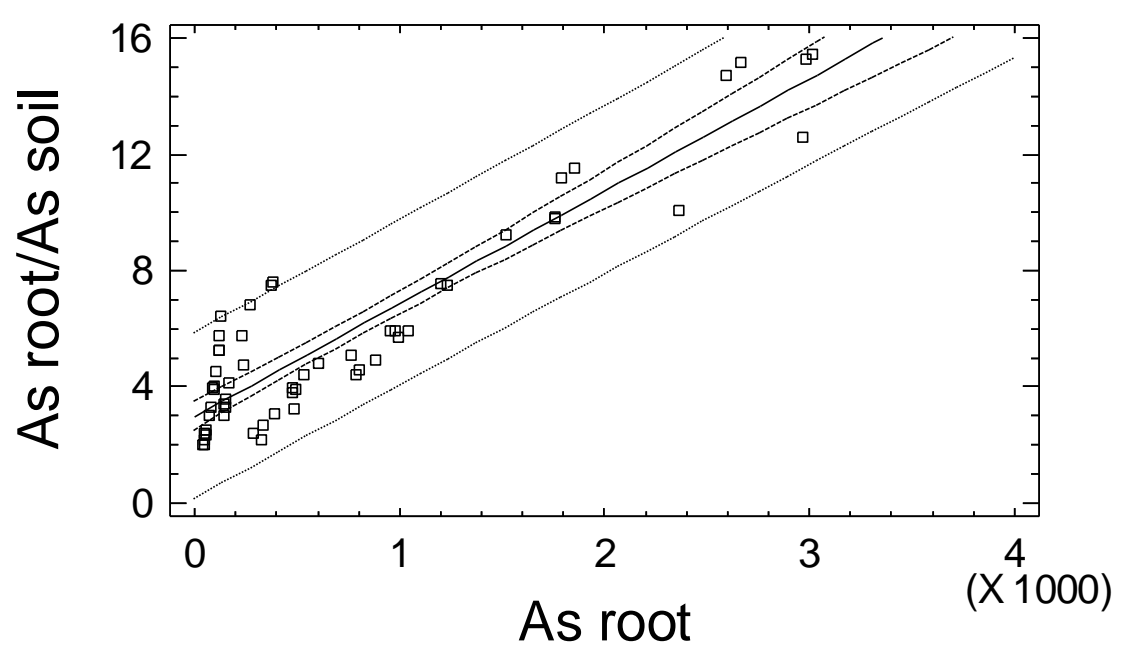

Figure 6. Linear form of the Langmuir equation. As concentration in water in $\mu \mathrm{gL}^{-1} ; 1$ : $0 ; 2: 20 ; 3: 50 ; 4: 100 ; 5: 150 . \mathrm{R}=0.92$. As concentration in root in $\mu \mathrm{gkg}^{-1}$. Confidence level $99 \%$. 


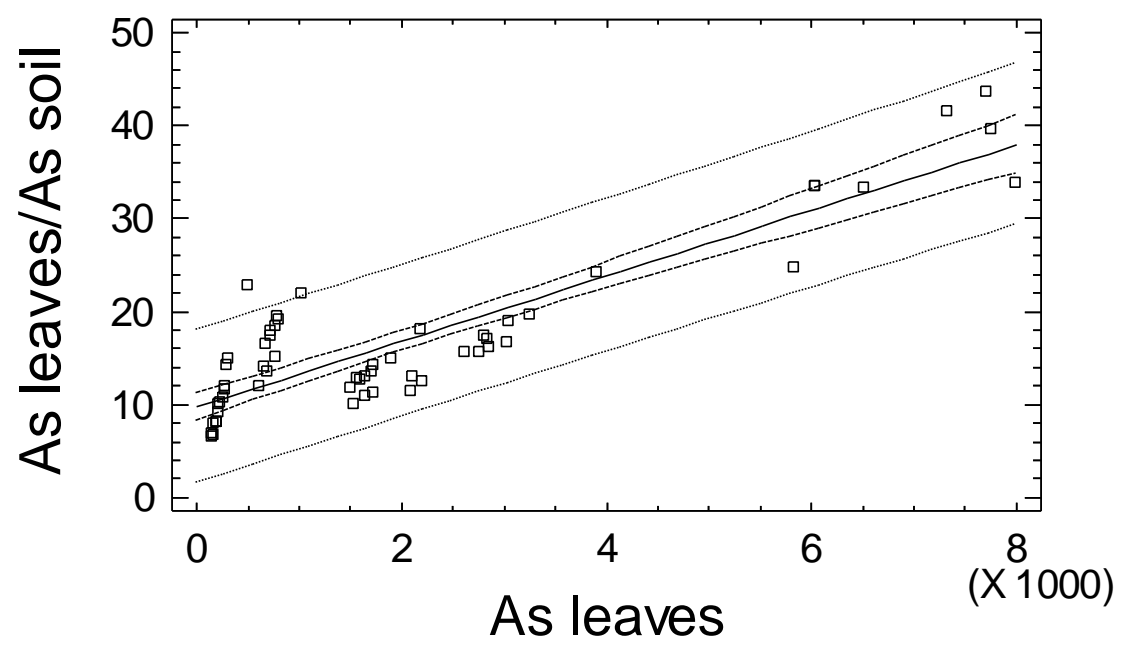

531 Figure 7. Relationship between the ratio of $\mathrm{As}_{\text {leaves }} / \mathrm{As}_{\mathrm{soil}}$ and $\mathrm{As}$ leaves. As concentration 532 in water in $\mu \mathrm{gL}^{-1} ; 1: 0 ; 2: 20 ; 3: 50 ; 4: 100 ; 5: 150$. As concentration in leaves in $\mu \mathrm{gkg}^{-1}$. $533 \mathrm{R}=0.89$. Confidence level $99 \%$. 